\title{
Marc Bloch
}

(1886-1944)

\section{L'étrange défaite}

(1946)

Un document produit en version numérique par Pierre Palpant, bénévole, Courriel : ppalpant@uqac.ca

Dans le cadre de la collection : "Les classiques des sciences sociales" fondée et dirigée par Jean-Marie Tremblay, professeur de sociologie au Cégep de Chicoutimi

Site web : http : //www.uqac.ca/Classiques_des_sciences_sociales/

Une collection développée en collaboration avec la Bibliothèque Paul -Émile Boulet de l'Université du Québec à Chicoutimi Site web : http : //bibliotheque.uqac.ca/ 
Cette édition électronique a été réalisée par Pierre Palpant, bénévole.

Courriel : ppalpant@uqac.ca

à partir de :

\section{Marc Bloch (1886-1944)}

\section{L'étrange défaite}

Témoignage écrit en 1940

Société des Éditions Franc-Tireur, Paris, 1946, pages 21-194.

L'édition papier contient un avant-propos de Georges Altman.

Polices de caractères utilisée : Times New Roman, 12 points. Mise en page sur papier format LETTRE (US letter), 8.5 x 11',

Édition numérique complétée à Chicoutimi le 15 août 2005. 
«... Je le dis franchement: je souhaite, en tout cas, que nous ayons encore $d u$ sang à verser... Je ne parle pas du mien auquel je n'attache pas tant de prix...»

Marc BLOCH, Septembre 1940. 


\section{T A B LE DES M A T I È R E S}

I. Présentation du témoin

II. La déposition d'un vaincu

III. Examen de conscience d'un Français

Testament de Marc Bloch 


\section{CHAPITRE PREMIER}

p.21 Ces pages seront-elles jamais publiées ? Je ne sais. Il est probable, en tout cas, que, de longtemps, elles ne pourront être connues, sinon sous le manteau, en dehors de mon entourage immédiat. Je me suis cependant décidé à les écrire. L'effort sera rude : combien il me semblerait plus commode de céder aux conseils de la fatigue et du découragement ! Mais un témoignage ne vaut que fixé dans sa première fraîcheur et je ne puis me persuader que celuici doive être tout à fait inutile. Un jour viendra, tôt ou tard, j'en ai la ferme espérance, où la France verra de nouveau s'épanouir, sur son vieux sol béni déjà de tant de moissons, la liberté de pensée et de jugement. Alors les dossiers cachés s'ouvriront; les brumes, qu'autour du plus atroce effondrement de notre histoire commencent, dès maintenant, à accumuler tantôt l'ign orance et tantôt la mauvaise foi, se lèveront peu à peu ; et, peut-être les chercheurs occupés à les percer trouveront-ils quelque profit à feuilleter, s’ils le savent découvrir, ce procès -verbal de l'an 1940.

Je n'écris pas ici mes souvenirs. Les petites aventures personnelles d'un soldat, parmi beaucoup, importent, en ce moment, assez peu et nous avons d'autres soucis que de rechercher le chatouillement du pittoresque ou de l'humour. Mais un témoin a besoin d'un état civil. Avant même de faire le point $_{\text {p.22 }}$ de ce que j'ai pu voir, il convient de dire avec quels yeux l'ai vu.

Écrire et enseigner l'histoire : tel est, depuis tantôt trente-quatre ans, mon métier. Il m'a amené à feuilleter beaucoup de documents d'âges divers, pou r y faire, de mon mieux, le tri du vrai et du faux; à beaucoup regarder et observer, aussi. Car j'ai toujours pensé qu'un historien a pour premier devoir, comme disait mon maître Pirenne, de s’intéresser « à la vie ». L'attention particulière que j'ai acc ordée, dans mes travaux, aux choses rurales a achevé de me convaincre que, sans se pencher sur le présent, il est impossible de comprendre le passé; à l'historien des campagnes, de bons yeux pour contempler la forme des champs ne sont pas moins indispensables qu'une certaine aptitude à déchiffrer de vieux grimoires. Ce sont ces mêmes habitudes de critique, d'observation et, j'espère, d'honnêteté, que j'ai essayé d'appliquer à l'étude des tragiques événements dont je me suis trouvé un très modeste acteur. 
La profession que j'ai choisie passe, ordinairement, pour des moins aventureuses. Mais mon destin, commun, sur ce point, avec celui de presque toute ma génération, m’a jeté, par deux fois, à vingt et un ans d'intervalle, hors de ces paisibles chemins. Il m'a, en outre, procuré, sur les différents aspects de la nation en armes, une expérience d'une étendue, je crois, assez exceptionnelle. J'ai fait deux guerres. J'ai commencé la première au mois d'août 1914, comme sergent d’infanterie : en pleine troupe, par conséquent, et presque au niveau du simple soldat. Je l'ai continuée, successivement, comme chef de section, comme officier de renseignements, attaché à un état-major de régiment, enfin, avec le grade de capitaine, dans les fonctions d'adjoint à mon chef de corps. Ma seconde guerre, j'en ai vécu la plus grande partie à l'autre extrémité de l'échelle, dans un état-major d'armée, en relations fréquentes p.23 avec le G.Q.G. Tranchant à travers les institutions et les milieux humains, la coupe, on le voit, n'a pas manqué de variété.

Je suis juif, sinon par la religion, que je ne pratique point, non plus que nulle autre, du moins par la naissance. Je n'en tire ni orgueil ni honte, étant, je l'espère, assez bon historien pour n'ignorer point que les prédispositio ns raciales sont un mythe et la notion même de race pure une absurdité particulièrement flagrante, lorsqu'elle prétend s'appliquer, comme ici, à ce qui fut, en réalité, un groupe de croyants, recrutés, jadis, dans tout le monde méditerranéen, turco-khazar et slave. Je ne revendique jamais mon origine que dans un cas: en face d'un antisémite. Mais peut-être les personnes qui sopposeront à mon témoignage chercheront-elles à le ruiner en me traitant de «métèque ». Je leur répondrai, sans plus, que mon arrière-grand-père fut soldat en 93 ; que mon père, en 1870, servit dans Strasbourg assiégé ; que mes deux oncles et lui quittèrent volontairement leur Alsace natale, après son annexion au II ${ }^{\mathrm{e}}$ Reich; que j'ai été élevé dans le culte de ces traditions patriotiques, dont les Israélites de l'exode alsacien furent toujours les plus fervents mainteneurs; que la France, enfin, dont certains conspireraient volontiers à m'expulser aujourd'hui et peut -être (qui sait? ) y réussiront, demeurera, quoi qu'il arrive, la pa trie dont je ne saurais déraciner mon coeur. J'y suis né, j’ai bu aux sources de sa culture, j’ai fait mien son passé, je ne respire bien que sous son ciel, et je me suis efforcé, à mon tour, de la défendre de mon mieux.

Un jeune officier me disait, alors que nous devisions sur le pas d'une porte, dans Malo-les-Bains bombardé : «Cette guerre m'a appris beaucoup de choses. Celle-ci entre autres: quil y a des militaires de profession qui ne

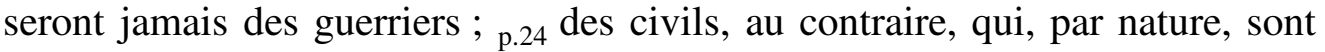
des guerriers. »Et il ajoutait: «Je ne m'en serais, je vous l'avoue, jamais douté avant le 10 mai : vous, vous êtes un guerrier. » La formule peut paraître naïve. Je ne la crois pas tout à fait fausse ; ni dans ses applications générales ni même, si je minterroge avec sincérité, quant à ce qui me touche personnellement. Un médecin de l'armée, qui fut mon compagnon au $4^{\mathrm{e}}$ bureau de l'état-major, aimait à me persifler gentiment en m'accusant, moi 
vieux professeur, «d'avoir plus que person ne l'esprit militaire »: ce qui, d'ailleurs, signifiait tout bonnement, j'imagine, que j'ai toujours eu le goût de l'ordre dans le commandement. Je suis revenu de la précédente guerre avec quatre citations; je ne pense pas me tromper en supposant que, si l'entrée inopinée des Allemands à Rennes n'avait arrêté net les propositions de la I ${ }^{\text {re }}$ Armée, je n'aurais pas regagné mes foyers, après cette guerre-ci, sans un ruban de plus sur ma vareuse ${ }^{1}$. En 1915, après une convalescence, j'ai rejoint le front avant mon tour, comme volontaire. En 1939, je me suis laissé maintenir en activité, malgré mon âge et mes six enfants, qui m'avaient, depuis longtemps, donné le droit de pendre au clou mon uniforme. De ces faits et de ces témoignages, je ne tire nulle vanité : j'ai, pour cela, vu trop de braves et humbles gens accomplir leur devoir, sans emphase, beaucoup mieux que moi et dans des conditions beaucoup plus difficiles. Simplement, si le lecteur, tout à l'heure, devant certains propos d'une franchise un peu rude, se sentait tenté de crier au parti pris, je lui demande de se souvenir que cet observateur, ennemi d'une molle indulgence, ne servit pas contre son gré et ne fut point, par ses chefs, ou ses camarades, jugé un trop mauvais soldat.

p.25 Voici, maintenant, l'exact bilan de ce qu'il m'a été donné de faire et, par conséquent, de voir, dans la dernière guerre.

Comme je l'ai dit plus haut, je m'étais, dans l'intervalle entre les deux guerres, constamment refusé à profiter des dispositions législatives qui m'auraie nt permis d'échapper à toute obligation militaire. Mais, bien qu'inscrit, dès 1919, au service d'état -major, je ne me pliai jamais à suivre le moindre cours dit «de perfectionnement». Dans le principe, je reconnais que j'eus tort. Mon excuse est que ces années-là, précisément, se trouvèrent coïncider avec la période de ma vie durant laquelle j'ai, tant bien que mal, produit l'essentiel de mon oeuvre d'historien, qui me laissait bien peu de loisirs. Ma consolation, je la puise dans les expériences mêmes de la campagne: assurément, le reflet de l'enseignement de l'École de Guerre, auquel je me suis ainsi soustrait, ne m'eût inspiré que bien peu d'idées justes. Comme l'armée de ce temps estimait, avant tout, les bons élèves, elle ne manqua point de me tenir rigueur de mon obstinée école buissonnière. Elle sut même m'en punir doublement. Capitaine de 1919, je n'avais pas cessé de l'être en 1938, lors de ma première mobilisation. Capitaine, je me retrouvai, encore, au mois d'août 1939, malgré une proposition d'avancement, signée par les chefs qui m'avaient vu au travail ; capitaine, toujours, lorsque, le 11 juillet 1940, je déposai l'uniforme. Tel fut mon premier châtiment, qui m’a laissé sans rancune comme sans tristesse. Le second m'atteignit dans mon affectation de mobilisation.

J'avais d'abord appartenu, sur le papier, à un deuxième bureau de corps d'armée : ce qui, le deuxième bureau étant chargé des renseignements, ne paraissait pas, on l'avouera, pour un historien, un trop mauvais emploi ; puis,

\footnotetext{
${ }^{1}$ La citation est venue à l'ordre du corps d'armée (juillet 1942).
} 
plus modestement déjà, à un état-major d’infanterie divisionnaire. Mais bientôt on me fit quitter les formations des ${ }_{\text {p.26 }}$ armées, pour me précipiter dans les inglorieux services du territoire: en l'espèce, l'état -major d'un groupe de subdivisions. Ce groupe-là, à vrai dire, avait son siège à Strasbourg, où chacun voyait alors la première proie offerte aux bombes allemandes. Il y aurait eu, me semblait-il, une certaine inélégance à me dérober à un poste ainsi placé. Ce sentiment, confirmé par la paresse naturelle à laquelle je succombe aisément, lorsqu'il s'agit de ma propre personne, m'empêcha de tenter les démarches qui m'auraient peut-être permis de trouver mieux. Un ami, cependant, s'efforça, peu avant la guerre, de me faire entrer au deuxième bureau du G.Q.G.; il ne put réussir à temps. Ce fut donc au groupe de subdivisions de Strasbourg, qu'après y avoir accompli deux brèves périodes d’instruction, je fus appelé d'abord en septembre 1938, lors de l'alerte de Munich; puis, une seconde fois, au mois de mars suivant, pour quelques heures seulement (ma convocation m'avait touché à Cambridge, d'où il me fallut revenir en toute hâte) ; enfin, le 24 août de cette même fatidique année 1939.

Je n'ai, au bout du compte, pas trop regretté cette affectation. La besogne d'u n état-major de groupe de subdivisions est, en soi, assez morne. Mais c'est, sur une entrée en guerre, un bon observatoire. Du moins, tel fut le cas, durant les deux ou trois premières semaines. La mobilisation, proprement dite, s'effectuait, pour une larg e part, sous notre contrôle. Que se passa-t-il, ensuite, dans les états-majors, de même type, qui fonctionnaient dans l'intérieur du pays ? J’imagine que, cette première fièvre une fois épuisée, ils conservèrent, malgré tout, une certaine activité, faite d'innombrables paperasses et de beaucoup de menues histoires. Le nôtre, qui avait bientôt quitté Strasbourg pour se replier sur Molsheim, au pied des Vosges, était, là encore, implanté en pleine zone des armées. Lorsque la VIe Armée se fut décidée, d'ailleu rs avec une étonnante lenteur, à mettre ${ }_{\text {p.27 }}$ en place ses propres organes de commandement, notre rôle, déjà progressivement amenuisé, se réduisit presque à néant. Alors se succédèrent d’interminables et torpides journées. Nous étions cinq: un général de brigade, un lieutenant-colonel, deux capitaines, un lieutenant. Je nous revois encore, face à face dans notre salle d'école, tous tendus vers un même souhait : que quelque papier, apporté par un courrier inopiné, nous fournît enfin l'occasion de rédiger un autre papier. Le plus jeune des deux capitaines était le plus heureux, il distribuait des laissez-passer ! Un historien ne s'ennuie pas facilement : il peut toujours se souvenir, observer, écrire. Mais l'inutilité, quand la nation se bat, est un sentiment insupportable.

Notre général appartenait au cadre de réserve. On finit par renvoyer cet excellent homme à ses études, c'est-à-dire, pour l'essentiel, à la pêche à la ligne. Le reste de l'état-major fut fondu avec celui du groupe de subdivisions de Saverne. Personnellement, je ne passai, pourtant, que deux jours dans cette aimable petite ville, alors fort encombrée. Je m'étais découvert une voie 
d'accès auprès d'un haut personnage du G.Q.G. Obtenir un meilleur poste, « par relations », l'acte ne compte point parmi ceux dont il y ait lieu de tirer beaucoup de fierté. Était-ce ma faute, cependant, si aucun autre moyen ne s'offrait de trouver pour ma bonne volonté un plus utile emploi ? Grâce à ce puissant intercesseur, je reçus, au début d'octobre, un avis de mutation. J'étais affecté à l'état-major de la $I^{\text {re }}$ Armée, que je rejoignis, sans tarder, à Bohain, en Picardie.

L'ordre du G.Q.G. m'assignait une fonction précise : celle d'officier de liaison avec les forces britanniques. Je devais figurer, à ce titre, au $2^{\mathrm{e}}$ bureau. Mais deux autres capitaines arrivèrent bientôt, précédés par des notes qui définissaient leur emploi mot pour mot dans les mêmes termes que le mien. Le chef d'état-major jugea qu'il y avait p.28 pléthore ; mieux valait, pensait-il, que chacun des principaux organes de l'armée eût ses moyens propres de contact avec nos voisins du corps expéditionnaire. Il nous répartit donc entre les divers bureaux, à l'exception, seulement, du premier dont le rôle, qui est de veiller sur les effectifs et la discipline, ne comporte guère de fenêtres ouvertes sur l'extérieur. Je me trouvai, pour ma part, versé au quatrième, qui a la charge de la circulation, de la main-d'oeuvre et des ravitaille ments. J'y conservais, en principe, le même service, mi d'information, mi de diplomatie. On verra plus loin comment, très malheureusement et bien contre mon gré, ces attributions se révélèrent, à l'expé rience, de plus en plus insignifiantes. Allaisje retomber dans l'oisiveté dont j’avais, une première fois, tant souffert ? je m'en désolais déjà quand l'officier chargé du ravitaillement en essence ayant été appelé à un autre poste, on me désigna pour prendre sa place.

Me voici donc devenu, du jour au lendemain, le grand maître des carburants, dans l'armée la plus motorisée de tout le front français. Ma première impression fut une terreur panique : car je me rendais bien compte que ce service ne manquerait pas d'entraîner, en cas d'opérations actives, les responsabilités les plus lourdes, et j'en ignorais jusqu'au rudiment. « Pourvu, écrivais-je à ma femme, que Hitler consente à rester sage encore pendant quelques semaines ! » Mais il n'est pas, je crois, de poste de direction que tout homme d'esprit un peu clair, s'il travaille d'arrache -pied, ne puisse se mettre en mesure de remplir convenablement. J'appris de mon mieux mon nouveau métier. Dans cet effort, j'eus une grande chance : je trouvai, dans le commandant du parc d'essence de l'armée, le guide le plus sûr et le plus désintéressé. C'est la première fois que j’inscris ic i le nom du capitaine Lachamp. Ce n'est assurément pas la dernière. L'amer ${ }_{\text {p.29 }}$ arrière-goût que me laisse cette guerre, mal conduite et plus mal terminée encore, ne fait que m'en rendre plus chers les rares souvenirs lumineux. Rencontrer un homme vraiment homme est toujours une joie ; travailler avec lui, dans une parfaite communauté d'intentions, et sentir cette collaboration s'épanouir, peu à peu, en une solide amitié, l'action ne connaît guère de récompenses plus que celles-là précieuses. 
A dire vrai, mes nouvelles fonctions ne me donnèrent beaucoup à faire que durant la période d'apprentissage. Après quoi, je glissai, comme tous mes camarades, à la vie sans fièvre d'un bureaucrate d'armée. Je n'étais pas oisif, certes ; je n'étais pas, non plus, fort oc cupé et mes besognes quotidiennes ne me procuraient qu'une faible dose d'excitation cérébrale. Je pus, par bonheur, leur adjoindre, pendant quelques semaines, une tâche supplémentaire, spontanément choisie. Je m'étais aperçu que nous n'avions, sur les dépô ts d'essence situés en territoire belge, que des renseignements absurdement insuffisants: carence redoutable pour une armée que sa mission propre, connue de nous tous, appelait à pénétrer en Belgique, aussitôt que les Allemands, de leur côté, en auraient eux-mêmes violé la frontière. Certaines relations personnelles me permirent de compléter et préciser sensiblement ce dossier. Il y fallut beaucoup de démarches, dont mon expérience des milieux d'états -majors tira de grands profits. J'appris alors, en particulier, comment, entre gens de bureaux, sils sont courtois, on traduit ce qui, en bon français, se dit simplement : «se mêler de ce qui ne vous regarde pas » — car, en somme, l'enquête, dont j'avais pris l'initiative, si utiles qu'en pussent être les rés ultats, n’appartenait, en aucune façon, à mon service régulier. Cela se nomme, en appuyant la phrase d'un discret sourire : «avoir du dynamisme ».

Mais cette occupation même n'eut qu'un temps. Réduit dorénavant, jour après jour, à recenser des ${ }_{\text {p.30 }}$ bidons ou à calculer, au compte-gouttes, des allocations d'essence, j'eus de nouveau, peut -être à tort, le sentiment que ce que je pouvais posséder de forces intellectuelles et d'esprit d'entreprise n'était pas trop bien employé. L'ennui de ces longs mois de l'h iver et du printemps 1939-1940, qui a rongé tant d’intelligences, pesait lourdement sur le morne Bohain. Plus ou moins intoxiqué sans doute, à mon tour, par ses subtils poisons, je songeais sérieusement, je l'avoue, à chercher autre chose, voire à solliciter, une fois l'été passé, de reprendre tout simplement ma place à la Sorbonne, quand éclata le coup de tonnerre du 10 mai.

Combien il fut inattendu, rien ne le montrera mieux qu'un petit souvenir personnel. Je m'étais rendu le 9 à Paris, pour gagner, le le ndemain matin, de bonne heure, Meaux. Là je devais me procurer, auprès du Service des Carburants de l'état-major général, quelques carnets de ces bons d'essence qui, distribués aux unités par mes soins, leur servaient à opérer réglementairement leurs perceptions. A mon arrivée à Meaux, j'ignorais encore tout des événements de la nuit. Ces messieurs du G.Q.G. furent naturellement fort étonnés de voir apparaître, en une pareille conjoncture, pour une mission si peu guerrière, un officier venu tout exprès d'un e des armées du front de Belgique. Après quelques minutes de quiproquo, je compris enfin les raisons de cet accueil un peu gêné : juste à temps pour me précipiter à la gare, traverser Paris et, y ayant pris d'assaut un train invraisemblablement bondé, rejoindre enfin mon poste. 
Ce que furent les trois semaines qui suivirent, je me suis promis de ne pas le raconter ici en détail. Il sera temps, tout à l'heure, d'en tirer les leçons. Quelques images, choisies parmi la foule de celles qui se pressent à ma mémoire, suffiront à jalonner p.31 le cours de ces journées et de ces nuits, toutes remplies par la grande tragédie de la campagne du Nord.

Voici, d'abord, le lycée de jeunes filles de Valenciennes désigné pour être notre P.C. de départ, avant ce P.C. belge que prévoyait le thème de la manoeuvre, et que nous n'occupâmes jamais. Tout près, nous allions contempler, d'un oeil encore neuf, les maisons ruinées par le premier bombardement. Je pus m'échapper, à deux reprises, pour des ra ndonnées en Belgique. Elles plaisaient à mon humeur nomade, que mes chefs n'approuvèrent pas toujours. Le 11, j'allai seulement jusqu'à Mons. Le 12, beaucoup plus loin, vers Nivelles, Fleurus et Charleroi. Le long des routes, profitant des loisirs de la Pentecôte, les mineurs du Borinage, du pas de leurs portes, acclamaient les autos françaises. Légèrement vallonnées, parées de leurs verdures printanières, les campagnes où, naguère, autour de Ligny et des Quatre-Bras, se battit l'armée de Ney, étaient charmantes. Mais déjà de longues colonnes de civils, chassés du pays de Liège, poussaient, sur les bascôtés, la classique voiture d'enfant de l'évacué, chargée des bagages les plus hétéroclites; et, symptôme plus inquiétant, des soldats belges, débandés, commençaient à se glisser à travers les villages. Puis vinrent, après les premiers espoirs, les premières angoisses. On se prit à parler de la brèche de la Meuse. Il fallut tenter de ravitailler par là-bas des divisions, jetées dans la bataille et tout aussitôt volatilisées. Enfin, l'armée refoulée vers le Sud-Ouest, l'état -major se replia, le 18 mai, sur Douai.

Nous y habitâmes moins de deux jours, une école encore, aux portes de la ville : logés déjà, à Bohain, à l'école des filles, nous étions décidément vou és aux lieux pédagogiques. Tout autour, les bombes pleuvaient : dru sur la gare, les rues principales, les terrains d'aviation. Cependant, j'apprenais, presque chaque jour, qu'un dépôt d'essence de plus, parmi ${ }_{\text {p.32 }}$ ceux de l'arrière, était tombé aux mains des Allemands. Nos beaux bacs de Saint-Quentin et de Cambrai, que nous avions jalousement réservés à assurer, par envoi progressif vers l'avant, le ravitaillement des unités au combat, nos chers dépôts « de bled », où les bidons se dissimulaient astucieusement sous les arbres des parcs ou les toits de briqueteries abandonnées : sur rien de tout cela, l'armée ne pouvait plus compter. Bientôt, il fallut de nouveau plier bagages. On avait d'abord décidé de me laisser, avec deux camarades, à Douai, en P.C. avan cé. Mais cette mission, comme tant d'autres alors, ne dura que quelques heures ; et, filant à travers le pays noir, parmi les crassiers, dont beaucoup, cocassement effondrés sous les bombes, commençaient déjà à perdre la netteté 
de leurs lignes d'épure, je rejoignis, à Lens, notre quatrième et dernière école (19 mai).

C'était, cette fois, une école maternelle. Fait au gabarit d'enfants en bas âge, le mobilier ne nous laissait le choix qu'entre deux formes de courbatures : fatigue de la station debout, indéfiniment prolongée ; contorsions d'un corps assis dans un espace trop étroit, les genoux, repliés à hauteur du ventre, venant s'écorcher au bord du pupitre. Encore n'était -il pas toujours commode de choisir : le besoin de rédiger quelque note de service nous avait-il contraints de nous asseoir? il fallait, pour s'extraire de la cangue, de longs efforts. Cet étrange supplice, la laideur du paysage, l'envahissante saleté des poussières de charbon, tout, en ces tristes lieux, semblait s'accorder à notre angois se grandissante. L'affreux P.C., vraiment, que ce groupe scolaire de Lens et bien digne d'une défaite ! Oublierai-je jamais la soirée du 20 mai ? Dans la nuit tombante, alors qu'au loin fumait Arras en feu, je vis mon chef de bureau s'approcher de moi. Il me dit, à mi-voix, désignant du doigt sur une carte murale pour écolier l'embouchure de la Somme : «Les Boches ${ }_{\text {p.33 }}$ sont là ! » Puis il revint et murmura : «Ne le racontez pas trop. » je venais de demander au téléphone le G.Q.G. ; ce fut seulement, je l'avoue, après avoir plusieurs fois répété ma tentative que je compris pleinement ce que comportent d'abandon ces mots tragiques : « une armée cernée ».

Nous émigrâmes peu après (le 22 mai), vers le Nord, à Estaires-sur-la-Lys. Mais ce carrefour était peu sûr. Les aviateurs allemands ne cherchaient guère à atteindre personnellement les états-majors; il y aurait eu beaucoup de présomption à leur demander de nous éviter. Dès la première après-midi, une bombe, sans toucher directement l'auberge où nous gîtions, en ébranla avec assez de force la cheminée et les murs pour couvrir nos habits, nos papiers et nos visages d'une innommable suie. L'avertissement fut entendu. En pleine nuit, un ordre de départ me tira du lit où, pour la première fois depuis bien des jours, pour la dernière de la campagne, je jouissais du doux sommeil que procurent de vrais draps. Ce fut, d'ailleurs, pour ne nous mettre en route que le jour depuis longtemps levé ; l'art, si nécessaire, du repos, manqua toujours à notre état-major. Dans la matinée, après un assez long circuit, destiné, comme d'habitude, à rameuter mon parc d'essence, je rejoignis, au sud de Lille, le château d'Attiches, où mes camarades étaient déjà rassemblés (23 mai).

Ce château était, dans un très beau parc, une lourde bâtisse, ornée, sur la façade, d'affreuses céramiques et meublée dans le style cossu, sombre et vaguement moyenâgeux que la haute bourgeoisie, vers la fin du siècle dernier, considérait comme le cadre obligé d'une existence prétendument seigneuriale. Dans un coin de la salle à manger, où nous travaillions, le châtelain, par une attention que nous jugeâmes prématurée, avait entassé tout un monceau de couronnes mortuaires. Ce fut là que, dès l'après -midi du 23, notre quatrième bureau se scinda, définitivement, en deux sections. L'une, formant ${ }_{\text {p. } 34}$ échelon arrière, se rendit immédiatement sur la côte, pour y régler les ravitaillements 
par mer. L'autre — dont je fus — demeura sur place, avec le commandant de l'armée. La plus éloignée du front était en fait destinée à subir les plus violents bombardements. Ce fut une ironie du destin que, sur le moment, personne, je crois, n'avait prévue. En toute innocence, nous nous tenions certainement, à l'avant, pour plus menacés par les bombes — qui, en vérité, ne cessèrent de tomber dans nos environs - surtout, pour plus exposés à la captivité. Et, comme l'échelon de repli, sill se trouva comprendre des hommes d'un indiscutable courage, en réunissait aussi quelques-uns auxquels cette retraite ne sembla pas trop désagréable, nous avions le sentiment de former, plus près de la ligne de feu, une petite société choisie, où régna constamment une excellente atmosphère de cordialité et d'entraide. Si bien qu'un de nos camarades, simple lieutenant de réserve mais, dans le civil, président d'une grande chambre de commerce du Nord, ayant été désigné pour s'en aller sur le littoral, il refusa hardiment de se soumettre. Notre sous-chef de bureau, qui, par une bizarre contradiction avec les usages militaires les mieux reçus, accompagnait, vers l'arrière, le chef même, prit fort mal une attitude si opposée à la sienne propre. Blanc de colère, il traîna le rebelle devant la plus haute autorité de l'état-major. Ce fut, à sa grande surprise, pour voir approuver cette brave désobéissance.

Une autre scène encore reste associée dans ma mémoire à l'image de la salle à manger d'Attiches : un des plus affreux spectacles humains, en vérité, auxquels il m'ait jamais été donné d'assister. Toute une matinée, nous y pûmes voir, affaissé sur une chaise, près de la porte, un personnage qui, le visage morne et l'oeil éteint, mâchonnait d'innombrables cigarettes. Aucun insigne n'était bien clairement visible sur sa manche, les passants le coudoyaient, ${ }_{\text {p. } 35}$ sans lui accorder plus d'attention qu'au dernier des plan tons. C'était, pourtant, un général de division placé, la veille encore, à la tête même d'une de nos plus brillantes unités. Mais un général depuis quelques heures cassé de son commandement. Pour ivrognerie, murmurait-on, à tort ou à raison. Il attendait d'avoir avec le chef de l'armée un ultime entretien longuement retardé. Il l'obtint, enfin, vers midi. L'entrevue ne dura que quelques minutes; et nous ne revîmes plus jamais notre hôte d'un lamentable matin.

Puis ce fut (depuis le 26) notre dernier P.C. de l'autre côté de Lille, vers le nord-ouest, à Steenwerk, une aimable villa, claire et de bon ton. Dans la maison voisine habitait le général Prioux. Il venait de prendre le commandement de l'armée, à la place du général Blanchard, passé au groupe d'armées. L'étreinte ennemie se faisait de plus en plus impérieuse, le problème commençait à se poser de la destruction, par le feu, des importants dépôts d'essence de Lille.

Toute la journée du 27 et la nuit suivante se passèrent, pour moi, à tenter d'obtenir une décision. Il n'y eut pas moins de quatre ordres et contre-ordres successifs. Le dernier, qui prescrivait de tout détruire, faillit bien ne pas atteindre le but. Mon motocycliste partit dans la nuit. Il n'arriva jamais. Quel 
qu'ait été son destin, je n'ai pas le droit d'avoir des remords. Mon devoir était d'assurer l'envoi du pli. J'aurais manqué à ma mission en le portant moi même. Comment, cependant, me défendrais-je d'un pincement de coeur, à la pensée que, sur un mot de moi, un brave garçon est peut-être allé à la mort ? La précédente guerre avait déjà chargé ma mémoire de quelques souvenirs de cette sorte : j’ai là de quoi venir parfois me lanciner, dans mes veilles, jusqu’à ce qu'en moi s'évanouisse toute conscience. Heureusement, je pus faire réexpédier l'ordre et le grand feu s'alluma à temps.

Juste à temps. Car l'armée se retirait déjà ${ }_{\text {p. } 36}$ derrière la Lys et, de là, vers la côte. Pas tout entière, cependant. Le soir du 28, le général Prioux nous fit savoir que, désespérant d'assurer la retraite de d eux au moins de ses divisions, il avait décidé de rester lui-même à Steenwerk et d'y attendre l'ennemi. Ne retenant à ses côtés que quelques officiers, il invitait la plupart d'entre nous à gagner, dans la nuit, le littoral, afin de nous y embarquer. J'all ai le trouver, peu après, pour me faire confirmer l'ordre de vider, mettre hors d'usage et abandonner les camions-citernes. C'était priver l'armée de ses dernières gouttes d'essence et je n'avais pas cru pouvoir prendre sur moi une résolution si grave, bien qu'elle découlât clairement des autres dispositions du moment. Notre grand chef arpentait mélancoliquement le vestibule de sa maison : triste destin, en vérité, que celui de cet homme, enlevé au corps de cavalerie qu'il avait, je crois, fort honorablement commandé, pour prendre, en dernière heure, la direction d'une armée en déroute et accepter, à la place du vrai responsable de la défaite, une ingrate captivité !

Puis je rentrai à notre villa. J'avais déjà, dans la journée, brûlé, conformément à nos instructions, mes archives, y compris le cahier sur lequel était inscrite, au jour le jour, toute l'histoire de mon service. Que ne donnerais-je, aujourdhui, pour le tenir en main, ce cher cahier vert ! Je précipitai également, dans le fourneau de la popote, ma correspondance personnelle - car il nous était interdit de nous alourdir de bagages — et je fis choix, dans ma cantine, pour les emporter avec moi, de quelques objets particulièrement précieux ou utiles. J'en oubliai d'ailleurs les trois quarts. Du moins, ai-je pu alors échanger ma vieille vareuse de travail contre un vêtement en meilleur état. Plus heureux, en cela, que le général commandant l'artillerie de l'armée. Ce très digne homme qui, par un point d'honneur peut -être excessif, avait voulu demeurer avec le général Prioux, ${ }_{p .37}$ ne disposait plus de ses cantines, prématurément expédiées sur Dunkerque. Il ne lui restait que la vareuse quill portait sur lui et elle était trouée au coude. Il en gémissait hautement : se faire faire prisonnier, passe encore : mais en haillons ! Rira qui voudra, je trouve, je l'avoue pour ma part, quelque noblesse à ce sentiment.

Nous partîmes donc dans la nuit, en une longue et lente colonne d'autos, qui se glissa à travers le territoire belge : car les routes françaises étaient déjà coupées. Au petit jour, nous avions à peine fait une dizaine de kilomètres. Comment avons-nous réussi à échapper aux éclaireurs motorisés de l'ennemi ? Encore aujourd'hui, je me l'explique mal. Le fait est, pourtant, 
que, tantôt en voiture, tantôt à pied, j'arrivai, vers la fin de la matinée, à Hondschoote. Restait à atteindre la côte. J'unis mes efforts à ceux du capitaine Lachamp, retrouvé là-bas, pour chercher à rejoindre le gros du parc d'essence, qui, parti bien avant nous, avait reçu comme point de rassemblement, Brayles-Dunes. Nous tentâmes, en voiture, les routes de Furnes. Ce fut pour nous heurter, d'abord à des ponts déjà coupés, puis, sur la chaussée principale, à un invraisemblable embouteillage de camions, arrêtés, tête-bêche, par files de trois. Par derrière, un officier de chars, arguant d'une mission urgente, réclamait à grands cris le passage. Nous nous employâmes, pendant plus d'une heure, à dégager au moins une trouée. Un général de division, rencontré par hasard, me demanda ce que je faisais là. Mis au courant, il se laissa recruter pour nous aider et s'en acquitta, je dois le dire, avec zèle. Nos efforts réussirent enfin. Mais il était trop tard pour songer à poursuivre notre chemin - aussi bien, qui nous garantissait que nous ne nous cognerions pas, plus loin, à de nouveaux obstacles ? — et, bredouilles, nous n'eûmes qu'à regagner Hondschoote.

De là, à la nuit tombante, nous repartîmes, à pied cette fois et par un trajet plus direct : un piéton pouvait se faufiler, là où une auto n'eût jamais passé. Marche affreuse, du moins dans ses dix derniers ${ }_{\text {p. } 38}$ kilomètres, qu'il fallut franchir parmi d'extraordinaires entassements de camions à peine visibles dans une obscurité de plus en plus épaisse. Le parc était bien à Bray. Il m'offrit l'hospitalité dans une maison abandonnée. Il m'offrit même à boire. Malheureusement - près de là, les chirurgiens de l'hôpital de Zuydcoote n'eurent que trop de raisons de le savoir, - tout ce littoral, bordé vers l'arrière de marais et de polders envah is par le sel, se trouvait alors, par suite de la rupture des canalisations, presque complètement privé d'eau. Nous n'eûmes, pour apaiser notre soif, qu'un verre de champagne. Combien une bonne lampée, à une fontaine bien fraîche, eût été plus douce à mon gosier !

L'armée ayant cessé d'exister, en tant que telle, je n'avais plus aucun service d'état-major à remplir. Mais j'avais encore charge d'âmes. Je ne commandais certes pas le parc d'essence ni ses compagnies de camions citernes. J'avais pourtant trop travaillé avec ces braves gens pour me croire en droit de m'occuper de moi -même avant d'avoir assuré leur sort, c'est -à-dire leur embarquement. Car telle était alors l'exclusive préoccupation de chacun. Fuir, avant que l'ennemi en forçât les dernières défe nses, cette côte maudite ; se dérober à la captivité par le seul chemin qui restât encore libre, celui de la mer : une véritable fièvre d'évasion s'était emparée de cette foule d'hommes, maintenant à peu près désarmés, qui, des rives où ils s'entassaient, voyaient les Anglais, avant eux, prendre le large. J'employai le plus clair de ma journée du 30 à tâcher de procurer à mes clients une place définie sur le tableau des départs. Je passai d'abord une partie de la matinée à Bray-les-Dunes, qu'emplissait une foule désordonnée de soldats courant après leurs unités et de camions que montaient des conducteurs d'occasion, pour les abandonner quelquefois au bout de quelques centaines de mètres. Une fois de plus, j’y fis 
de la régulation ${ }_{\text {p.39 }}$ routière, m'efforçant, sans grand succès, d'engager à une activité un peu plus efficace les malencontreux gendarmes, absurdement entassés, par paquets, vers le centre des carrefours. Puis on put m'apercevoir au cabaret du «Perroquet », sur la frontière belge, siège, pendant quelques heures, d'un éphémère commandement de zone ; à Malo-les-Bains, où je retrouvai les principaux éléments de mon quatrième bureau. Ma nuit s'écoula au bivouac, dans les dunes. Les obus allemands y rythmaient notre repos. Par bonheur, ces méthodiques artilleurs ne cessèrent d'arroser constamment le même point, vers la gauche de l'hôtel de Malo-Terminus. Les premiers coups firent d'assez nombreuses victimes. Puis personne ne passa plus par là ou seulement au pas de course. Si le tir avait été moins précis, quel massacre sur notre couche de sable, parmi les oyats !

Le lendemain matin, j'eus la certitude que mes gens embarqueraient. Comment aurais-je prévu qu'une bombe coulerait leur bateau ? La plupart, d'ailleurs - non pas tous, hélas! — purent être repêchés. Rien ne m’interdisait donc plus, désormais, de vaquer à mon propre destin. Notre ancien sous-chef d'état-major, qui nous gouvernait alors, ne montrait pas beaucoup d'empressement à faire partir, avant lui, ses aides de camp. Il m'autorisa, cependant, à me débrouiller. Le mot sonnait mal à mes oreilles. S'agissait-il de me glisser à la place d'un autre ? Heureusement, vers le début de l'après -midi, l'obligeance du commandant du corps de cavalerie me permit d'obtenir, avec deux camarades, un ordre de mis sion régulier. Nous n'avions plus qu'à chercher le navire qui nous était assigné.

Un renseignement mal donné fit que mes deux compagnons de route et moi, nous dûmes traverser par deux fois Dunkerque, d'abord d'est en ouest, puis en sens inverse. Je conserve un souvenir aigu de la ville en décombres, avec ses façades creuses, sur p.40 lesquelles flottaient de vagues fumerolles et, épars parmi ses rues, moins des cadavres que des débris humains. J'ai dans les oreilles encore l'invraisemblable fracas, qui, comme le finale au terme d'un grand opéra, vint peupler de ses sonorités nos dernières minutes, sur les rives de la Flandre: éclatements de bombes, éclatements d'obus, tac-tac des mitrailleuses, tirs de D.C.A., et, pour mieux scander la symphonie, le rythme obstiné du petit canon-revolver du bord. Mais, je l'avoue, si j’évoque cette journée du 31, ce ne sont pas ces images d'horreur et de danger qui adhèrent le plus fortement à ma mémoire. Je revis, avant tout, notre départ de la jetée. Un admirable soir d'été déployait sur la mer ses prestiges. Le ciel d'or pur, le calme miroir des eaux, les fumées, noires et fauves, qui, s'échappant de la raffinerie en flammes, dessinaient, au-dessus de la côte basse, des arabesques si belles qu'on en oubliait la tragique or igine ; jusqu'au nom de conte hindou, enfin, inscrit à la poupe de notre bateau (Royal-Daffodil, «La Jonquille du Roi ») ; tout, dans l'atmosphère de ces premières minutes de voyage, semblait conspirer à rendre plus pleine l'égoïste et irrésistible joie d un soldat échappé à la captivité. 
Ce fut ensuite, après notre débarquement à Douvres, un trajet de toute la journée, en train, à travers l'Angleterre du sud. Il m'a laissé le souvenir d'une longue torpeur, coupée par un incohérent défilé de sensations et d'images, qui, pareilles aux épisodes d'un rêve, n'affleuraient à la conscience que pour sombrer aussitôt : plaisir de dévorer à belles dents les sandwiches au jambon et au chester que nous tendaient, à travers la portière, des girls aux robes multicolores ou des clergymen aussi dignes que s'ils avaient distribué la communion ; parfum, légèrement sucré, des cigarettes, offertes avec la même profusion ; acidité des limonades, fadeur d'un thé, chargé de trop de lait ; douceur des gazons, paysages de ${ }_{\text {p.41 }}$ parcs, flèches de cathédrales, haies et rochers de Devon; hourras des enfants groupés au passage à niveau. Devant tant d'attentions : «Ils sont vraiment bien gentils ! », disaient mes camarades. Vers le soir, nous nous réembarquâmes à Plymouth, pour jeter l'ancre, à l'aube, devant Cherbourg. Là, il fallut rester de longues heures en rade. «Vous comprenez, disaient les officiers du paquebot, français cette fois, qui nous avait transportés, ces messieurs de la Préfecture maritime n'arrivent pas à leur bureau avant neuf heures. » Nous retrouvions, hélas ! la France militaire de l'arrière. Plus de vivats ; plus de sandwiches ni de cigarettes. Mais, une fois à terre, un accueil bien officiel, bien sec, un peu méfiant; comme lieu de repos, un camp inhospitalier et sordide, où seules quelques dames de la CroixRouge mettaient une note de bonne grâce. Puis, après un nouveau cahotement dans des wagons passablement inconfortables, nous arrivâmes, au milieu de la nuit, à Caen, où personne ne semblait nous attendre, mais où, heureusement, il est de bons hôtels et même des salles de bains.

Comment on chercha à refaire, avec les débris d'une armée, quelque chose qui pût encore servir ; comment et pourquoi on n'y réussit guère : il y aura lieu, par la suite, de réfléchir sur cette mélancolique histoire. Après un assez long séjour en Normandie, nous avions échoué, le 16 juin, à Rennes. La Ire Armée n'était plus. Mais son état-major ou ce qui en restait était mis à la disposition du général commandant le «groupement» qu'on ve nait de constituer pour défendre, disait-on, la Bretagne. Le 17, Rennes fut bombardée par avions. Nous habitions fort au-delà de la zone des points de chute ; et, si le formidable ébranlement que produisit l'explosion pourtant lointaine, d'un dépôt de cheddite, put, un moment, en brisant les vitres jusque tout autour de nous, minspirer quelque doute sur mon étalonnage des distances, je me rassurai bien vite. "Il est doux, p.42 dit le poète latin, d'écouter la tempête, quand on est tranquille sur le rivage. » Citation banale, aveu peut-être odieux : quel soldat, pourtant, tendant l'oreille au bruit d'un danger qu'il sait ne pouvoir l'atteindre, n'a senti, lui aussi, au plus obscur de soi -même, son coeur se dilater d'un animal soulagement ?

Le 18 au matin, le bruit se répandit que l'ennemi approchait. Notre bureau était situé sur un boulevard, dans le haut de la ville. De l'autre côté de la chaussée, une rue descendait vers le centre. Là cantonnait mon ordonnance. Vers onze heures du matin, j'allai le trouver pour l'inviter à fermer, en toute 
hâte, mes valises. Après l'avoir quitté, je remontais la rue, lorsque j'aperçus, à son extrémité, une colonne allemande qui défilait sur le boulevard : entre le bureau et moi, par conséquent. Pas un coup de feu. Des soldats français, des officiers regardaient. J'appris plus tard que lorsque les Allemands croisaient, par hasard, un soldat armé, ils se contentaient de le forcer à briser son fusil et à jeter ses cartouches. J'étais farouchement résolu, depuis longtemps, à tout tenter pour ne pas me laisser faire prisonnier. Si javais pu me croire encore utile, j'aurais eu, je l'espère, le courage de rester à mon poste. En l'absence de toute résistance, mon inutilité devenait flagrante ; ou plutôt il m'apparaissait clairement que le seul moyen de continuer à servir, en quelque façon, mon pays et les miens était de m'échapper, avant que le piège achevât de se refermer.

Essayer de m'enfuir vers l'ouest - à supposer qu'il me fût encore possible de découvrir une route libre - cette tentative n'eût abouti, de toute évidence, qu'à me faire prendre un peu plus loin, dans le cul-de-sac de la péninsule. Vers le sud, de même, je risquais fort de ne pouvoir passer la Loire. Du moins, ainsi raisonnais-je, sur le moment. J'ai appris depuis que, contre mon attente, les Allemands n'occupèrent Nantes que le lendemain. Aurais -je, p.43 cependant, réussi à atteindre cette ville, et comment ? Il m'est arrivé aussi de penser qu'à Brest j'aurais peut -être trouvé le moyen de m'embarquer pour l'Anglet erre. Mais me serais-je cru le droit d'abandonner mes enfants pour un exil indéfini ? Quoi qu’il en soit, après quelques minutes de réflexion, sur le trottoir de la rue en pente, je choisis l'issue qui me parut la plus simple et, par suite, la plus sûre. Je me rendis dans la maison où je logeais. J'enlevai ma vareuse - mon pantalon de toile écrue n'avait rien qui évoquât particulièrement l'uniforme. De mon propriétaire qui, ainsi que son fils, fit preuve, en l'occurrence, de beaucoup de courage, j'obtins, s ans peine, le prêt d'un veston et d'une cravate. Puis, après avoir pris contact avec un de mes amis, professeur à Rennes, j'allai me faire donner une chambre dans un hôtel. Estimant que l'on ne se cache jamais mieux que sous son propre personnage, j'inscri vis, sur la fiche qu'on me tendit, mon vrai nom, avec ma profession. Mes cheveux gris m'assuraient que, sous l'universitaire, personne ne chercherait l'officier. A moins que la Kommandantur ne s'avisât de confronter, avec les listes des hôtels, le tableau d'encadrement de l'armée. L'idée ne semble pas lui en être jamais venue. Sans doute, nos maîtres étaient ils déjà blasés sur le bonheur de faire des prisonniers.

Je passai ainsi une douzaine de jours à Rennes. Sans cesse, dans la rue, au restaurant, à l'hôtel même, j'y coudoyais des officiers allemands, partagé chaque fois entre le poignant chagrin de voir les villes de mon pays livrées à l'envahisseur, la surprise d'une cohabitation pacifique avec des hommes que j'aurais abordés, quelques jours plus tôt, seulement revolver au poing, le malicieux plaisir, enfin, de jouer, sans quills s'en doutassent, un bon tour à ces messieurs. A vrai dire, cette dernière satisfaction n'était pas elle-même sans mélange. Il y a toujours, à mon goût, une certaine gêne à vivre dans le p.44 
mensonge ; et bien que celui-là eût, je crois, aisément trouvé grâce devant les plus sévères casuistes, je m'étonnais parfois de réussir à le soutenir avec tant de persévérance. Les trains une fois rétablis, je gagnai Angers, où j'ai des amis ; puis, de là, par la route, Guéret et les miens. De ces doux moments de la « revoyure », comme disait si bien notre vieux langage, on ne trouvera rien ici. Pour en parler, ils font trop fort bondir mon coeur. Que le silence soit sur eux!

$*$

On voit donc comment se circonscrit mon expérience. J'entends de cette guerre-ci ; car la précédente n'aura à intervenir que comme fond de tableau. J'ai participé au travail et à la vie d'états -majors d'un rang assez élevé. Je n'ai certes pas su tout ce qui s'y fais ait. Il m'est arrivé parfois, on s'en rendra compte, d'ignorer jusqu'aux renseignements les plus nécessaires à mon service propre. Mais j'ai pu observer, au jour le jour, les méthodes et les hommes. Je n'ai, par contre, jamais vu de près, moi -même, le combat. Avec la troupe, je n'ai eu que de trop rares contacts. Là-dessus, force m'est de m'en remettre, avant tout, à d'autres témoignages, que j'ai été bien placé pour recueillir et peser. C'est assez, sans doute, sinon pour remplacer la vision directe, dont rien n'égale jamais, si les yeux sont bons, l'authenticité ni la saveur humaine, du moins pour justifier certaines réflexions. Aussi bien, nul ne saurait prétendre avoir tout contemplé ou tout connu. Que chacun dise franchement ce qu'il a à dire ; la vérité naîtra de ces sincérités convergentes.

$$
\begin{gathered}
* \\
* *
\end{gathered}
$$




\section{CHAPITRE II}

\section{La déposition d'un vaincu}

p.45 Nous venons de subir une incroyable défaite. A qui la faute ? Au régime parlementaire, à la troupe, aux Anglais, à la cinquième colonne, répondent nos généraux. A tout le monde, en somme, sauf à eux. Que le père Joffre était donc plus sage ! «Je ne sais pas, disait-il, si c'est moi qui ai gagné la bataille de la Marne. Mais il y a une chose que je sais bien : si elle avait été perdue, elle l'aurait été par moi. » Sans doute entendait-il surtout rappeler, par là, qu'un chef est responsable de tout ce qui se fait sous ses ordres. Peu importe qu'il n'ait pas eu lui -même l'initiative de chaque décision, qu'il n'ait pas connu chaque action. Parce qu'il est le chef et a accepté de l'être, il lui appartient de prendre à son compte, dans le mal comme dans le bien, les résultats. La grande vérité que cet homme simple exprimait si simplement prend cependant aujourd'hui un sens encore plus plein. A u retour de la campagne, il n'était guère, dans mon entourage, d'officier qui en doutât ; quoi que l'on pense des causes profondes du désastre, la cause directe - qui demandera elle-même à être expliquée - fut l'incapacité du commandement ${ }^{1}$. ${ }_{\text {p.46 }}$ Je crains bien que ce propos, par sa brutalité, ne choque, chez beaucoup, des préjugés puissamment enracinés. Notre presse, presque tout entière, et tout ce qu'il y a, dans notre littérature, de foncièrement académique, ont répandu dans notre opinion le culte du convenu. Un général est, par nature, un grand général ; et lorsqu'il a mené son armée à la débâcle, il arrive qu'on le récompense par un cordon de la Légion d'honneur. Ainsi simagine-t-on, sans doute, entretenir, par un voile pudiquement jeté sur les pires erreurs, la confiance de la nation; alors qu'en réalité on ne fait que semer, parmi les exécutants, un dangereux agacement. Mais il y a plus, et peut-être, plus respectable.

Une singulière loi historique semble régler les rapports des États avec leurs chefs militaires. Victorieux, ceux-ci sont presque toujours tenus à l'écart du pouvoir ; vaincus, ils le reçoivent des mains du pays qu'ils n'ont pas su faire triompher. Mac-Mahon, malgré Sedan, Hindenburg, après l'effondrement de 1918 ont présidé aux destiné es des régimes issus de leurs défaites; et ce n'est pas le Pétain de Verdun, non plus que le Weygand de Rethondes, que la France a mis ou laissé mettre à sa tête. Je n’gnore certes

\footnotetext{
1 Au surplus, c'est le général Weygand, ancien directeur du Centre des hautes études militaires, ancien généralissime, qui l'a dit, le 25 mai 1940 (Les Documents secrets de l'ÉtatMajor général français, p. 140) : «La France a commis l'immense erreur d'entrer en guerre n’ayant ni le matériel quïl fallait, ni la doctrine militaire qu'il fallait [Juillet 1942.]
} 
point que dans ces réussites tout n'est pas spontané. Elles n'en réponden t pas moins à une sorte de psychose de l'affectivité collective. Aux yeux des peuples vaincus, ces uniformes, semés d'étoiles et de médailles, symbolisent, avec les sacrifices consentis sur le champ de bataille, les gloires du passé et peut-être de l'avenir. Je ne crois pas qu'une opinion qui heurte la vérité mérite jamais qu'on évite de la contredire. Je pense, avec Pascal, que le zèle est étrange «qui s’irrite contre ceux qui accusent des fautes publiques, et non pas contre ceux qui les commettent »... « Jamais les saints ne se sont tus », a-t-il encore écrit ailleurs. Ce n'est pas une devise pour la censure. Elle n'en mérite pas moins d'être méditée par quiconque, sans prétendre, hélas ! à p.47 la sainteté, s'efforce simplement vers la modeste moralité de l'honnête homme. Mais, du moment que le sentiment est sincère, on ne saurait le battre en brèche sans un peu de chagrin.

Je viens de parler du «commandement ». A peine, cependant, le mot est-il sorti de ma plume qu'en moi l'historien se scandalise de l' avoir écrit. Car l'A.B.C. de notre métier est de fuir ces grands noms abstraits pour chercher à rétablir, derrière eux, les seules réalités concrètes, qui sont les hommes. Les erreurs du commandement furent, fondamentalement, celles d'un groupe humain.

J'ai peu approché les grands chefs, dont m'éloignait la modestie de mon grade et de mes fonctions. Le seul qu'il m'ait été donné de voir, quelquefois, d'un peu plus près, fut le général Blanchard. Je garde de lui surtout le souvenir d'un homme très bien élevé. La dernière fois quill me fit l'honneur de m'adresser la parole, ce fut, m'ayant rencontré en Normandie, après mon retour des Flandres, pour me dire obligeamment : «Eh bien ! vous vous êtes donc, vous aussi, tiré indemne de cette aventure. » La formule me parut désinvolte. «Bénissons notre heureuse aventure!»s'écrie de même Félix, dans la dernière scène de Polyeucte. Et Voltaire de commenter : "Ces mots, après avoir coupé le cou de son gendre, font un peu rire. » Dans l'aventure des Flandres, Blanchard avait, pour sa part, perdu plus de la moitié de son armée, et laissé en arrière, comme prisonniers volontaires, avec son propre chef d'état-major, l'officier qu'il s'était donné lui -même pour successeur. Mais je sais qu'il ne faut juger personne sur un propos de hasard. Au château d'Attiches, comme un jour, dès l'aube, on m'avait appelé pour téléphoner au G.Q.G. britannique, je passai plus d'une heure dans la pièce où se tenait le général: sans un mot, presque sans un geste, figé dans une immobilité tragique, il contemplait fixement la carte, étalée sur la table qui nous séparait, comme pour y p. 48 chercher la décision qui le fuyait. A Attiches, de même, j'ai, fort involontairement, surpris de sa bouche quelques mots, sur lesquels j'aurai à revenir. Dans l'ensemble, cependant, je n'ai guère pu le connaître qu'à travers ses actes de commandement. Or, sur ce point, il m'est difficile d'établir le départ entre son action personnelle et celle de son entourage. 
J'ai eu, cela va de soi, une familiarité beaucoup plus grande avec les milieux d'officiers d'état -major, mes chefs immédiats ou mes camarades, pour la plupart d'active et brevetés de l'École de Guerre.

Si grande, à la vérité, que je me trouve, d'avance, prémuni contre la tentation de camper ici un portrait, qui serait naturellement tout arbitraire, de l'officier d'état -major en soi. Quand, les yeux clos, je feuillette mes souvenirs, c'est une galerie de figures nettement individualisées qui défilent devant ma conscience : les unes, vouées, à jamais, au sourire, les autres, qui, tant que je vivrai, resteront douces à ma mémoire.

Le capitaine B..., du troisième bureau, levant haut vers le ciel sa tête vide, semblait offrir éternellement à la vénération des foules, comme un saint sacrement, la science livresque, jadis reçue en dépôt aux cours de tactique. Le capitaine X... - de chez nous celui-ci - fort en gueule, plutôt que grand dans l'action, avait réussi, en quelques mois, à s'attirer la haine de tout le personnel des secrétaires, qu’il se croyait, par la grâce d'une vocation native au commandement, chargé de «mettre au pas »: quand il s'en allait coucher à la cave, quels ricanements derrière son dos! Avec ces fiers-à-bras, comment confondre notre charmant popotier, si serviable, si modestement brave, si discrètement efficace dans ses fonctions d'adjoint au chef de bureau, puis d'officier de liaison, et auquel je ne trouve vraiment à reprocher qu'une chose : l'accès de découragement ou de dépression physique qui, devant l'écroulement ${ }_{\text {p.49 }}$ de ses rêves de guerrier pour images d'Épinal, l'entraîna un soir, dans la lourde atmosphère de Steenwerk, à se laisser faire inutilement prisonnier. Qu'il avait dû souffrir pour en arriver là — et souffrir plus encore quand il aura su, par quelque journal allemand, l'ar mistice ! Ceux que je viens de nommer, nous les avions déjà bien jaugés dès le temps de Bohain. Mais les jours brûlants de la campagne devaient, en des sens divers, nous apporter plus d'une révélation.

Cet officier supérieur, qui avait fait la guerre de 1914-1918 et en avait rapporté de belles citations, certes, nous connaissions bien d'avance, avec ses qualités, qui n'étaient pas sans attrait, ses redoutables défauts : son sens du concret, mais son désordre, son esprit de «débrouillage », mais son obstinée répugnance à rien prévoir; sa gentillesse, mais, parfois, son manque de franchise. Qui nous eût fait prévoir, cependant, son effondrement, dans l'action ? En toute sincérité, je crois, aujourd'hui, que, sur le moment, nous avons été injustes envers lui. Méchamment, nous avons attribué, sans plus, à la faiblesse devant le danger ce qui - entretenant, chez lui, cette nervosité, par les apparences, si voisine de la peur - était, avant tout, conscience, presque prématurée, de la catastrophe grandissante, anxiété sous le poids d'une charge trop lourde, sentimentalité excessive aussi : ne m'a-t-il pas avoué, à Attiches, qu'il ne s'était pas senti la force de désigner lui -même ceux de ses collaborateurs qui devraient rester au poste jugé alors le plus exposé ? Mais un fait est sûr: alourdi sans doute par des années de bureau et de 
pédagogie, ce soldat de carrière avait complètement cessé d'être — avec tout ce que le mot comporte de domination de soi et d'implacabilité — un chef,

Sur l'autre volet du diptyque, co mment résisterais-je au plaisir d'évoquer la longue et blonde silhouette ${ }_{\mathrm{p} .50} \mathrm{du}$ cher capitaine d'artillerie qui, aux heures troubles d'Attiches et de Steenwerk, exerça, à l'échelon avancé, le commandement de notre bureau ? Naguère, à Bohain, où il avait sous ses ordres la section du ravitaillement, nous avions pu le juger tatillon et, parfois, de mauvais poil. Il n'avait pas l'esprit très prompt et, cavalier passionné, se vantait volontiers de détester le travail intellectuel. Sa franchise à soutenir, fût-ce contre ses supérieurs, les opinions qu’il croyait vraies, forçait l'estime ; mais son humeur contredisante agaçait. Son goût, peut-être un peu artificiel pour les plaisanteries scatologiques, fatiguait les moins prudes. Ses préjugés politiques, sociaux (car il était de haute bourgeoisie) et, j’imagine, raciaux s'écartaient, autant qu'il est possible, de ma propre vision du monde. Nous étions de corrects camarades : sans beaucoup de chaleur, je le crains, ni d'une part ni de l'autre.

Vint la campagne du Nord. Quand tout fut consommé, le général Prioux décida que chaque bureau désignerait un officier pour attendre l'ennemi avec lui. T..., je l'ai dit, était alors notre chef. Il estima que., parce qu'il était le chef, cette mission de sacrifice ne pouvait appartenir qu'à lui. De jugement assez ferme, d'ailleurs, pour ne pas ranger le consentement à une inutile prison parmi les devoirs d'honneur du soldat, il m'a, d'ailleurs, confessé plus tard avoir passé la soirée qui suivit, l'oeil fixé sur le trou de haie par où, dès l'arrivée des Allemands, il comptait bondir loin de leurs prises, revolver au poing. Il l'eût tenté certainement si, presque à la dernière heure, un incident inopiné n'était venu lui rendre sa liberté de mouvement. Dans la nuit, on vit apparaître au P.C. le général commandant le $4^{\mathrm{e}}$ corps ; les unités sous ses ordres se trouvant presque toutes dans l'incapacité de repasser la Lys, il avait résolu de joindre sa destinée à celle du commandant de l'armée. Notre popotier, qui faisait auprès de lui fonction d'agent de liaison, p.51 l'accompagnait. Comme je l'ai dit plus haut, ce pauvre ami refusa de mettre à profit la chance, qui lui fut offerte, de gagner la côte. Son abnégation lassée sauva T... Car le général n'avait demandé qu'un prisonnier d'offic e par bureau. T... reçut l'autorisation de partir. Nous eûmes, le lendemain matin, la surprise et la joie de le voir surgir, à peine un peu en retard, à notre premier rendez-vous, non loin de Hondschoote, juché sur une belle bicyclette neuve qu'il avait dé couverte, en cours de route, dans les rues désertées de Bailleul. Mais nous nous étions, lui et moi, fait nos adieux, la veille au soir. Nous étions, l'un et l'autre, passablement émus ; et si nous ne nous dîmes pas alors, en autant de mots, que nous nous étions autrefois mutuellement méconnus et que nous en avions beaucoup de regrets, c'est parce que ces choses -là ne se disent guère; il suffit qu'on les sente ensemble. La vie nous a aujourd'hui séparés. Au point que j'ignore, au moment où j'écris, s'il es t encore de ce monde. Si jamais elle doit nous rapprocher de nouveau, ce sera, j'en ai peur, 
pour recommencer à nous opposer. Pas comme avant, cependant. Pour ma part, il me serait impossible de rayer de ma mémoire ces quelques minutes, chargées d'électric ité humaine, dans le jardin de Steenwerk.

Ni non plus ce qui les avait précédées et justifiées. Un des privilèges du véritable homme d'action est, sans doute, que, dans l'action, ses travers s'effacent, tandis que des vertus, jusque-là en sommeil, paraissent alors chez lui avec un éclat inattendu. Telle fut la métamorphose dont notre camarade donna un remarquable exemple. Consciencieux et sincère il l'avait toujours été ; il cessa de s'attacher aux petites choses et son goût de la contradiction disparut. Toujours prêt à donner un renseignement ou une directive, il fut le chef qui sait laisser aux exécutants la liberté nécessaire, tout en prenant la responsabilité de tout. Il fut patient, calme aux pires heures, prodigue de sa propre fatigue autant que ${ }_{\text {p.52 }}$ ménager de celle des autres. Et si bon garçon avec cela! J'avais fait la découverte d'un homme.

Dans aucun groupe humain, cependant, les individus ne sont tout. A plus forte raison, leurs particularités tendent-elles à s'estomper, dès lors quills appartiennent à une communauté fortement constituée. Une formation première, conduite, pour chacun, sur des lignes à peu près semblables, l'exercice d'une même profession, la soumission à des règles de vie communes ne sont peut-être pas les ciments les plus forts. Il y faut encore, avec les traditions transmises d'ancien à jeune ou de chef à subordonné, le sentiment d'une sorte de prestige collectif. Tel est, éminemment, le cas de ce qu'on pourrait appeler les corporations militaires. Dans la nation, les milieux d'officiers de carrière forment déjà une petite société bien caractérisée : par maintes survivances, la plus propre, assurément, à restituer à notre civilisation, relativement nivelée, l'image de ce que fut, dans l'ancienne France, la notion moins de classe encore que d' " ordre ». Dans la noblesse d'autrefois, en dépit d'énormes différences de rang, régnait la conscience d'une véritable égalité de principe, si bien que le roi, en personne, n'était, au regard de ce code, rien de plus que «le premier gentilhomme de son royaume ». Aujourd'hui de même, un général, fût-il parmi les plus étoilés, s’il pénètre dans la pièce où travaille un modeste sous-lieutenant ne saurait, sans manquer à la plus élémentaire courtoisie, omettre de lui tendre la main. Mis en face d'un sous -officier - ne parlons pas d'un simple soldat - il faudra, pour l'engager à ce geste, les circonstances les plus exceptionnelles. A l'intérieur de l'armée, le monde des officiers d'état-major fait figure, à son tour, d'une collectivité remarquablement homogène.

Parmi ses traits généraux les plus incontestables, un de ceux qui lui font le plus d'honneur est certainement le respect du devoir professionnel. Ce penchant lui est d'ailleurs commun, je crois, avec la ${ }_{\text {p.53 }}$ plupart des officiers de tout rang. Je suppose que, chez les brevetés de l'École de Guerre, comme partout, il existe des paresseux, sans conscience. A une exception près peutêtre - encore s'agissait-il d'un personnage évidemment jaugé déjà par ses pairs, et relégué dans un état-major sans importance - je n'en ai jamais 
rencontré. C'est là une grande vertu et que bien peu d'autres corps de fonctionnaires possèdent, aujourd'hui, j'en ai peur, à ce degré.

On a souvent parlé du dédain de l'officier d'état -major pour l'officier de troupe. Je ne nierai certes point, chez quelques vaniteux à tout prendre assez rares, les manifestations d'une irritante morgue d'École de Guerre. Il n'est que juste, cependant, de le dire : presque tous les brevetés que j’ai connus faisaient sonner très haut leur désir de reprendre leur place dans la troupe. Peut-être y avait-il là une part de mode. J'en sais qui, mis au pied du mur, perdirent visiblement beaucoup de leur enthousiasme. Mais il m'a semblé que, du moins chez les jeunes, ces propos, dans l’immense majorité des cas, répondaient à un sentiment parfaitement sincère. Aussi bien est-il déjà caractéristique que le bon ton ait exigé l'expression d'une pareille estime pour les services du rang.

Quant aux malentendus qui, dans tant d'armées, de toute nation, s'élèv ent, par moments, entre les exécutants et le personnel dirigeant, ce dernier n'en est assurément pas seul responsable. Car les difficultés n'apparaissent pas, aux divers échelons, sous le même angle et se mettre par la pensée à la place d'autrui fut toujours, au bas comme au sommet de la hiérarchie, une gymnastique mentale singulièrement difficile. On ne saurait contester, pourtant, que les états-majors n'aient, sur ce point, beaucoup péché. Mais ce fut bien moins, je crois, par mépris que par pauvreté d’im agination et manque de sens concret.

p.54 Au temps où l'on ne se battait pas encore, nous étions fréquemment occupés à mouvoir les unités, sur la carte: combien d'entre nous se représentaient, avec une vivacité suffisante, la somme de gênes matérielles et, sur le plan moral, de découragement, qu'entraîne dans la troupe, l'abandon en plein hiver d'un cantonnement où, déjà, le soldat a adroitement fait son nid, pour un nouveau gîte qui ne lui offre bien souvent que des installations médiocres et mal adaptées ? Mais il y a pis. Durant la précédente guerre, j’ai, à plusieurs reprises, constaté l'incapacité du commandement à calculer avec exactitude le temps qu'un ordre, lancé depuis un quartier général, met à atteindre, d'étape en étape, le point où il pourra être mis à exécution : à qui font défaut les yeux de l'esprit, les meilleurs mémentos n'apprendront jamais à mesurer le cheminement, voire les erreurs d'un agent de liaison sur des pistes boueuses. Le 22 juillet 1918, me trouvant à l'armée Mangin — dont les méthodes, à cet égard, étaient particulièrement fâcheuses — j'eus l'angoisse de recevoir ainsi, moi-même, en dépôt, un ordre d'attaque, bien avant qu'il ne fût possible de le transmettre aux intéressés, alors en cours de mouvement. Il arriva finalement si tard à son but que le bataillon, chargé de l'opération, n'eut pas le loisir de reconnaître le terrain avant l'aube, partit à l'assaut tout de travers et se fit, presque en entier, inutilement massacrer. Je ne suis pas sûr que la conduite de cette guerre-ci ait été, à son tour, complètement exempte de pareils errements. A ce sujet, c'est toute une formation intellectuelle qui doit être incriminée. Nous aurons à y revenir. 
Un remède existe, il est vrai, simple et bien connu. Il suffit d'établir, par fractions, un va-et-vient entre les deux groupes d'officiers. Mais les grands chefs n'aiment guère changer de collaborateurs. On se souvient qu'en 1915 et 1916, leurs répugnances à s'y résigner avaient abouti à un véritable divorce entre $_{\text {p.55 }}$ le champ de vision des combattants et celui des états-majors. Lorsque la relève s'imposa enfin, on dut, pour l'avoir trop longtemps différée, la faire beaucoup trop massive ; et la troupe décimée avait cessé de pouvoir fournir, en nombre nécessaire, les éléments appropriés : car tout bon commandant de compagnie ou de bataillon ne sera pas forcément un bon officier d'état-major. Je n'avais pas vu sans inquiétude, pendant l'hiver 1939 -1940, se renouveler cette cristallisation des cadres ; j'ai cherché alors à en signaler les dan gers en haut lieu. La crise des mois de mai et juin fut trop brusque pour quils aient eu le temps de se manifester, dans toute leur activité.

Honnêtes, éminemment désireux de bien faire, profondément patriotes, plus déliés aussi d'esprit, pour la plupart, que la masse polytechnicienne ou saint-cyrienne, dont ils sont issus, parfois même véritablement brillants, les officiers d'état-major constituent donc, dans leur ensemble, un corps digne d'estime. Il est pourtant indiscutable que par eux -mêmes ou par les chefs sortis d'eux, ils nous ont conduits à la défaite. Pourquoi ? Avant de chercher à l'expliquer, mieux vaudra, sans doute, tâcher de décrire comment.

Je ne prétends nullement écrire ici une histoire critique de la guerre, ni même de la campagne du Nord. Les documents, pour cela, me manquent ; et aussi, la compétence technique. Mais il est, dès maintenant, des constatations trop claires pour qu'on hésite à les formuler, sans plus attendre.

Beaucoup d'erreurs diverses, dont les effets s'accumulèrent, ont mené nos armées au désastre. Une grande carence, cependant, les domine toutes. Nos chefs ou ceux qui agissaient en leur nom n'ont pas su penser cette guerre. En d'autres termes, le p.56 triomphe des Allemands fut, essentiellement, une victoire intellectuelle et c'est peut-être là ce qu'il y a eu en lui de plus grave.

On peut, je crois, préciser encore davantage. Un trait, entre tous décisif, oppose la civilisation contemporaine à celles qui l'ont précédée . depuis le début du $\mathrm{XX}^{\mathrm{e}}$ siècle, la notion de distance a radicalement changé de valeur. La métamorphose s'est produite, à peu près, dans l'espace d'une génération et, si rapide qu'elle ait été, elle s'est trop bien inscrite, progressivement, dans nos moeurs, pour que l'habitude n'ait pas réussi à en masquer, quelque peu, le caractère révolutionnaire. Mais l'heure présente se charge de nous ouvrir les yeux. Car les privations, issues de la guerre ou de la défaite, ont agi sur 
l'Europe comme une machine à remonter le temps et c'e st aux genres de vie d'un passé, hier encore considéré comme à jamais disparu, qu'elles nous ont brusquement ramenés. J'écris ceci de ma maison de campagne. L'an dernier, quand mes fournisseurs et moi disposions d'essence, le chef-lieu de canton, qui est notre petit centre économique, semblait à notre porte. Cette année, où il nous faut, pour les personnes les plus ingambes, nous contenter de bicyclettes et, pour les matières pondéreuses, de la voiture à âne, chaque départ vers le bourg prend les allures d'une expédition. Comme il y a trente ou quarante ans! Les Allemands ont fait une guerre d'aujourd'hui, sous le signe de la vitesse. Nous n'avons pas seulement tenté de faire, pour notre part, une guerre de la veille ou de l'avant-veille. Au moment même où nous voyions les Allemands mener la leur, nous n'avons pas su ou pas voulu en comprendre le rythme, accordé aux vibrations accélérées d'une ère nouvelle. Si bien, qu'au vrai, ce furent deux adversaires appartenant chacun à un âge différent de l'humanité qui se heurtèrent sur nos champs de bataille. Nous avons en somme renouvelé les combats, familiers à notre histoire coloniale, de la p.57 sagaie contre le fusil. Mais c'est nous, cette fois, qui jouions les primitifs ${ }^{1}$.

Relisez la liste des P.C. de la $\mathrm{I}^{\mathrm{re}}$ Armée, durant la campagne du Nord : Valenciennes, Douai, Lens, Estaires, Attiches, Steenwerk. A chaque nouvelle pression de l'ennemi, un recul a répondu. Rien de plus naturel. Mais, de combien, les bonds ? Entre 20 et 35 kilomètres, chaque fois. Pas davantage. En d'autres termes - car, ainsi que nous l'enseignait déjà Vidal de La Blache, c'est en distances horaires qu'il convient aujourd'hui de penser - au grand maximum, une demi-heure d'auto. Naturellement, les déplacements de la ligne de résistance étaient en proportion. Du moins, tels que le commandement s'imaginait pouvoir en imposer le tracé à l'ennemi. De notre école de Lens, nous entendîmes distinctement le combat à la mitrailleuse. Si suggestif qu'ait pu paraître, à de vieux soldats de 1914, ce rappel de sonorités un peu oubliées, je ne crois pas que la volonté de nos chefs eût été d'en procurer le plaisir à leur état-major. Les Allemands, tout simplement, avaient avancé plus vite qu'il ne semblait conforme à la bonne règle. Il en fut ainsi, à peu près constamment. "Stratégie à la petite semaine», disait, de nos méthodes, un de mes camarades : un de ces jeunes qui, du moins, savaient être de leur temps et souffraient de voir leurs supérieurs lui tourner, si résolument le dos. Il n'eût pourtant pas été nécessaire d'avoir usé ses fonds de culottes sur les bancs de l'École de Guerre ou du « C.H.E.M. » (le Centre ${ }_{\text {p. } 58}$ des Hautes Études Militaires) pour comprendre une situation trop claire. De toute évidence, une fois enfoncée l'armée de la Meuse, cependant que, sur notre

\footnotetext{
${ }^{1}$ Sur l'acc élération du rythme que les métamorphoses du présent imposent à la pensée, on trouvera d'intelligentes observations dans un petit livre où on ne songerait sans doute guère à les chercher: celui de Charlesworth sur Les Routes et le trafic commercial dans l'Empire romain. Voir le développement de la page 225. Notamment: Les hommes doivent aujourd'hui prendre leurs résolutions avec une promptitude qui eût stupéfié nos aïeux. » [Juillet 1942.]
} 
propre front, l'ennemi se faisait chaque jour plus insistant, une seule chance de salut subsistait : après s'être " décrochés », rétablir une nouvelle ligne de défense, assez loin à l'arrière, pour ne pas être balayée avant même d'être garnie. Au lieu de cela, on se borna à précipiter dans la brèche, tour à tour, de petites unités, vouées à un écrasement immédiat, tandis qu'on s'obstinait, d'autre part, à vouloir tenir en pointe vers Valenciennes et Denain ; jusqu'au moment où, la retraite vers le littoral enfin décidée, les divisions, qui avaient été laissées là-bas, se trouvèrent incapables de rejoindre, à temps. Si Joffre, après Charleroi et Morhange, avait procédé de la sorte, il n'aurait pas gagné la bataille, sur la Marne ; il l'aurait perdue, vers Guise. Et cependant, de son temps, les troupes adverses ne marchaient qu'à pied.

Dans ces erreurs, j'ignore quelle fut, au juste, la part des divers échelons du commandement : I ${ }^{\mathrm{re}}$ Armée, Grand Quartier et, au degré intermédiaire, $1^{\mathrm{er}}$ Groupe d'armées. Ce dernier eut à sa tête d'abord le général Billotte, puis, à partir du 25 mai, le général Blanchard. Mortellement blessé, le 21, dans un accident d'auto, Billotte n'est plus là pour se défendre. Cette disparition opportune le désignait tout naturellement pour le rôle de bouc émissaire. Si j'en juge par certaines conversations, surprises dans notre triste petite salle à manger de Malo-les-Bains, on ne se privera pas de le lui faire jouer.

Non, sans doute, tout à fait à tort. En cas d'invasion de la Belgique par les Allemands, quelle forme devait prendre la riposte des armées francobritanniques ? Ce problème avait, tout l'hiver durant, agité les bureaux «opérations » des états-majors. Deux solutions se partageaient les préférences. Les uns proposaient d'attendre l'ennemi, de pied ferme, sur p.59 une position jalonnée, en Belgique, par l'Escaut, puis, vers l'Est, par la ligne, malheureusement assez incomplète, de blockhaus et de fossés antichars qui suivait, à peu près, notre frontière, quitte, cela va de soi, à lancer en avant quelques éléments de reconnaissance et de retardement. D’autres, au contraire, voulaient immédiatement la guerre tout entière en dehors de notre territoire national ; ils nous invitaient, pour cela, à occuper, d'un bond, la rive gauche de la Dyle, celle de la Meuse belge et, dans l'intervalle entre les deux cours d'eau, une diagonale tirée, de Wavre à Namur, à travers les hautes plaines de la Hesbaye, presque complètement dépourvues d'obstacles naturels. Chacun sait que la seconde solution finalement l'emporta. Il semble bien que, dans cette décision, l’influence du général Billotte ait été prépondérante.

Le choix était peut-être, en lui-même, imprudent. Il le devint, incontestablement, aussitôt que la résistance belge, autour de Liège, eut commencé de faiblir. On avait compté qu'elle nous donnerait le répit de quelques jours, nécessaire pour garnir et organiser notre nouveau front. Or, les ponts entre Liège et Maestricht n'ayant pu être coupés tous au moment voulu, la place se trouva tournée presque dès le début de l'offensive allemande, et les témoignages de nos agents de liaison ne permettaient pas de douter qu'elle ne dût, elle-même, rapidement succomber. En même temps, les premières rencontres avaient révélé d'autres surprises. Les chars ennemis n'étaient pas 
seulement beaucoup plus nombreux que nos services de renseignements ne l'avaient jamais supposé ; certains d'entre eux possédaient en outre une puissance inattendue. L'aviation allemande surclassait affreusement la nôtre. La mission d'établir le contact, en avant de la Dyle et de la position Wavre Namur avait été confiée au corps de cavalerie, entièrement motorisé, malgré son nom traditionnel: «la seule formation à laquelle je n'ai p.60 jamais affaire », me disait un jour, le vétérinaire de l'armée. Le général Prioux, qui commandait alors cette grande unité, proposa, dès le 11 , de renoncer à la manoeuvre prévue. Notre ligne de défense aurait été reportée, incontinent, sur l'Escaut et la frontière. Ici encore, Billotte se mi t à la traverse. Lorsqu'un chef d'un rang si élevé prend la peine d'exercer lui -même une pression personnelle, elle demeure rarement tout à fait inefficace. J'ai des raisons de croire qu'après un entretien avec le commandant du groupe d'armées, Prioux se laissa aller à édulcorer, du moins, son rapport. De celui-ci, en tout cas, il est sûr qu'on ne tint aucun compte.

Quel aurait été, cependant, le sort de la Ire Armée et des forces britanniques et françaises placées à sa gauche, si, vers sa droite, ne s'était ouverte, inopinément, la plaie béante de la Meuse? Je ne me sens certes pas la compétence nécessaire pour prophétiser là-dessus, après coup. Le 14 mai, un segment du front, qui nous avait été assigné, fut enfoncé ; il était tenu par une de ces divisions marocaines dont les éléments indigènes semblent avoir au début du moins, particulièrement mal supporté les bombardements aériens et les attaques par chars. Mais le rétablissement s'opéra, assez vite.

Incontestablement, ce fut la débâcle des armées de la Meuse et de Sedan qui, en découvrant brusquement les arrières des troupes engagées en Belgique, voua leur manoeuvre à un irrémédiable échec. Comment expliquer que l'abrupte vallée d'un large fleuve, qu'on eût imaginée si facile à défendre, ait été si mal défendue ? Sur ce fait, un des plus considérables de la guerre et peut-être le plus surprenant, je n'ai pu jusqu'ici recueillir que des on -dit sans consistance. Ce que je sais trop bien, c'est qu'on tarda beaucoup à en tirer les conséquences nécessaires.

Le 13 mai, nous apprîmes la rupture de la ligne de la Meuse ; le même jour, un ordre, signé Gamelin, p.61 prescrivait encore de résister sur la ligne Wavre-Namur. La retraite ne fut décidée que le 15 et j'ai déjà eu l'occasion de rappeler qu'elle s'opéra au c ompte-gouttes. A ces méthodes, rien ne parut avoir été changé ni par la substitution de Weygand à Gamelin (qui eut lieu le 20) ni par la visite que, le lendemain, le nouveau généralissime fit à lord Gort et au général Billotte ${ }^{1}$ : voyage dramatique qu'il fallut accomplir en avion, les communications terrestres étant déjà coupées jusqu'à la mer. Ce fut au retour de cette entrevue que le commandant du groupe d'armées qui, disait-on, se

\footnotetext{
${ }^{1}$ Je donne ici le récit, tel qu'il m'a été fait, sur le moment. $\mathrm{S}$ i je comprends bien son rapport du 22 mai, au Comité de guerre franco-britannique (Les Documents secrets de l'État-Major français, p. 130), Weygand n'aurait pourtant pas réussi à joindre lord Gort. [Juillet 1942].
} 
faisait toujours conduire à tombeau ouvert, eut sa voiture écrasée contre un camion. Dans les événements qui s'étaient succédé depuis le 13, quel avait été son rôle personnel ? Je ne dispose, à ce sujet, d'aucune lumière particulière. Une chose est certaine : les erreurs alors commises furent, par leurs effets, beaucoup plus décisives; elles semblent en elles-mêmes beaucoup moins pardonnables que, si téméraire qu'elle ait pu être, la conception première du plan d'opérations. Après tout, se tromper au départ, il est peu de grands capitaines qui ne s'y soient laissé quelquefois en traîner; la tragédie commence quand les chefs ne savent pas réparer. Billotte une fois disparu de la scène, personne n'eut d'ailleurs l'impression qu'un esprit nouveau soufflait sur le commandement. Probablement ses fautes, qu'on ne saurait guère nier, lui étaient communes avec toute une école.

La campagne du Nord, avec ses dures leçons, réussit-elle du moins à convaincre nos maîtres que le rythme de la guerre avait changé ? La réponse sera donnée par l'histoire des dernières convulsions p.62 dans lesquelles devaient se débattre les morceaux d'armées échappés au désastre des Flandres. Les vaisseaux qui nous avaient permis de fuir la captivité avaient jeté sur les côtes françaises des éléments disjoints par la retraite, par l'embarquement même, quelquefois par les naufrages, et totalement désarmés ; il fallait recoller les unités, les réencadrer, les équiper à nouveau, de pied en cap. Or, pour cette reconstitution, délicate et nécessairement assez lente, le haut commandement fit choix d'une zone qui s'étendai $t$ à peu près d'Évreux à Caen. Le front, dès lors mouvant, de la Somme, courait à moins de 150 kilomètres de là, en moyenne. C'eût été beaucoup sous Napoléon, suffisant, sans doute, en 1915. En l'an de grâce 1940, autant dire rien. Les Allemands nous le firent bien voir. Force fut, bientôt, de se rabattre vers le Sud, d'abord, selon l'usage, d'une faible longueur, puis beaucoup plus loin. Mais, déjà, la grande débâcle avait commencé. En vérité, c'est sur la Charente, sinon sur la Garonne, qu'il eût convenu de nous rassembler : bien placés pour nous porter, de là, dans n’importe quelle direction, nous aurions peut-être eu le temps de nous rendre utiles. La rage me mord encore le coeur, quand j'y pense, comme naguère dans nos châteaux normands. De cette étonnante imperméabilité aux plus clairs enseignements de l'expérience, nous ne devions, d'ailleurs, pas être les seules victimes, ni, vraisemblablement, les plus déplorables. A l'avance allemande, vers la plaine de la Saône, le Jura et le Rhin, tout le loisir ne fut-il pas laissé de cerner les armées françaises de l'Est et, presque, celle des Alpes ? D'un bout à l'autre de la guerre, le métronome des états-majors ne cessa pas de battre plusieurs mesures en retard.

Un épisode, en lui-même sans portée pratique, mais significatif, acheva, sur le moment, de me prouver que cette curieuse forme de sclérose mentale ne se limitait pas aux autorités supérieures, p.63 coupables de nous avoir assigné pour lieu d'asile les proches arrières du front. Depuis que le général commandant le $\mathrm{XVI}$ e corps s'était vu confier, après mille péripéties, la charge 
de diriger le travail de regroupement, l'état-major de la I ${ }^{\mathrm{re}}$ Armée, oisif et mal en cour, avait été relégué dans deux manoirs écartés, au sud de Caen. Le 15 juin, nous reçûmes enfin l'ordre de nous rendre à Rennes. Le déplacement devait se faire, partie par voie ferrée, partie par la route. Comme nous ne disposions que d'un petit nombre d'autos, elles furent d'abord employées à assurer le transport, jusqu'à la gare, du détachement désigné pour prendre le train. Quand ce va-et-vient fut terminé, vers le soir, nous allâmes, un de mes camarades et moi, trouver le lieutenant-colonel qui était, parmi nous, le personnage le plus élevé en grade. Nous avions convenu de lui proposer de partir, sans plus tarder. Chacun savait, en effet, que les colonnes motorisées allemandes sinfiltraient en Normandie, menaçant, en particulier, nos communications vers le Sud. Dans un tête-à-tête inopiné avec des autosmitrailleuses, une caravane d'officiers, munis, pour toute arme, de quelques revolvers, aurait fait piètre figure. Nous risquions de nous laisser stupidement capturer, au vol, et cette perspective nous déplaisait à l'extrême. Le lieutenant colonel, à son habitude, commença par tergiverser. Mais il jugeait incommode d'arriver, à Rennes, dans la nuit et ce souci de confort le décida, finalement, à attendre, pour lever le camp, les premières lueurs du jour. La vérité m'oblige à dire que nous ne fîmes pas de mauvaises rencontres. L’imprudence n'était $\mathrm{p}$ as, pour cela, moins grave. Elle minclina à ne pas tenir pour purement légendaire la mésaventure de ce chef, d'un rang beaucoup plus considérable, qui, dit-on, avait vu, sur l'Oise, sa salle à manger brusquement cernée par un parti de feldgrau.

Aussi bien, avons-nous jamais, durant toute la campagne, su où était l'ennemi ? Que nos chefs aient p.64 toujours imparfaitement connu ses véritables intentions et, pis encore peut-être, ses possibilités matérielles, la mauvaise organisation de nos services de renseignements suffit à l'expliquer. Mais l'ignorance où, sur le moment même, nous avons perpétuellement été de ses mouvements, eut pour cause, avant tout, un constant décalage dans l'appréciation des distances. Notre propre marche était trop lente, notre esprit, également, trop dépourvu de promptitude, pour nous permettre d'accepter que l'adversaire pût aller si vite. Au départ de Lens, le 22 mai, il avait été décidé que le Quartier Général se diviserait en deux groupes: le P.C. actif, à Estaires ; la fraction «lourde», plus loin du combat, croyait-on, à Merville. La surprise fut grande de devoir constater, à l'expérience, que l'échelon dit «arrière » se trouvait plus près de la vraie ligne de feu que l'échelon qualifié «avant ». Déjà, lorsque s'ouvrit la b rèche de la Meuse, il avait fallu s'efforcer de modifier hâtivement, en cours de route, les points de débarquement d'une division, que, sous prétexte de colmater la poche, on s'apprêtait à jeter dans la gueule du loup.

Après notre arrivée dans les Flandres, les faux calculs de ce genre se multiplièrent. Il arriva qu'un général de division, s'approchant du point qui lui avait été désigné pour P.C., s'aperçut que l'ennemi l'avait devancé. J'ai encore froid dans le dos au souvenir de la tragédie dont je faillis, un jour, 
devenir l'auteur, l'innocent auteur, oserais -je dire, car je n'avais pas les moyens de minformer mieux et ce n'était certes pas ma faute si l'on ne me communiquait même pas toujours, en temps voulu, les renseignements dont les autres bureaux de l'état-major pouvaient disposer. A une des compagnies de camions-réservoirs, j'avais fait prescrire un changement de cantonnement : par mesure de sécurité, l'emplacement précédent ayant été jugé trop proche du front oriental de l'armée. Une fois l'ordre expédié, j’appris que, venant par le sud-ouest, les Allemands p.65 occupaient déjà le village choisi. Par miracle, la compagnie, qu'un embouteillage arrêta, n'arriva jamais à destination. Une fraction d'un groupe de transport automobile fut moins heureuse : aux abords du lieu de stationnement que l'armée lui avait fixé, elle fut accueillie à coups de mitrailleuses et tout entière massacrée ou prise.

Pourrais-je oublier, enfin, comment nous sûmes que la route de la mer, en territoire français, allait nous être coupée ? Depuis plusieurs jours déjà, nous avions, Lachamp et moi, renvoyé dans un cantonnement voisin de la côte la plus grande partie du Parc d'Essence. Comme nos dépôts fixes s'étaient progressivement réduits à ceux de Lille et que, si par hasard, nous découvrions sur les voies quelques wagons chargés de bidons, le plus simple était de laisser les unités y puiser à peu près à leur gré, le personnel d'exploitation, presque tout entier, était devenu inutile. Nous avions gardé près de nous seulement, avec un petit détachement d'hommes de troupe, plusieurs officiers, occupés, en majorité, à assurer nos liaisons avec les Corps d'Armée. Cependant, l'armée refoulée de toutes parts se ramassait dans un espace de plus en plus étroit : si bien que les P.C. de ses différents Corps se trouvèrent, finalement, assez proches les uns des autres pour pouvoir être aisément visités tous en une ou deux tournées. Il nous parut alors médiocrement sage de continuer à exposer aux dangers d'une captivité menaçante plus d'offici ers que nous n'en avions réellement besoin. Nous décidâmes, le 26 mai au soir, de prescrire à l'un d'eux de regagner, le lendemain, le gros du Parc. Or le 28, dans la matinée, je le vis revenir à Steenwerck. Sur l'itinéraire qui lui avait été indiqué, entre Steenwerck et Cassel, il s'était heurté à des chars allemands. La nouvelle était grave. Je me préoccupai immédiatement d'en avertir nos chefs. «Êtes-vous bien sûr que ce ne soit pas des chars français? » demanda le premier camarade du $3^{\mathrm{e}}$ bureau, à qui ${ }_{\text {p.66 }}$ nous eûmes affaire. F... répliqua qu'il avait toutes les raisons du monde de penser le contraire, ne fût-ce que les coups de feu échangés, sous ses yeux, entre ces engins et nos troupes. Le général Prioux, à qui nous le menâmes ensuite, fut moins incrédule; il encaissa le coup, sans broncher. Mais je me demande encore combien de temps le renseignement se serait fait attendre, si notre brave lieutenant ne s'était, par hasard, trouvé à passer par là.

Il serait certainement peu équitable de borner aux échelons supérieurs les observations qui précèdent. Les exécutants n'ont pas, à l'ordinaire, beaucoup mieux réussi à accorder leurs prévisions ni leurs gestes à la vitesse allemande. Les deux carences étaient, d'ailleurs, étroitement liées. Non seulement la 
transmission des renseignements s'opérait fort mal, tant de bas en haut que de haut en bas ; les officiers de troupe avec, pour la plupart, moins de subtilité de doctrine, avaient été formés à la même école, en somme, que leurs camarades des états-majors. Tout le long de la campagne, les Allemands conservèrent la fâcheuse habitude d'apparaître là où ils n'auraient pas dû être. Ils ne jouaient pas le jeu. Nous avions entrepris, à Landrecies, vers les débuts du printemps, l'établissement d'un dépôt d'essence « semi-fixe »: grande pensée du G.Q.G., conçue à l'échelle d'un type de guerre qui ne se réalisa jamais que sur le papier. Un beau jour du mois de mai, l'officier, qui avait la charge de l'installation, rencontra dans la rue un détachement de chars. Il le s jugea d'une couleur singulière. Mais quoi ! connaissait-il tous les modèles en usage dans l'armée française ? Surtout, la colonne lui parut bizarrement engagée : elle filait vers Cambrai, alors que la direction du «front » était, de toute évidence, à l'opposé. Dans une petite ville, aux voies un peu tournantes, n'arrive-t-il pas que les guides s'orientent de travers ? Notre homme s'apprêtait à courir après le chef ${ }_{\text {p.67 }}$ du convoi, pour le remettre dans le droit chemin, quand un quidam, mieux avisé, le héla : «Attention! ce sont les Allemands. »

Cette guerre a donc été faite de perpétuelles surprises. Il en résulta, sur le plan moral, des conséquences qui semblent avoir été fort graves. Je vais toucher, ici, à un sujet délicat et sur lequel, on le sait, je n'ai le droit que d'avoir des impressions un peu lointaines. Mais il importe que certaines choses soient dites, brutalement, s’il le faut. L'homme est ainsi bâti qu'il se bande à affronter un danger prévu, au lieu où il l'a prévu, beaucoup plus aisément qu'il ne supportera jamais le brusque surgissement d'une menace de mort, au détour d'un chemin prétendument paisible. J'ai vu naguère, après la Marne, une troupe qui, la veille, était montée bravement en ligne, sous un affreux bombardement, succomber à la panique, parce que trois obus étaient tombés, sans blesser personne, le long d'une route, au bord de laquelle on venait de former les faisceaux, pendant la corvée d'eau. "Nous sommes partis parce que les Allemands étaient là » : j'ai entendu plusieurs foi s ces mots, en mai et juin derniers. Traduisez : là où nous ne les attendions point, où rien ne nous avait permis de supposer que nous devions les attendre. En sorte que certaines défaillances, qui, je le crains, ne sont guère niables, ont eu leur principale origine dans le battement trop lent auquel on avait dressé les cerveaux. Nos soldats ont été vaincus, ils se sont, en quelque mesure, beaucoup trop facilement laissé vaincre, avant tout parce que nous pensions en retard.

$*$

Les rencontres avec l'ennemi n'ont pas seulement été trop souvent, par le lieu et l'heure, inattendues. Elles se produisaient aussi, pour la plupart, et se p.68 produisirent surtout avec une fréquence croissante, d'une façon à laquelle 
ni les chefs ni, par suite, les troupes ne s'étaient préparés. On aurait bien admis de se canarder, à longueur de journée, de tranchée à tranchée — fût-ce, comme nous le faisions jadis, dans l'Argonne, à quelques mètres de distance. On eût jugé naturel de se chiper, de temps à autre, un petit poste. On se serait senti fort capable de repousser, de pied ferme, un assaut, derrière des barbelés, même plus ou moins démolis sous les «minen »; ou de partir soi-même à l'attaque, héroïquement, vers des positions déjà pilonnées - bien qu'imparfaitement peut -être — par l'artillerie. Le tout, réglé par les états majors, sur de belles idées de manoeuvres, longuement, savamment mûries, de part et d'autre. Il paraissait beaucoup plus effrayant de se heurter, soudain, à quelques chars, en rase campagne. Les Allemands, eux, couraient un peu partout, à travers les chemins. Tâtant le terrain, ils s'arrêtaient là où la résistance s'avérait trop forte. S'ils tapaient « dans du mou », ils fonçaient au contraire, exploitant, après coup, leurs gains pour monter une manoeuvre appropriée, ou plutôt, selon toute apparence, choisissant alors dans la multitude des plans que, conformément au méthodique opportunisme, si caractéristique de l'esprit hitlérien, ils avaient, d'avance, tenus en réserve. Ils croyaient à l'action et à l'imprévu. Nous avions donné notre foi à l'immobilité et au déjà fait.

Rien de plus significatif à cet égard, que les derniers épisodes de la campagne auxquels il m'ait été donné d'assister : à l'époque, précisément, où il eût pu sembler que les leçons de l'expérience auraient enfin fait entendre leur voix. On avait décidé de défendre la Bretagne, en y recueillant les forces en retraite depuis la Normandie et que l'avance ennemie, à l'ouest de Paris, déjà coupait des armées repliées sur la Loire. Qu'imagina -t-on ? On dépêcha, incontinent, un honorable général du génie, pour reconnaître une «position », d'une mer à l'autre. Car, pas p.69 moyen de tenir, n'est-ce pas, si l'on n'a, préalablement, tracé sur la carte, puis piqueté sur le sol, une belle «position » continue, avec bretelles, ligne avancée, ligne de résistance, et ainsi de suite. Il est vrai que nous n'avions ni le temps nécessaire à l'organisation du terrain, ni canons pour garnir en nombre suffisant les futurs ouvrages, ni les munitions pour tous ces canons, à supposer qu'on les eût pu trouver. Le résultat fut qu'après quelques rafales de mitrailleuses, échangées, m'a -t-on dit, à Fougères, les Allemands entrèrent, sans combat, à Rennes (que la «position » eût dû mettre à l'abri), se répandirent dans toute la péninsule et y firent des foules de prisonniers.

Est-ce à dire qu'à ce moment même - celui, exactement, où Pétain annonça qu'il demandait l'ar mistice — toute défense fût devenue impossible ? Plus d'un officier pensait le contraire. Parmi les jeunes, surtout : car, depuis que les événements s'étaient précipités, une frontière de plus en plus tranchée tendait à séparer les générations. Mais les chefs n'appartenaient malheureusement pas à celle qui jouissait des artères cérébrales les plus souples. Je pense encore aujourd'hui que nos « jusqu'au boutistes », comme on disait en 1918, n'avaient pas tort. Ils rêvaient d'une guerre modernisée, 
d'une chouannerie contre chars et détachements motorisés. Quelques -uns même, si je ne me trompe, en avaient dressé les plans, qui doivent dormir maintenant dans leurs dossiers. La motocyclette, dont l'ennemi faisait un si grand et bon usage, ne circule vite et sans trop d'accidents que sur d'honnêtes chaussées ; même le véhicule à chenillettes se déplace sur le macadam moins lentement qu'en pleins champs ; le canon ou le tracteur du type normal n'admet pas d'autres voies. C'est pourquoi, fidèles à leur programme de rapidité, les Allemands, de plus en plus, lançaient leurs éléments de contact à peu près exclusivement sur routes. Il n'était donc nul besoin de se garder par des p.70 positions allongées sur plusieurs centaines de kilomètres, presque impossibles à garnir et terriblement faciles à repérer. Quel mal, au contraire, n'auraient pas fait aux envahisseurs quelques îlots de résistance, bien placés auprès des itinéraires routiers, bien camouflés, suffisamment mobiles et pourvus de quelques mitrailleuses et de quelques canons antitanks, voire de modestes 75 ! Quand j'aperçus, dans Rennes, la colonne allemande, qui, composée, pour une très large part, de motocyclistes, défilait paisiblement sur le boulevard Sévigné, je sentis se réveiller en moi de vieux réflexes de fantassin : bien inutilement, car nous n'avions sous la main que nos secrétair es ou les hommes du Parc d'Essence, les uns comme les autres, dès le début de la campagne, absurdement démunis d'armes. Il eût été pourtant bien tentant de l'attendre, la maudite colonne, au coin de quelques boqueteaux, dans ce pays breton, si favorable aux embûches ; fût-ce seulement avec le modeste matériel d'une compagnie d'engins. Puis, une fois le premier effet de désarroi obtenu, on aurait vite regagné le «bled» pour recommencer plus loin. Je suis bien sûr que les trois quarts de nos soldats se seraient promptement passionnés au jeu. Hélas! les règlements n'avaient rien prévu de pareil.

Cette guerre accélérée, il lui fallait, naturellement, son matériel. Les Allemands se l'étaient donné. La France non, ou, du moins, pas en suffisance. On l'a dit et redit : nous n'avons pas eu assez de chars, pas assez d'avions, pas assez de camions, de motos ou de tracteurs et, par là, nous avons été empêchés, dès le principe, de mener les opérations comme il eût convenu de le faire. Cela est vrai, incontestablement et il n'est pas moins certain que de cette lamentable et fatale pénurie, les causes ne furent pas toutes ${ }_{\text {p.71 }}$ d'ordre spécifiquement militaire ${ }^{1}$. Nous saurons, là-dessus aussi, le moment venu, ne

\footnotetext{
1 Je me rends mieux compte aujourd'hui que ce matériel, certainement insuffisant, ne manquait cependant point autant qu'on l'a dit. Il manquait sur le front. Mais nous avions, à l'arrière, des chars immobilisés dans les magasins et des avions qui ne volèrent jamais. Les uns comme les autres, parfois, en pièces détachées. Que se passa-t-il à Villacoublay, lors de l'avance de l'armée allemande sur Paris ? Est-il exact que, comme on me l'a dit, il fallut détruire sur le terrain, un grand nombre d'avions, faute d'aviateurs capables de leur faire
} 
rien taire. Les fautes des uns, cependant, n'excusent point celles des autres et le haut commandement aurait mauvais gré, pour sa part, à plaider l'innocence.

Passons, si l'on veut, condamnation sur le crime stratégique, qui voua les troupes du Nord à abandonner, soit directement aux mains de l'ennemi, soit sur les plages des Flandres, l'équipement de trois divisions motorisées, de trois divisions légères mécaniques, de plusieurs régiments d'artillerie tractée et de tous les bataillons de chars d'une armée. Qu'il eût été utile pourtan $t$, sur les champs de bataille de la Somme ou de l'Aisne, ce beau matériel, le meilleur assurément dont disposât la nation en armes ! Mais il ne s'agit ici que de la préparation de la guerre. Si nous n'avons pas eu assez de chars, d'avions ou de tracteurs, ce fut, avant tout, parce qu'on engloutit, dans le béton, des disponibilités d'argent et de main-d'oeuvre qui n'étaient assurément pas infinies, sans pourtant avoir la sagesse de bétonner suffisamment notre frontière du Nord, aussi exposée que celle de l'E st; parce qu'on nous apprit à faire reposer toute notre confiance sur la ligne Maginot, construite à grands frais et à grand renfort de publicité, pour, p.72 l'ayant arrêtée trop court sur sa gauche, la laisser finalement, tourner, voire, sur le Rhin, entamer (mais de cet étonnant épisode du passage du Rhin, je sais seulement ce qu'en raconta la presse : autant dire zéro); parce qu'en dernière minute, on préféra se hâter encore de couler en ciment, dans le Nord, des blockhaus, qui, pourvus de défenses efficaces seulement vers l'avant, furent pris par derrière et que nos troupes durent employer tous leurs efforts, à creuser, afin de couvrir Cambrai et Saint-Quentin, un splendide fossé antichars, que les Allemands atteignirent, un beau jour, en partant de Cambrai et de Saint-Quentin; parce qu'une doctrine, couramment répandue parmi les doctrinaires, nous affirmait arrivés à un de ces moments de l'histoire stratégique où la cuirasse dépasse en puissance le canon - entendez : où la position fortifiée est pratiquement inexpugnable — sans d'ailleurs que le commandement ait eu même le courage, au moment décisif, de demeurer strictement fidèle à une théorie, par où, du moins, l'aventure de Belgique eût dû se trouver, d'avance, condamnée ; parce que beaucoup de savants professeurs de tactique se méfiaient des unités motorisées, jugées trop lourdes à mouvoir (les calculs leur attribuaient, en effet, des déplacements très lents; car on les imaginait, par sécurité, ne bougeant que de nuit; la guerre de vitesse eut lieu, presque uniformément, en plein jour); parce quill fut enseigné, au cours de cavalerie de l'École de Guerre, que les chars, passables pour la défensive, étaient de valeur offensive à peu près nulle; parce que les techniciens ou soi-disant tels estimaient le bombardement par artillerie beaucoup plus efficace que le bombardement par avions, sans réfléchir que les canons ont besoin de faire venir de fort loin leurs munitions, au lieu que les avions vont eux-mêmes, à tire-d'aile, se recharger des leurs; en un mot, parce que nos chefs, au milieu de beaucoup de

prendre l'air ? Ce dernier trait ne me parait point invraisemblable. Je connais un aviateur civil, dûment mobilisé, qui, durant toute la guerre, n’a jamais été autorisé à monter un avion militaire. 
contradictions, ont prétendu, avant tout, renouveler, en 1940, la guerre ${ }_{\mathrm{p} .73}$ de 1915-1918. Les Allemands faisaient celle de $1940{ }^{1}$.

On a raconté que Hitler, avant d'établir ses plans de combat, s'était entouré d'experts en psychologie. J'ignore si le trait est authentique. Il ne paraît pas incroyable. Certainement, l'attaque aérienne, telle que les Allemands la pratiquèrent avec tant de brio, attestait une connaissance très poussée de la sensibilité nerveuse et des moyens de l'ébranler. Qui, l'ayant une fois entendu, oubliera jamais le sifflement des avions «piquant » vers le sol, qu'ils s'apprêtaient à couvrir de bombes ? Ce long cri strident n'effrayait pas seulement par son association avec des images de mort et de ruines. En lui-même, par ses qualités, si j'ose dire, proprement acoustiques, il crispait l'être tout entier et le préparait à la panique. Or, il semble bien avoir été volontairement rendu plus intense à l'ai de d'appareils vibrants appropriés. C'est que le bombardement par avions n'avait pas été conçu, par les Allemands, uniquement comme un procédé de destruction et de massacre. Si serrés qu'on en imagine les points de chute, des projectiles ${ }_{\text {p.74 }}$ ne réussissent jamais à atteindre qu'un nombre d'hommes relativement faible. Un choc des nerfs, au contraire, peut se propager fort loin et anémier la capacité de résistance des troupes, sur de vastes espaces. Tel était, sans nul doute, un des principaux objets que se proposait le commandement ennemi, en lançant sur nous, vague après vague, son aviation. Le résultat ne répondit que trop bien à ses espérances.

Une fois de plus, je me vois contraint d'aborder un sujet que j'ai scrupule à devoir même effleurer, du moins, en ce qui regarde cette guerre-ci. Seuls les vrais combattants ont le droit de parler de danger, de courage et des hésitations du courage. Je relaterai, néanmoins, en toute franchise, une brève expérience. Mon baptême du feu de 1940 (celui de 1914 datait de la Marne), je l'ai reçu le 22 mai, sur une route de Flandre : car je ne compte pas les bombardements, relativement lointains, de Douai ou des environs de Lens. Ce

\footnotetext{
${ }^{1}$ La machine, c'est le neuf. Voilà pourquoi, sans doute, les pro fesseurs de stratégie ne l'ont jamais beaucoup aimée. Au moins chez nous J. de Pierrefeu (Plutarque a menti, p. 300) écrivait naguère : «Robert de Beauplan, qui fut un des délégués du Matin lors du fameux Circuit de l'Est au cours duquel la France comprit le miracle de son aviation, m'a raconté une étonnante conversation qu'il eut à l'issue de la triomphale épreuve avec le général Foch, commandant le $\mathrm{X}^{\mathrm{e}}$ corps. Sur le plateau de Malzéville, comme le cortège regagnait les voitures, Foch le prit familièrement par le bras et lui dit: «Tout ça, voyez-vous, c'est du sport : mais pour l'Armée, l'avion, c'est zéro. » On comparera, avec ce propos, une célèbre préface du maréchal Pétain sur les dangers de la motorisation. Seulement, de 1914 à 1918, même les stratèges avaient eu le temps de comprendre. [Juillet 1942].
} 
jour-là, au matin, le convoi, où ma voiture s'était insérée, fut successivement mitraillé, par avions, puis, par d'autres, bombardé. La mitraille, qui tua un homme, non loin de moi, ne me fit pas grande impression. Il n'est, assurément, jamais agréable de frôler la mort et, lorsque les rafales eurent cessé, j’en éprouvai une satisfaction bien nat urelle. Mais mon inquiétude était demeurée, d'un bout à l'autre, beaucoup plus raisonnée qu'instinctive. C'était une crainte à froid : rien qui ressemblât le moins du monde à de la vraie peur. Le bombardement aérien, à ma connaissance, fut sans victimes, au moins dans mon voisinage. Il ne m'en laissa pas moins tout pantois et quand je me relevai du fossé où je m'étais accroupi durant l'orage, je dus m'avouer que j'y avais assez vilainement frissonné. Vers la fin de la campagne, j’ai subi quelques bombardements par artillerie, dont je serais bien le dernier, en ayant connu jadis de tout autres, à exagérer l'ampleur, mais qui ne manquèrent pas p.75 cependant d'être assez sérieux. Je les ai supportés, sans aucune peine, ni rien perdre, je crois, de ma sérénité. Jamais les bombes d'avions ne m'ont permis de conserver, sinon au prix d'un rude effort, une pareille égalité d'humeur.

Sans doute, y avait-il, dans mon cas, une part de réflexe acquis. Depuis l'Argonne de 1914, le chant d'abeilles des balles s'est inscri t dans mes circonvolutions cérébrales comme, dans la cire d'un disque, un refrain prêt à jouer dès le premier tour de manivelle et je n'ai pas l'oreille si mal bâtie que d'avoir, en vingt et un ans, oublié l'art d'apprécier au son la trajectoire d'un obus et le point de chute probable. J'avais été beaucoup plus rarement bombardé du haut des airs, et je me trouvai, devant ce danger-là, presque aussi béjaune que mes conscrits. Pourtant, la différence de température, entre les trois types d'émotions que je viens de décrire, a été un trait si général que force est de lui reconnaître des raisons moins personnelles et plus profondes. Même l'absence, presque constante, de nos chasseurs, dans le ciel hostile, et la déplorable impunité ainsi procurée aux bombardiers ennemis ont beau avoir été pour beaucoup dans le découragement des troupes. Elles ne suffisent pas à tout expliquer.

Le bombardement aérien n'est probablement pas, en soi, plus réellement dangereux que tant d'autres menaces auxquelles le soldat est exposé. Du moins, en plein air. A l'intérieur des maisons, l'effondrement des murs et l'ébranlement de l'atmosphère, répercutant ses ondes dans un espace trop confiné, aboutirent toujours à de véritables massacres. A découvert, par contre, un tir d'artillerie, ta nt soit peu dense, fait, je crois, pour le moins autant de victimes; et la rafale de mitrailleuse est seule à n'épargner littéralement personne. Nous avons, dès les premiers jours de la campagne, été frappés par le nombre relativement faible des pertes attribuables aux avions ennemis, dont les rapports, venus du p.76 front, dépeignaient l'activité sous de si vives couleurs. Mais il possède, ce bombardement descendu des cieux, une capacité d'épouvante, qui n'appartient véritablement qu'à lui.

Les projectiles tombent de très haut et semblent, à tort, en tomber tout droit. Le jeu combiné du poids et de l'altitude leur imprime un élan 
visiblement formidable, auquel les obstacles les plus solides paraissent incapables de résister. Il y a, dans une pareille direction d'attaque, doublée d'une pareille force, quelque chose d'inhumain. Comme devant un cataclysme de la nature, le troupier courbe la tête sous ce déchaînement, incline à se croire absolument sans défense. (En réalité, un fossé, même «un plat ventre », exécuté à temps, protègent fort bien des éclats, généralement moins nombreux que ceux d'un bon obus. Toute réserve faite, bien entendu, des coups directs de la bombe. Mais, qu'il s'agisse d'aviation ou d'artillerie, il y a, comme disent les vieux soldats, «beaucoup de place à côté »). Les bruits sont odieux, sauvages, énervants à l'extrême : tant le sifflement, intentionnellement accru, dont je parlais à l'instant, que la détonation par où tout le corps est secoué dans ses moelles. Cette déflagration même, brassant l'air ambiant avec une violence inouïe, impose à l'esprit une image de déchirement, que confirme trop bien le spectacle des cadavres abominablement déchiquetés et enlaidis, jusqu'à l'horreur, par les traces des gaz échappés à l'explosion. Or, l'ho mme, qui redoute toujours de mourir, ne supporte jamais plus mal lidée de sa fin que s'il s'y ajoute la menace d'un écharpement total de son être physique ; l'instinct de conservation n'a peut -être pas de forme plus illogique que cellelà ; mais aucune, non plus, qui soit plus profondément enracinée. Probablement, si la guerre véritable avait duré davantage, nos armées auraient-elles fini par acquérir, vis-à-vis des affres du bombardement par avions, un peu de cette accoutumance qui est un ${ }_{\text {p.77 }}$ des éléments presque indispensables de toute résistance au péril. Le raisonnement eût montré que, terribles assurément, les effets matériels n'en sont pourtant pas sans égal. Dans une guerre de vitesse, les calculs de la psychologie allemande devaient nécessairement toucher juste. Quelles gorges chaudes cependant, dans nos états-majors, si on avait seulement émis l'hypothèse qu'on pût tirer de leur laboratoire, pour les consulter sur la stratégie, quelques savants bizarrement occupés à mesurer des sensations !

\section{$*$}

Dans quelle mesure est-il loisible de parler du désordre des états-majors ? Outre que les habitudes variaient, naturellement, beaucoup selon les groupes ou les chefs, le terme même est d'emploi délicat. Car il y a plus d'une espèce d'ordre et, par suite, de désordre. Tous les états-majors que j'ai connus avaient, parfois jusqu’à une agaçante minutie, le culte du beau «papier ». Il faut que les écritures soient disposées avec beaucoup de netteté. Les formules de style obéissent aux lois d'une tradition rigoureuse. Dans les tableaux, les chiffres s'alignent par colonnes, comme à la parade. Les dossiers sont soigneusement classés; les pièces, au départ, comme à l'arrivée, dûment enregistrées. C'est là, en somme, ce qu'on pourrait appe ler la forme bureaucratique de l'ordre. Rien de plus naturel que de la voir fleurir chez des 
hommes dressés, en temps de paix, à un genre de vie lui-même éminemment bureaucratique. Je suis très loin de la mépriser : elle force les esprits à la clarté ; elle épargne les pertes de temps. Il est dommage seulement que cet estimable souci de la propreté, dans les écrits, ne s'étende pas toujours aux locaux. Je n'ai jamais rien vu de plus sale ni de plus fétide que la demeure où travaillait un p.77 certain état-major de secteur fortifié; et l'adjudant de compagnie, qui aurait laissé s'accumuler, dans ses chambrées, la moitié de la poussière qui couvrait, à Bohain, nos tables et nos armoires, n'aurait pas fait long feu dans son grade. Il est vrai que je sais telles antichambres de ministères, très civils, qui ne présentent pas un aspect plus attrayant. Mais ce n'est pas une excuse. M'accusera -t-on de m'attacher à des vétilles ? Je n'apprécie guère, je l'avoue, le négligé dans les choses ; il passe aisément à l'inte lligence. Voilà une utile réforme à proposer au « redressement » français.

Telle qu'elle était pratiquée, l'estimable régularité administrative des notes ou tableaux d'états -majors avait d'ailleurs son revers. Elle gaspillait des forces humaines, qui auraient pu être mieux employées. J'ai rencontré, parmi mes camarades de la réserve, de hauts fonctionnaires, des chefs de grandes entreprises privées. Tous, comme moi, s'effaraient d'être contraints à des besognes paperassières que, dans le civil, ils auraient abandonnées aux plus modestes de leurs sous-ordres. Chargé du ravitaillement en essence d'une armée, j'ai, durant plusieurs mois, tous les soirs, additionné moi-même les chiffres de ma situation journalière. Je n'y passais pas, à vrai dire, beaucoup de temps et je m'y suis perfectionné dans une gymnastique arithmétique qui m'avait d'abord, je l'avoue, trouvé un peu rouillé. Mais, une fois établis les principes de la comptabilité, n’importe quel scribe s'en serait tiré au moins aussi bien que moi. Mon cas n'avait rien d'exceptionnel. Qu'on veuille bien ne pas invoquer le principe du «secret». Car mon brouillon était ensuite copié par un simple soldat. Aussi bien, un tour de quelques minutes à travers notre bureau, que tapissaient les cartes des dépôts de munitions de l'armée, de ses dépôts d'essence et de ses gares de ravitaillement, aurait suffi à mettre aux mains d'un mouchard., s'il s'en était trouvé dans notre personnel, des renseignements ${ }_{\text {p.79 }}$ autrement précieux. La vérité est que les états-majors ressemblaient à une maison d'affaires qui, pourvue au sommet de chefs de service - représentés, ici, par les officiers —, à la base de dactylos, eût été, par contre, au niveau intermédiaire totalement démunie d'employés proprement dits. Combien il aurait été cependant aisé de recruter, parmi nos sous-officiers de réserve, d'excellents collaborateurs de ce type ! Or, il n'est jamais bon que des hommes, chargés de responsabilités assez lourdes, et qui doivent conserver un sens aigu de l'initiative, aient l'esprit constamment tiré en arrière par des tâches presque purement mécaniques. D'autre part, si les états-majors avaient été mieux dotés en sous-officiers, il aurait probablement été possible, du moins là où les soucis du champ de bataille n'étaient pas trop proches, de les alléger d'un certain nombre d'officiers, qui eussent tout naturellement trouvé leur place ailleurs. 
Comment se fait-il, cependant, qu'à beaucoup d'entre nous, et, si j'en juge par certaines confidences, avant tout aux exécutants, le commandement, une fois les opérations entamées, ait donné, fréquemment, une incontestable impression de désordre ? C'est que, je crois, l'ordre statique du bureau est, à bien des égards, l'antithèse de l'ordre, actif et perpétuellement inventif, qu'exige le mouvement. L'un est affaire de routine et de dressage ; l'autre, d'imagination concrète, de souplesse dans l'intelligence et, peut -être surtout, de caractère. Ils ne s'excluent certes pas l'un l'autre ; mais le premier ne commande pas le second et, parfois, si l'on n'y fait attention, risque d'y mal préparer. Durant la longue période d'attente qui vit se prolonger, au plus grand dam de l'armée française, les habitudes du temps de paix, le bon ordre dont nous étions si fiers n'était acquis qu'au prix d'une grande le nteur. Quand il fallut aller vite, nos chefs, trop souvent, confondirent la fièvre avec la promptitude.

p.80 Aussi bien, établir au jour le jour des papiers de bonne apparence n'exige pas un effort très considérable. Une toute autre maîtrise de soi est nécessaire pour s’imposer, longtemps à l'avance, la peine de dresser, avec soin et souplesse à la fois, les plans d'action qui attendront leur application jusqu'à une date incertaine et devront alors pouvoir s'adapter aux nécessités nouvelles d'une époque troublée. Ce que j'ai vu, pour la première fois, en 1939, de la mobilisation, m'avait beaucoup effrayé. Je ne discuterai pas ici le système des centres mobilisateurs, substitué, après la précédente guerre, à la mise sur pied directe par les corps d'origine. Je sais que leur institution avait rencontré plus d'un adversaire, jusque dans le haut commandement. Elle m'a paru de nature à entraîner, inévitablement, beaucoup de retards et de difficultés. La plupart des vêtements et équipements continuant d'être fourni s par les corps, force était, pour les amener aux centres, d'organiser tout un jeu de transports, incommodes et forcément assez lents. Par surcroît, on ne semblait pas s'être avisé qu'à prétendre habiller des réservistes d'une quarantaine d'années avec les tenues de jeunes conscrits ou à vouloir harnacher de lourdes montures de réquisition au moyen des laissés pour compte abandonnés par des chevaux de hussards, on aboutissait à proposer aux malheureux centres, "principaux» ou «secondaires", des problèmes proprement insolubles. Ajoutez qu'en raison même de ce que le travail y avait de tristement minutieux, leurs commandants n'étaient pas toujours trop bien choisis. J'en ai connu de parfaitement compétents ; mais d'autres aussi qui, recrutés parmi des capitaines ou chefs de bataillon au terme de leur carrière, avaient tous les défauts communément prêtés aux vieux adjudants. Du moment que le système était admis, il eût convenu, du moins, d'en confier le fonctionnement, qui ne pouvait manquer de se montrer fort délicat, à des officiers, triés sur le volet, et auxquels ${ }_{\text {p. } 81}$ les années passées là auraient servi de titres exceptionnels à l'avancement. L'armée s'est toujours difficilement résignée à l'idée que lỉmportance ni le mérite d'une tâche ne se mesurent à ce qu'elle peut avoir, extérieurement, de brillant. 
Mais, bon ou mauvais — et j'imagine qu’il avait, tout de même, ses avantages - le régime des centres n'excuse pas des fautes qui n'avaient rien à voir avec le principe. Quel officier, ayant servi dans une région ou un groupe de subdivisions, peut se remémorer, sans un triste sourire, linvraisemblable maquis des «mesures » prévues, numéro après numéro, pour la période dite « de tension», qui devait précéder la mobilisation générale ? Tiré en pleine nuit, d'un demi-sommeil, par le télégramme qui prescrivait, par exemple, «Appliquez la mesure $81 »$, on se reportait au «tableau», sans cesse tenu à portée de la main. C'était pour y apprendre que la mesure 81 faisait jouer toutes les dispositions de la mesure 49, à l'exception des décisions d'ores et déjà entrées en vigueur par application de la mesure 93, si celle-ci, d'aventure, avait devancé, dans l'ordre des temps, la place qu'eût semblé lui assigner son numéro, cela toutefois en ajoutant les deux premiers articles de la mesure 57. Je donne ces chiffres un peu au hasard. Ma mémoire ne me permet pas une exactitude littérale. Tous mes camarades reconnaîtront que, pour le fond, je simplifie plutôt. Allez vous étonner, dans ces conditions, que des erreurs aient été commises. Ce fut pour avoir lu un peu vite notre commun guide-âne qu'en septembre 1939, la gendarmerie d'Alsace-Lorraine procéda au massacre prématuré de tous les pigeons voyageurs de trois départements. Assurément, les officiers qui, là-bas, dans un bureau mal aéré de la rue Saint-Dominique, avaient, ajoutant les chiffres aux chiffres, perpétré ce casse-tête chinois, ne manquaient pas, à leur façon, d'imagination : ce n'était pas celle qui p.82 permet de se représenter, à l'avance, l'exécution des o rdres.

Il y eut plus grave. Nos fameux centres, j'en sais un qui, logé à Strasbourg, dans un quartier assez voisin du Rhin, était à portée de l'artillerie légère de l'ennemi, voire de ses mitrailleuses. Un autre s'abritait dans un fort des environs, encore proche du fleuve. On y accédait par un seul pont, jeté sur les fossés: une bombe ou un obus bien placés en auraient fait une vraie souricière. Rien de tel ne se passa, dira-t-on peut-être. D'accord. Mais qui prévoyait que les Allemands ne tireraient pas sur Strasbourg ? La vérité est que ce dispositif n'avait guère eu d'inconvénients, tant que la tête de pont de Kiel resta démilitarisée ; par la suite, le haut commandement oublia de le modifier ou ne le modifia qu'insuffisamment.

Comment taire enfin l'abo minable désordre de la seule mobilisation qu’il m'ait été donné de suivre de tout près : celle des éléments territoriaux, qui dépendaient directement du groupe de subdivisions ? Quand notre général prit son commandement, nous découvrîmes avec stupeur que nous ne disposions d'aucune liste des unités qui passaient sous ses ordres. Il fallut improviser le tableau, tant bien que mal et plutôt mal que bien, à coups de fouilles à travers des archives affreusement embrouillées. Et quel chaos dans ces unités! Que de chevauchements, sur le terrain, de l'une à l'autre ! Ici, nous avions, dans notre zone, deux sections dont le commandant de compagnie appartenait à un autre groupe. Là, quelques compagnies, mais point de colonel. Nos braves gardes-voies étaient des hommes d’âge ; leur bonne volonté égalait leur esprit 
de débrouillage. Si peu d'entre eux réussirent à être convenablement chaussés, aucun, par miracle, ne mourut de faim. Mais je ne saurai jamais comment vécut une section, que je cherchai, en vain, tout un jour durant, le long de la ligne de Saint-Dié. Sans doute, il serait injuste ${ }_{\text {p. } 83}$ de conclure du particulier à l'ensemble. J'ai des raisons de penser que, dans notre coin, la mobilisation n'avait pas été très heureusement préparée. Dirigée, en principe, par un officier supérieur qui, de son éducation d'état-major, avait retenu surtout certaines manières un peu désinvoltes, la tâche avait été largement abandonnée, en fait, à des subalternes. L'exemple, malgré tout, ne manquait pas d'être inquiétant. En 1940, nous pûmes constater que diverses erreurs avaient été réparées. Toutes, non pas. Les centres, notamment, n'avaient pas bougé ; et les gardes-voies continuèrent longtemps à fouler le ballast en sandales ou en petits souliers, s'ils n'avaient pas eux -mêmes apporté de plus fortes chaussures.

A la première Armée, dès avant le mois de mai, il n'était nul besoin d'un esprit d'observation extraordinairement aiguisé pour percevoir et redouter certaines fissures qui, alors à peu près inoffensives, menaçaient de se transformer, dans la tempête, en véritables voies d'eau. Telle la mauvaise organisation des liaisons.

A ce sujet, je n'ai personnellement pas à me plaindre. Durant toute la campagne, j'ai pu communiquer, sans peine, avec les divers détachements du Parc d'Essence; sans difficultés sérieuses, avec les unités quil fallait ravitailler. L’intelligente abnégation de Lachamp nous y a beaucoup aidés. Je prenais soin, naturellement, toutes les fois que cela m'était possible, de ne pas empiéter sur ses prérogatives de chef ; il les exerçait avec trop d'autorité et de compétence pour qu'on éprouvât la moindre tentation de manquer à les respecter. Mais il était entendu, entre nous, que, plus près que lui de la source des renseignements et moins nomade, je pouvais toujours, en cas de véritable urgence, passer directement les instructions de l'armée à ses subordonnés. A sauter ainsi un échelon, nous avons, p.84 parfois, gagné bien du temps ${ }^{1}$. L'expérience d'une autre guerre nous avait d'ailleurs inspiré, à tous les deux, jusqu'à la hantise, une saine terreur de l'affreux jeu de colin -maillard auquel conduisent forcément des liaisons mal préparées. Malgré les fréquents va-etvient du P.C. de l'armée et du parc, nous n'avons jamais cessé de savoir exactement où nous joindre ; et, en dehors de tout règlement, nous réussîmes à

\footnotetext{
${ }^{1}$ En vérité, nous en sautions plus d'un. Régulièrement, le Parc d'Essence ne dépendait du commandant de l'armée que par lintermédiaire du général commandant l'artillerie de l'armée, représenté lui-même, au degré inférieur, par le chef d'escadron directeur du service des Munitions et Essence. La voie hiérarchique eût donc exigé que tout ordre, de l'armée au parc, passât, avant d'atteindre son but, par ces deux autorités superposées. Tel était bien le chemin que suivaient invariablement, à Bohain, les papiers officiels; et la lenteur du détour n'avait pas laissé de nous préoccuper beaucoup, Lachamp et moi, quand nous évoquions les nécessités d'une époque plus active. Heureusement nous pûmes, le moment venu, courtcircuiter la ligne. Sans étincelles, grâces en soient rendues à l'obligeante bonne volonté des officiers intéressés.
} 
monter privément tout un système de transmissions à l'intérieur de notre service.

J'avais, constamment, à mon bureau, deux motocyclistes fournis, chacun, par une des deux compagnies de camions-réservoirs. L'un et l'autre devaient avoir reconnu, à l'avance, au moins l'emplacement de leur propre compagnie et celui du commandement du parc. En outre, Lachamp détachait, en permanence, auprès de moi, un de ses officiers. Quatre autres officiers du parc faisaient la liaison avec les corps d'armée. Chacun d'eux, tous les jours et, parfois, à plusieurs reprises dans la même journée, se rendait successivement au P.C. de l'armée, puis au corps qui lui était assigné. Ces braves gens, dont beaucoup n'étaient plus de pre mière jeunesse, ont souvent rudement trotté, sur des routes qui n'étaient pas des ${ }_{\text {p.85 }}$ plus sûres. J'en sais un qui, lors de notre premier repli, après l'offensive sur la Belgique, chercha son corps pendant plus de vingt-quatre heures. Ils finissaient toujours par arriver et ils nous ont été singulièrement utiles. Du 11 au 31 mai, pas une fois, pour envoyer un ordre ou recevoir une demande de ravitaillement, je n'ai eu besoin de recourir au bureau du «Courrier» chargé, en principe, des communications entre l'état-major et les unités subordonnées. Qu'ordres ou demandes parvinssent à destination, l'événement ne me permet guère d'en douter. Car jamais, je crois, les troupes, au combat, n'ont manqué de l'essence que, jusqu'à quelques centaines de mètres, parfois, de la ligne de feu, leur portaient bravement les «Mickeys » (ainsi avait-on surnommé, dans l'armée, les voitures du parc, dont un agile petit «Mickey » était l’insigne). Jamais, non plus, nous n'avons abandonné à l'ennemi des dépôts où il pût encore s'approvisionner. Allumant tout le long de notre retraite, de Mons jusqu'à Lille, plus d’incendies que n'en fit flamber Attila, Lachamp et ses officiers ont vidé, par le feu, jusquà la dernière goutte, bac après bac. Il me faut cependant faire une réserve sur ceux de Saint-Quentin, j'ignore encore aujourd'hui quelle fut leur destinée, nous en avons été si vite et si complètement coupés. Nos chefs ayant reconnu, à l'expérience, que tout marchait bien, nous avaient, de bonne heure, laissé, à peu près complètement, la bride sur le cou. De cela, du moins, je leur garde beaucoup de reconnaissance.

Je crains bien, par contre, que là où cette autonomie ou cette entente n'avaient pu être réalisées, les contacts entre les divers échelons du commandement, ou, à niveau égal, entre les unités de même rang, n'aient pas toujours fonctionné de façon bien satisfaisante. J'ai plusieurs fois entendu des officiers de troupe se plaindre d'être demeurés trop longtemps sans ordres ; et, certainement, j'en ai donné plus haut des exemples, les états-majors ne p.86 connaissaient quimparfaitement et beaucoup trop tard ce qui se passait sur le front. Sur des routes encombrées, comme les nôtres le furent de bonne heure, en particulier par les réfugiés, il n'est guère qu'un moyen de tra nsport capable de se faufiler partout : la motocyclette. Le courrier de l'armée n'en possédait, si je ne me trompe, aucune. Le nombre même de nos autos était insuffisant, et on les répartissait mal. Nous étions plusieurs à nous être inquiétés, dès l'hiver, 
de cet état de choses, né avant tout d'un défaut d'organisation et de surveillance. Personne n'y porta remède. Les effets ne s'en firent que trop sentir, durant la campagne.

Dès le début des opérations actives, le P.C. de l'armée avait été transféré, on s'en souvient, de Bohain à Valenciennes : dans le dessein, évidemment, de diminuer la distance avec la Belgique, où pénétraient nos troupes. Quand j'arrivai à Valenciennes, le 11, dans les premières heures de l'après -midi, je me préoccupai aussitôt de me rendre à Mons, pour régler, avec l'état-major belge de la place, la réquisition des dépôts de carburants. La mission, chacun en convenait, était urgente. Or, je découvris que, toutes nos voitures se trouvant soi-disant employées à nous déménager, par va-et-vient entre l'ancien et le nouvel emplacement du P.C., il m'était absolument impossible de bouger. A quoi bon avoir quitté Bohain, si c'était pour se voir ainsi fermées les routes de l'avant ? Par bonheur, je reçus dans la journée la visite de l'aimable not aire lillois, qui exerçait les fonctions d'adjoint au commandant d'un groupe de transport. Il venait me demander de l'essence. Cyniquement, je lui répondis : «Donnant, donnant. Pas d'essence, si vous ne me fournissez une auto. » Le marché fut conclu ; et je partis, enfin, pour Mons. La leçon me servit et j'établis ensuite mes liaisons, pour mon propre compte, comme je l'ai raconté il y a un instant.

Aussi bien, par quel miracle les ordres seraient-ils ${ }_{\text {p.87 }}$ parvenus à temps alors que l'armée, trop souvent, ne savait où toucher ses divers corps ? Un jour que le Corps de Cavalerie avait fait mouvement, l'officier de liaison du Parc d'Essence alla, comme à l'ordinaire, prendre contact avec ces bons clients. A son retour chez nous, je le menai au troisième bureau. Il me paraissait sage de m'assurer si nos grands tacticiens connaissaient, bien exactement, le site du nouveau P.C. Vérification faite, il fallut constater un décalage d'une trentaine de kilomètres entre l'emplacement réel et le point qu'ils avaient déjà marqué au fusain sur la carte. J'entends encore le «merci », jeté du bout des lèvres, qui récompensa notre intervention. Mêmes incertitudes, dans les liaisons latérales. J'eus, un peu plus tard, besoin de dépêcher Lachamp à l'état-major des forces britanniques. L'affaire était d’importance : il ne s'agissait de rien moins que de la destruction des dépôts de Lille. Où trouver le Quartier Général de lord Gort ? Franchissant, une fois de plus, la porte redoutable du troisième bureau, j'allai le demander. B... me répondit, sans sourciller, qu'on n'en savait rien. Heureusement, je réussis à mettre la main sur un bout de papier qui traînait dans les environs et, entre autres indications de nature analogue, portait celle-là. Nos camarades étaient moins mal informés qu'ils ne le supposaient eux -mêmes. Mais, qu'un officier, chargé des opérations, ait pu supporter une minute l'idée d'être, faute d'une indication topographique élémentaire, privé de tout moyen de communiquer avec le commandement des troupes alliées, appelées à combattre immédiatement à notre gauche, et qu'il n'ait pas craint d'avouer froidement 
cette ignorance même prétendue, le trait en dit long sur les conditions de travail qui nous étaient imposées.

«Les Anglais », d'ailleurs, avons-nous su jamais organiser notre coopération avec eux ? Nulle part, ${ }_{\text {p.88 }}$ la fatale insuffisance de nos liaisons, au sens plein du mot, n'apparut sous un jour plus cruel.

Mais le problème de l'alliance ratée est trop complexe, il a prêté aussi à de trop ardentes et trop vilaines polémiques pour souffrir de n'être abordé que de biais. Il faut, une bonne fois, avoir le courage de le prendre corps à corps. Du moins, à la mesure de mon expérience.

J'ai, en Grande-Bretagne, de chers amis. Ils m'ont facilité l'accès de leur civilisation, qui me fut hospitalière et pour laquelle j'éprouve, de longue date, un goût très vif. Ils sont, aujourd'hui plus que jamais, proches de mon coeur, depuis que je les vois, avec leurs compatriotes, seuls à défendre, au péril de leur vie, la cause pour laquelle j'aurais volontiers accepté de mourir. J'ignore si, quelque jour, les lignes qui vont suivre leur tomberont sous les yeux. S'ils les lisent, elles les choqueront, peut-être. Mais ils sont sincères et sauront, je l'espère, me pardonner ma franchise.

L'anglophobie de beaucoup de milieux français fait aujourd'hui l'objet d'une misérable exploitation. En elle-même, elle n'est pas niable. Elle a des origines diverses. Les unes remontent à des réminiscences historiques, plus tenaces qu'on ne l'imagine parfois : ni l'ombre de la Pucelle ni même les fantômes hargneux de Pitt et de Palmerston n'ont tout à fait cessé de se profiler à l'arrière -plan d'une opinion collective douée de mémoire. Peut-être serait-ce un bienfait, pour un vieux peuple, de savoir plus facilement oublier : car le souvenir brouille parfois l'image du présent et l'homme, avant tout, a besoin de s'adapter au neuf. D'autres sources sont plus factices et beaucoup plus impures. Les lecteurs d'un certain hebdom adaire, fort répandu dans l'armée, ont appris naguère, au temps de la campagne italienne contre l'Éthiopie, que notre devoir nous appelait à la « destruction» de l'Angleterre. L'article était p.89 signé, d'une signature soi-disant française. Ses véritables inspirateurs ? Chacun sait qu'ils n'étaient pas de chez nous. Mais il y a plus. On doit sans doute tenir pour inévitable que deux nations, très différentes, en dépit des idéaux communs qui les animent, aient peine à se connaître, à se comprendre, par suite, à s'aimer. Cela est vrai, d'une égale vérité, sur les deux rives de la Manche ; et je ne pense pas que chez l'Anglais moyen, dans la petite bourgeoisie en particulier, les préjugés classiques contre le vis-à-vis «gaulois» aient, non plus, perdu toute leur antique verdeur. Mais, incontestablement, au cours de notre récente et trop courte confraternité d'armes, certains épisodes n'ont pas contribué à dissiper le malentendu. 
Dans les forces britanniques, qui furent, durant de longs mois d'expectative, no s voisines sur la terre de Flandre, qui occupaient nos villages et réglaient la police de nos routes, l'armée nationale de la conscription comptait encore pour peu de choses. La troupe, au moins, était, quasiment tout entière, composée de professionnels. Elle avait toutes les qualités, sans doute, d'une armée de métier. Quelques -uns de ses défauts, aussi. Le soldat à la Kipling obéit bien, et se bat bien : il devait le prouver, une fois de plus, de son sang, sur les champs de bataille de la Belgique. Mais il est pillard et paillard. Ce sont deux vices que notre paysan, quand ils s'exercent aux dépens de sa basse-cour ou de sa famille, pardonne difficilement. D'ailleurs l'Anglais, sur le continent, se montre rarement à son avantage. Du moins, sil n'appartien $t$ pas à des milieux particulièrement raffinés. Chez lui, il est, presque invariablement, d'une parfaite obligeance. Une fois passé le détroit, il incline toujours un peu à confondre l'hôte européen avec le « native » - entendez l'indigène des colonies, hom me, par définition, de rang inférieur - et ce qu'il y a en lui de timidité naturelle ne fait que le confirmer dans sa raideur. Bien petites p.90 choses, assurément, que tout cela, au regard des sentiments profonds et des grands intérêts nationaux. Qui niera, cependant, leur poids sur une opinion villageoise, comme la nôtre, volontiers méfiante de l'étranger et un peu repliée sur elle-même ?

Vinrent, après d'âpres semaines, les jours de l'embarquement. Que les Britanniques aient nettement marqué leur volonté de passer d'abord, sans permettre à aucun de nous, à bien peu d'exceptions près, de mettre le pied sur un pont de navire avant que leurs propres troupes, au complet, n'eussent quitté la côte, je ne me rangerai point parmi ceux qui leur en font un âpre grief. A la réserve de celles de nos forces qui défendaient le front de mer, leur armée avait été la plus proche du littoral. Par ailleurs, ils refusaient, assez naturellement, de se laisser englober, corps et biens, dans un désastre dont ils ne se jugeaient pas responsables. Lorsque les marins de l'Union Jack eurent fini d'assurer le salut de leurs compatriotes, ils s'employèrent au nôtre. Leur abnégation, devant le danger, leur cordiale sollicitude aussi, demeurèrent alors, envers nous, égales à ce qu'elles avaient été pour leurs premiers passagers.

Cependant, ici encore, tâchons de comprendre les inévitables réactions du sentiment. Nos soldats qui, privés par leurs chefs mêmes de toute capacité de combattre, attendaient désespérément, sur la longue plage de Flandre ou parmi les dunes, le moment d'échapper aux prisons du II I ${ }^{\mathrm{e}}$ Reich, qui, sentant l'ennemi chaque jour plus près, exposés eux-mêmes à des bombardements chaque jour plus violents, savaient bien quils ne pourraient pas tous partir et, en effet, ne partirent pas tous, quels coeurs surhumainement charitables ne leur aurait-il pas fallu pour contempler, sans amertume, les vaisseaux l'un après l'autre emportant, vers la liberté, leurs camarades d'une nation étrangère ? Héros tant qu'on p.91 voudra, ils n'étaient pas des saints. Ajoutez, par endroits, l'aiguillon d'incidents, peut -être difficiles à prévenir dans une 
pareille fièvre, mais fort propres à irriter une sensibilité déjà à vif. Telle histoire — parfaitement authentique, je m'en porte garant — de cet agent de liaison français auprès d'un régiment britannique qui, après plusieurs mois de camaraderie au cantonnement et dans le combat, se vit abandonné sur le sable, toute barrière close, en face du paquebot dont ses amis de la veille franchissaient les passerelles. Les touchantes attentions, dont un grand nombre de nos hommes se trouvèrent entourés, une fois sur le sol anglais, firent beaucoup pour panser ces plaies. Il arriva pourtant que, parfois, ce baume même vint à manquer. L'accueil des populations fut invariablement affectueux. Celui des autorités, par contre, ne sut pas toujours se dégager d'une raideur un peu trop soupçonneuse. Le camp, çà et là, prit des allures de pénitencier. Des troupes harassées sont toujours incommodes à manier. On ne saurait s'étonner qu'une administration, chargée d'une tâche délicate et soucieuse avant tout de bon ordre, ait commis quelques fautes de doigté ; il n'est pas moins naturel que ces erreurs, là où elles se sont produites, aient laissé, dans les mémoires, leurs sillons.

On a beaucoup dit que les Britanniques nous avaient insuffisamment aidés. Comme on le disait afin d'excuser nos propres défaillances, on est allé jusqu'à user de chiffres mensongers. J'ai les meilleures raisons de savoir que leurs divisions, en Flandre, étaient beaucoup plus que trois. Mais cette pernicieuse propagande n'a pas eu à inventer tous ses aliments.

Aux yeux de qui connaît un peu des traditions politiques et sociales fort éloignées des nôtres, l'établissement de la conscription passera toujours pour un grand acte de courage. Il est difficile de nier que ${ }_{\mathrm{p} .92}$ ce courage n'ait été un peu tardif et nul ne s'étonnera si, présent sur la ligne de feu, le Français de trente à quarante ans se demandait parfois pourquoi l'Anglais de son âge demeurait au foyer. La Grande-Bretagne, depuis, n'a que trop bien rattrapé son retard, dans le sacrifice. Qui prévoyait alors l'avenir ?

Il n'est pas moins certain que, lorsque, à la $\mathrm{I}^{\mathrm{re}}$ Armée, il fut question de tenter une percée du nord au sud, vers Arras, en la conjuguant avec le mouvement entrepris, en sens inverse, par les troupes françaises de la Somme, le commandement britannique retira, presque au dernier moment, le secours qu'il avait d'abord promis. Le geste laissa, naturellement, de longues rancunes. Il eut aussi ses profiteurs : tout comme, un peu plus tard, cette capitulation belge, dont un sceptique, dans notre troisième bureau même, devait dire, dès qu'il l'apprit : "Voilà une grande chance pour le général Blanchard. » Notre encerclement était acquis bien avant la défection de Léopold III ; plus qu'à moitié accompli déjà, quand les Britanniques firent faux bond à l'offensive projetée. A nos erreurs, est-il plus commode paravent que les fautes d'autrui ?

Il fallut, au bout du compte, renoncer, du côté du nord, à tout effort sérieux pour crever la «poche allemande». Le refus anglais avait certainement contribué à ruiner, d'avance, l'entreprise. Il ne fut, je le crains, pas très 
élégant, dans la forme. Au pis-aller, si, en raison du changement de la situation stratégique, il paraissait désormais impossible de donner suite aux engagements pris, l'état-major du Corps Expéditionnaire eût été mieux inspiré de ne pas laisser aussi longtemps que, semble-t-il, il le fit, le commandement français dans l’illusion ou l'incertitude. (Mais, là-dessus, je n'ai, naturellement, entendu qu'un son de cloche : le nôtre.) Pour le fond, la décision n'était probablement pas sans p.93 justification ${ }^{1}$. L'historien, en tout cas, qui cherche beaucoup moins à juger qu'à compr endre, n'aura pas de peine à l'expliquer. C'est ici qu'il faut commencer à regarder de l'autre côté de la toile.

Notre propre offensive, vers le sud, se montait avec lenteur. Les reconnaissances, la mise en place, la préparation d'artillerie, toutes ces opérations préliminaires, en un mot, que la doctrine estimait indispensables, exigeaient beaucoup de temps. Elles avaient forcé, une première fois, à retarder le déclenchement de l'action. C'était, en projet, toute une bataille de la Malmaison au petit pied. J'ignore si l'on eût pu faire plus vite. Peut -être le dispositif de l'armée, étirée jusqu'à l'Escaut, ne le permettait -il déjà plus. Ce que je sais bien, c'est qu'à aller de ce train, on risquait de se laisser devancer par l'ennemi. Ne lui accordait-on pas ainsi tout le loisir nécessaire pour renforcer, dans l'intervalle entre notre armée et celle du sud., ses troupes, d'abord de simple avant-garde, tout en accentuant sa pression sur nos autres fronts ? Vraisemblablement nos alliés, qui, entre temps, avaient été euxmêmes assez violemment attaqués, sentirent le péril. Ils se dégagèrent, pour ne pas être entraînés dans l'échec, quiils prévoyaient.

Ils y mirent d'autant moins de scrupules qu'ils avaient, dès ce moment, commencé de juger sans indulgence nos méthodes. Ce retrait de confiance fut, je crois, le grand ressort psychologique de leur conduite, durant les deux dernières semaines de la campagne des Flandres. En quelques jours, nous pûmes voir le thermomètre de l'alliance baisser de ${ }_{\text {p.94 }}$ plusieurs dizaines de degrés. Les Britanniques, on le sait, avaient, dès le début de la guerre, accepté le commandement unique. Sous une forme, à vrai dire, quelque peu incomplète et dont l'application entraînait de bizarres effets. Le G.Q.G. britannique était aux ordres de notre généralissime. Mais sans intermédiaire. De sorte que le chef de notre premier Groupe d'Armées, qui dirigeait les opérations françaises, depuis les Ardennes jusqu'à la mer, voyait s’insérer, en plein milieu des troupes dont il avait la responsabilité, tout un très important détachement, qu'il ne pouvait manoeuvrer directement. Telle quelle, la concession que nous avait consentie le gouvernement de Londres avait certainement coûté fort cher à un orgueil national très chatouilleux et, chez les militaires, à un orgueil professionnel plus prompt encore à se cabrer. Elle se

\footnotetext{
${ }^{1}$ Je suis de plus en plus persuadé qu'elle était la seule sage. Qu'eût été l'avenir de la guerre, si toute l'armée britannique en mai-juin 1940 s'était usée sur le continent ? Dure sagesse, cependant, à laquelle un exécutant français, alors, pouvait difficilement s'élever. [Juillet 1942.]
} 
justifiait, sans doute, par la prépondérance numérique de nos forces terrestres, qui était écrasante. Mais aussi par l'estime qu’inspirait notre dressage stratégique. Foch, après Doullens, avait mené les armées alliées à la victoire. On s'en remettait à son successeur pour l'imiter. De cette supériorité prétendue de notre science d'état-major, nos officiers, en tout cas, étaient profondément persuadés. J'imagine qu'ils le montrèrent par fois un peu trop ${ }^{1}$. Or, il arriva qu'en peu de jours l'invraisemblable effondrement de nos armées, sur la Meuse, vint brusquement menacer d'encerclement tout ce qui combattait plus au nord. Dans ce désastre, dont pouvait sortir la perte de leur corps $_{\text {p.95 }}$ expéditionnaire entier, les Britanniques avaient le sentiment de n'être pour rien. Leur foi en fut déjà ébranlée. La lenteur et la gaucherie de notre parade firent le reste. Notre prestige avait vécu et on ne nous le cacha guère. Était-ce la faute de nos Alliés?

Après que l'action commune, projetée sur Arras, eut avorté, il semble que, des deux parts, sous l'empire d'une sorte de désillusion mutuelle, les états majors aient presque totalement renoncé à collaborer. Que de ponts les Britanniques n'ont-ils pas alors fait sauter, pour couvrir leur retraite, sans se préoccuper de savoir s'ils ne coupaient pas la nôtre ! On les vit, de même, malgré les protestations de l'ingénieur, détruire prématurément le central téléphonique interurbain de Lille, retirant ainsi à la Ire Armée à peu près tous ses moyens de transmission. Nous les jugions sans gêne, et je crois bien, en effet, que leur déception, sans doute légitime, devant les insuffisances de notre commandement, porta certains d'entre eux à oublier parfois les égards dus aux exécutants, dont la bravoure n'était pas en cause.

Une meilleure définition des zones, assignées à chaque année, aurait probablement évité de fâcheux incidents. Aucun pouvoir n'existait plus, qui eût le droit d'imposer ces limites. Le soin en avait appartenu naguère au G.Q.G. français, qui était la seule source d'autorité commune. Or, depuis notre encerclement, il avait cessé de nous gouverner. Un accord amiable, pourtant, était-il impossible ? J'ignore si on le tenta. Ce fut, en ce cas, san s succès. A Lille, en particulier, qui commandait? Personne ne l'a jamais su. La ville, avant le 10 mai, avait certainement fait partie de la zone britannique. Mais c'était autour d'elle que la Ire Armée s'était finalement concentrée. Là, notamment, nous puisâmes, pendant quelques jours, le plus clair de nos ressources en essence. Quand il s'agit de préparer la mise hors d'état des dépôts, nous résolûmes de ne pas en ${ }_{\text {p. } 96}$ abandonner la charge à nos alliés. Leurs procédés de destruction — par mélange de goudron ou de sucre à l'essence - nous semblaient insuffisants, au regard du nôtre, qui était le feu. Le général Prioux, quand la question lui eut été exposée, fit établir une lettre

\footnotetext{
1 Dans le procès-verbel du comité de guerre du 26 avril 1940 (Les Documents secriets de l'État-Major général français, p. 98), je relève une phrase qui en dit long sur l'insupportable vanité de nos états-majors,. La parole est au général Gamelin : "C'est aux Anglais à fourrnir l'effort principal [en Norvège]... Au surplus, il faut les soutenir moralement, les aider à organiser le commandement, leur donner la méthode et le cran. Hélas ! [juillet 1942.]
} 
et un ordre. Par la lettre, qui s'adressait à lord Gort, il paraissait laiss er à celuici, courtoisement, la décision. Par l'ordre, qui était à notre usage, il se la réservait tout entière. Diplomatie subtile, qui mettait au jour, assez crûment, l'incertitude où l'on était des droits de chacun. La confusion dura, d'ailleurs, jusqu'au bout. Un seul dépôt ne fut pas incendié. Il était situé au-delà d'un canal, dont les Britanniques avaient déjà rompu les ponts et que, j’ignore pourquoi, ils interdirent à nos hommes de passer en barque. Qui était responsable d'un pareil chaos ? Les Britanniques y avaient probablement leur part. Nous nous en accommodions, cependant, avec trop de facilité pour en être tout à fait innocents.

Mais sans doute la rupture morale eût-elle été moins profonde et ses conséquences moins graves si nos liaisons, avec nos Alliés, avaient été, par avance, plus solidement établies. La situation, il faut l'avouer, n'était pas sans complexité. L'état-major de lord Gort fonctionnait à la fois comme G.Q.G. des forces britanniques et comme G.Q. d'armée. Au premier titre, il communiquait directement avec notre G.Q.G. ; et la Mission française, que cornmandait le général Voruz, représentait auprès de lui le général Gamelin. Au second, il était ou aurait dû être en relations constantes avec les deux armées de chez nous, qui tenaient, l'une, la VII ${ }^{e}$, limitrophe de la côte, sa gauche, l'autre, la Ire, sa droite. Ici, la Mission n'avait plus grand-chose à voir. Il appartenait aux armées elles-mêmes d'organiser, à leur échelon, le contact. A vrai dire, ces rapports mitoyens se réduisaient, le plus souvent, durant la période d'attente, à d'assez minces questions de ${ }_{\text {p.97 }}$ bornage. Pouvait-on douter, cependant, qu'une fois les opérations actives déclenchées, de tout autres problèmes viendraient à se poser? et que leur heureuse solution dépendrait alors, pour une large part, de ce qui aurait été fait, auparavant, pour préparer l'entente, en même temps que pour se renseigner mutuellement? L'événement, là-dessus, devait d'ailleurs dépasser toutes les prévisions : puisque le G.Q.G., par suite de la percée allemande, ayant disparu de notre horizon, il n'y eut bientôt plus, en pratique, entre les Britanniques et nous, de trait d'union possible qu'au niveau des armées.

J'avais été, on s'en souvient, désigné, en principe, comme officier de liaison auprès des forces britanniques. Pendant mes premières semaines de Bohain, je m'employai de mon mieux à ces fonctions. On me laissait faire, sans beaucoup pousser à la roue. Une fois chargé du service de l'essence, je n’interrompis pas pour autant mes eff orts. Au Quartier Général britannique, alors dispersé, pour des raisons de sécurité, dans quelques misérables villages des environs d'Arras, je visitai, plus particulièrement, le « $\mathrm{Q}{ }^{1}$ (prononcez $\mathrm{Kiou}$ ), qui est à peu près l'équivalent de notre quatrième bureau. J'allai trouver un état-major de corps d'armée, à Douai. Je pris langue avec la Mission française. Bien vite, je me rendis compte que ces voyages intermittents, s'ils pouvaient servir à régler, au fur et à mesure des besoins,

\footnotetext{
${ }^{1}$ Abréviation de « Quarter-Master General's Branch ».
} 
quelques menues difficultés de détail, se manifestaient impuissants à créer un véritable contact.

Il n'est pas, sur le plan de l'action, de liens efficaces sans un peu de camaraderie, point de camaraderie sans un peu de vie commune. Cela est vrai, sans doute, de tous les hommes. Cela l'est au plus haut degré des Britanniques, affables et confiants, quelquefois jusqu'à la candeur, aussitôt qu'ils vous p.98 ont accepté dans leur familiarité; volontiers distants, par contre, malgré leur parfaite politesse, envers l'hôte de passage. Se présentaiton à leurs bureaux ? Ils vous donnaient correctement le renseignement demandé. Juste celui-là ; et nous n'en aurions, sans doute, pas fait davantage. Était-ce assez ? Le but aurait dû être d'apprendre à manier les ressorts d'une machine de guerre assez différente de la nôtre et qui, pourtant, était appelée à sharmoniser avec elle ; d'en pénétrer les faiblesses, si elle en avait (et quelle armée n'en a ? ) ; de comprendre, pour pouvoir ensuite les faire comprendre, des points de vue qui, fatalement, ne coïncidaient pas toujours avec ceux de notre commandement ; de nouer, surtout, ces relations directement humaines qui seules permettent, des deux parts, les suggestions fécondes, sans blessures d'amour-propre, et évitent, au jour du danger, la funeste tentation du chacun pour soi. Quelques visites d'occasion n'y pouvaient suffire. Il y eût fallu le thé de cinq heures, le whisky and soda, l'atmosphère de club qui se prolonge, devant la table de travail, en amicale coopération. Il eût fallu, en un mot, de toute évidence, maintenir en permanence, auprès du Quartier Général allié, un officier de la Ire Armée. Tel était, comme le mien, le sentiment du chef d'état major de la Mission française ; telle aussi, la pratique de la VIIe Armée, dont, malheureusement, les soins, à cet égard, étaient destinés, par la faute des événements, à demeurer à peu près sans effets. Car, à l'exception du XV Ie Corps, réservé à la défense de Dunkerque, elle devait être, dès le 15 ou le 16 mai, je crois, retirée presque tout entière du front d'Anvers, pour se voir jeter dans la brèche de la Meuse et de l'Oise, et s'y faire, presque tout entière, pulvériser.

A la $I^{\text {re }}$ Armée, nous nous contentions d'accueillir, à notre troisième bureau, un représentant du Quartier Général britannique. Le premier que j'ai connu était un ancien officier de carrière, devenu banquier ${ }_{\text {p.99 }}$ dans la cité. Ses manières, à la fois prévenantes et brusques, ses allures de bon vivant, son humour, plus original sans doute, chez nous, qu'il n'eût paru chez lui , l'avaient rendu populaire. Très dévoué à son métier, on le disait assez jaloux de l'autorité qu’il tenait de sa mission. Peut -être, de notre côté, le zèle un peu intempérant de quelques-uns de nos camarades ne lui avait-il pas suffisamment épargné la menace d'empiètements, qu'il était bien décidé à ne pas souffrir. Je n'ai jamais, pour ma part, entretenu avec lui que les meilleurs rapports. Mais il préférait, certainement, garder entre ses mains tous les fils de liaison. Je crains que son influence, auprès de nos chefs, n'ait pas toujours été, de ce point de vue, sans dangers. Il était, par-dessus tout, suprêmement adroit. En outre, profondément imbu des partis pris sociaux, dont la grande 
bourgeoisie anglaise est rarement exempte, il n'échappait pas non plus, j’imagine, bien qu'il eût trop de tact pour les étaler, aux préjugés nationaux inhérents, de même, à la vieille tradition «tory ».

Bien naïf, qui eût compté sur lui pour nous renseigner sur les insuffisances éventuelles de l'équipement ou des méthode s britanniques. Il nous quitta, peu avant le 10 mai, pour un poste dans le ministère du Blocus, à Londres : trop tôt pour les services que, dans une période plus active, il n'eût pas, j'en suis persuadé, manqué de nous rendre. J'ai beaucoup moins fréquenté son successeur qui, avec autant de courtoisie, avait moins d'entregent. Professionnellement, je n'ai guère eu affaire à lui qu'une fois, à Lens ; il me parut, alors, soucieux surtout de se garer de toute responsabilité. Cependant, quelles que fussent les idiosyncrasies personnelles de ces délégués de l'armée alliée, les meilleurs d'entre eux ne nous donnaient, à bien réfléchir, qu'une moitié de représentation diplomatique. Pour maintenir les liens avec un pays ami, savoir ce qui s'y passe et établir l'amit ié même sur la base solide d'une mutuelle p.100 compréhension, quel gouvernement se satisfait d'accorder l'hospitalité à l'ambassadeur de la nation étrangère ? et, sous prétexte qu’il n'a qu'à se louer de ce plénipotentiaire, renonce à dépêcher lui -même, là-bas, son propre agent?

Un jour, donc, prenant mon courage à deux mains, je demandai audience à notre sous-chef d'état-major qui, alors, tenait les fonctions de chef. Je lui exposai de mon mieux les arguments que je viens de développer. Je n'omis point de lui faire entendre que je ne postulais nullement, pour moi, les fonctions d'officier détaché auprès du Quartier Général de lord Gort ; elles me semblaient revenir à des camarades plus rompus à l'art militaire. Mais je fus maladroit. Craignant que mon avis personnel ne parût de peu de poids, je crus bon de l'appuyer sur l'opinion plus autorisée du chef d'état -major de la Mission française. Hélas! le lieutenant-colonel auquel s'adressait mon plaidoyer était l'intime ennemi de l'autre lieutenant -colonel que j'allais ainsi chercher comme garant. Je n'avais certes point, par là, avancé mon affaire. Les chemins de l'École de Guerre sont semés d'embûches sous les pas de qui n'a point été nourri dans le sérail ! Mon interlocuteur me laissa parler, fort courtoisement. Puis il manifesta que je ne l'avais en aucune façon convaincu : à son gré, la présence, chez nous, d'un officier britannique suffisait à tout. Plus tard, je tentai de faire saisir de la question le G.Q.G. Ce fut, de nouveau, sans profit. Et, sans que personne y trouvât à redire, renonçant à m’imposer, pour quelques minutes de vagues et oiseuses conversations, mes va-et-vient d'antan, sur la route d'Arras, je me consacrai désormais, de plus en plus exclusivement, au service de l'essence.

Pendant la campagne, un officier supérieur de notre état-major qui avait déjà eu auparavant quelques contacts avec les Britanniques, fut notre agent ordinaire auprès de leur Q.G. Intelligent et d'esprit beaucoup plus large que la plupart de ses pairs, il p.101 fit, j'en suis persuadé, non seulement de son mieux, mais mieux qu'aucun autre n'aurait pu faire. Mais il n'avait jamais vécu dans 
l'intimité de nos alliés ; au moment même, il n'y vivait point, passant le plus clair de son temps à courir de P.C. en P.C. Surtout, les circonstances étaient plus que jamais défavorables à l'établissement d'une confiance qui eût pu résister aux événements seulement si elle avait eu pour elle un long enracinement. Une alliance véritable est une création continue; elle ne s'écrit pas sur le papier ; elle ne subsiste que par une multiplicité de petits rapports humains, dont le total fait un lien solide. Nous l'avions, à la $\mathrm{I}^{\mathrm{re}}$ Armée, beaucoup trop oublié. Nous souffrîmes durement de notre négligence ${ }^{1}$.

J'avai s, je l'ai dit, passé, lors de mon arrivée à l'armée, quelques jours à son $2^{\mathrm{e}}$ bureau, qui est celui des renseignements. Par la suite, mes efforts pour nous procurer une liste, précise et à jour, des dépôts d'essence belges me mirent en rapport aussi avec les $2^{\text {es }}$ bureaux du groupe d'armées et du G.Q.G. J'aurais d'ailleurs été un piètre historien si je n'avais toujours porté un intérêt particulièrement vif à ces questions d'information et de témoignage. Mais, précisément parce que j'étais un historien, les mé thodes en usage autour de moi ne tardèrent pas à m’inspirer de cruelles inquiétudes.

Qu'on veuille bien me comprendre. Je ne prétends nullement englober ici, dans une condamnation a priori tout un groupe d'hommes parmi lesquels, qu'il s'agît d'active ou de réserve, il se rencontrait ${ }_{\text {p.102 }}$ certainement beaucoup de travailleurs dévoués et compétents. Dans le cours de mon enquête, j’ai trouvé au $2^{\mathrm{e}}$ bureau du G.Q.G., sinon un secours bien efficace, du moins un accueil toujours aimable ; au groupe d'armées, une compréhension et une aide véritablement précieuses. A l'armée, nous étions peu favorisés et, à l'état major, quand se déliaient les langues, on n'en faisait guère mystère. L'officier, d'allures avantageuses, qui commandait notre $2^{\mathrm{e}}$ bureau, eût certainement figuré avec honneur, un jour de revue, en tête d'un bataillon bien astiqué. Je n'ai aucune raison de douter qu'il ne se fût aussi fort estimablement comporté sur le champ de bataille. Mais la tâche qui lui avait été assignée le dépassait, évidemment, de beaucoup. Là encore, cependant, quelle que fût l'insuffisance de la direction, il n'y avait pas que des ombres. J'ai eu d'excellents cama rades, presque des amis, au $2^{\mathrm{e}}$ bureau, notamment dans la section des interprètes, que gouvernait, avec une savoureuse et diserte autorité, un industriel lyonnais. Ces gens-là besognaient de leur mieux, avec beaucoup d'abnégation, et dans leur sphère, nécessairement un peu limitée, non sans une incontestable intelligence.

1 Sur ces insuffisances de liaison, entre nos forces et le Corps Expéditionnaire, voir l'intervention de Churchill au comité de guerre franco- britannique du 22 mai et son télégramme du 24. (Les Documents secrets de l'État-Major général français, p. 57 et 132, juillet 1942.) 
Il faut bien le dire, cependant : que nous fûmes donc mal informés ! J'ai pu suivre de près une partie du travail de renseignements sur la Belgique. J'ai déjà raconté que, sur les emplacements, la capacité et la contenance des dépôts d'essence, le G.Q.G., dès le principe, ne nous avait fourni que des indic ations vagues et souvent erronées. Pis encore, il ne se préoccupait nullement de nous en procurer de meilleures. Dans l'armée belge, elle-même, comment était organisé le service du ravitaillement en carburants, avec lequel, en cas d'alliance contre un agre sseur commun, nous étions nécessairement appelés à collaborer ? Je cherchai à le savoir. Le général Blanchard voulut bien signer, en personne, la lettre qui demandait, là-dessus, quelques précisions. Elle ${ }_{\text {p.103 }}$ n'obtint jamais de réponse. J'ai de fortes ra isons de penser que ces ignorances n'étaient pas particulières à mon service. Elles tenaient à des raisons diverses.

Tout d'abord, à la pléthore des organes d'information et à l'esprit de rivalité qui, conformément à un fâcheux penchant, sur lequel nous aurons à revenir, s'établissait presque fatalement entre eux. Les attachés militaires dépendaient non du G.Q.G., mais du ministère, éminemment jaloux de ses prérogatives. Sous couvert d'un fallacieux respect de la neutralité, ministère et G.Q.G. s'accordaien t, à leur tour, pour interdire aux états-majors subordonnés toute prospection directe, en Belgique. A la vérité, ni le Groupe d'Armées ni les Armées ne se faisaient pourtant faute de travailler indépendamment. Plus d'une indication utile nous est arrivée $\mathrm{p}$ ar cette voie plus ou moins subreptice. N'eût-il pas mieux valu organiser la convergence des efforts ?

Il eût convenu aussi de les mieux diriger, avec un sens plus aigu du concret. Un $2^{\mathrm{e}}$ bureau devrait être conçu comme une sorte d'agence qui, pour clients aurait les multiples organes du commandement. Elle répondrait à leurs demandes : celles de l'artillerie, de l'aviation, des chars, des services appelés à régler la circulation par voie ferrée ou par route, aussi bien que des bureaux d'études stratégiques, qui coiffent le tout; car chacun de ces organes du commandement a ses questions particulières à poser, que les non-spécialistes risquent toujours de négliger. Elle chercherait à prévoir et satisfaire d'avance leurs besoins. Elle diffuserait à chacun, aussitôt reçues, les données de nature à leur servir.

Au lieu de cela, la recherche du renseignement n'a presque jamais cessé de se mouvoir dans le même cercle, étroitement borné par des traditions qui ne tenaient à peu près aucun compte de la guerre de matériel. Avant tout, on s'attachait à reconstituer, hypothétiquement « l'ordre de bataille ennemi » c'est-à-dire le dispositif de ses unités — qui est ${ }_{\text {p.104 }}$ censé avertir de ses intentions, mais, le plus souvent, en raison de la rapidité actuelle des mouvements, demeure chaque fois susceptible de trois ou quatre interprétations opposées. Il s'y ajoutait, accessoirement, certaines enquêtes, d'ordre moral ou politique, où s'étalait ordinairement une candide ignorance de l'analyse sociale véritable. Je me souvie ns d'une brochure sur la Belgique qui croyait en dire bien long, sur les ressorts internes du pays, en nous 
apprenant, dans le meilleur style de l'Almanach de Gotha, que le royaume était une «monarchie constitutionnelle ». On l'a bien vu, à l'expérience !

Quant à la diffusion des informations, c'est une vieille plaisanterie, dans les états-majors, de raconter comment un $2^{\mathrm{e}}$ bureau, aussitôt qu'il sait quelque chose, s'empresse d'en faire un papier, d'écrire sur celui -ci, à l'encre rouge, «très secret », puis de l'enfermer, loin des yeux de tous ceux qu'il pourrait intéresser, dans une armoire à triples serrures. J'eus un jour la preuve que le trait n'était pas purement légendaire. J'avais obtenu de notre $2^{\mathrm{e}}$ bureau qu'il communiquât aux Corps d'Armées la li ste commentée des dépôts d'essence belges, telle que nous étions finalement parvenus à l'établir. Quelque temps après, nous eûmes l'occasion d'adresser aux grandes unités une instruction générale relative à leur alimentation en carburants, dans le cas de pénétration en Belgique. Elle traitait essentiellement des réquisitions, ensuite de l'installation, par l'armée, de ses propres dépôts, et, sur la géographie des ressources locales, se bornait à se référer au tableau précédemment expédié. Dans chaque état-major, elle fut, comme de juste, remise au $4^{\mathrm{e}}$ bureau, chargé de tous les ravitaillements. Le jour même, je reçus un coup de téléphone un peu acerbe du camarade qui, dans un des corps, dirigeait le service parallèle au mien : «Vous nous parlez d'un tableau. Nous ne l'avons jamais vu. » On sinforma. L'envoi avait parfaitement eu lieu ; mais, ce qui vient d'un bureau p.105 déterminé allant, par une pente irrésistible, rejoindre, à l'échelon inférieur, le bureau de même signe, c'était le $2^{\mathrm{e}}$ bureau du Corps qui en avait été le destinataire. Là, le papier avait été, incontinent, muré dans le fameux coffrefort aux secrets, sans que personne se préoccupât une minute d'en donner connaissance au seul officier capable de l'utiliser. Autour de moi, on haussa les épaules : «Ils n'en font jamais d'autres !» Quant à infliger un blâme ou prendre les mesures nécessaires pour que pareil errement ne se renouvelât point, nul n'y songea. Tant la routine semblait indéracinable.

Notre $2^{\mathrm{e}}$ bureau, nous le savions bien, n'était pas un modèle. Les documents que nous le vîmes établir, durant la période d'attente et, théoriquement, d'études, qui précéda l'offensive allemande, ne laissaient pas, néanmoins, d'étonner parfois les plus endurcis. Une certaine carte des chemins de fer fut célèbre; un malencontreux tracé de la frontière semblait, d'Aix-la-Chapelle, faire une ville belge, et la voie ferrée Hambourg-Berlin était classée parmi les lignes de faible débit. Mais, après tout, on ne pouvait guère s'y tromper. Le «bulletin de renseignements », qui paraissait à courts intervalles, attestait des erreurs de conception plus subtiles et, par suite, plus graves. Imaginez un chercheur occupé à dresser, de temps à autre, le bilan de son enquête, un archéologue, par exemple, qui publie les procès-verbaux successifs de ses fouilles, un médecin livrant à ses élèves les feuilles d'observation d'une maladie, ou encore le fameux carnet d'expériences de Pasteur. Qu'attendrons -nous de ces sincères états ? Qu’ils nous disent, à chaque stade : voici un témoignage qui, incertain la dernière fois, se trouve aujourd'hui confirmé ; une interprétation, au contraire, naguère considérée 
comme presque indiscutable et que maintenant les progrès de notre information forcent de tenir pour ruinée ; ailleurs - s'il s'agit non de choses passées, mais de phénomènes étudiés dans leurs cours - voilà un fait nouveau, p.106 indice, peut-être, d'une transformation capitale. En d'autres termes, toute connaissance étant, par elle-même, mouvement progressif de l'esprit et la c onnaissance d'événements par nature changeants ne pouvant, en outre, résulter que de l'examen de leur courbe, un compte rendu de recherches, pris isolément, sera toujours de peu de poids, sil ne se raccorde aux comptes rendus précédents. Or, nos divers «bulletins » se suivaient, sans que, jamais ou presque jamais, leur lien fût apparent. A les confronter avec soin, on observait, assez souvent, qu'ils se contredisaient, ou bien qu'ayant attiré l'attention, une première fois, sur un groupe de données, appar emment riches de possibilités, ils abandonnaient, ensuite, sans crier gare, cette ligne. Mais, était-ce que le second renseignement rendait caduc le premier ? qu'on avait volontairement omis de se répéter? que la situation s'était réellement modifiée ? Bien fin qui eût pu le dire. Je crains un peu, en avouant toute ma pensée, de verser dans le péché de la calomnie. Je me suis, cependant, plus d'une fois demandé quelle était, dans cette incohérence, la part de la maladresse et celle de l'astuce ? Tout chef de $2^{\mathrm{e}}$ bureau vit dans la terreur qu'au jour du « coup dur», les faits viennent démentir les prétendues certitudes dont il a armé le commandement. Offrir à celui-ci un grand choix d'indications contradictoires n'est-ce pas se réserver le moyen de dire triomphalement, quoi qu'il arrive : «Si vous m’aviez cru ${ }^{1}$ »?

p.107 Une fois les opérations actives commencées, de quel profit les services du $2^{\mathrm{e}}$ bureau furent-ils, jour par jour, aux stratèges de l'état-major ? Là-dessus, je serais fort en peine de me prononcer. Car, de ce quill put faire ou dire, à peu près rien n'a transpiré jusqu’à moi. Une chose est sûre : les fameux «bulletins», gardant désormais un silence total autant que prudent, les officiers pourvus de fonctions du même type que les miennes ne surent jamais sur l'ennemi que le peu qu'ils arrivaient à attraper, par raccroc et au hasard des conversations ou des rencontres. Autant dire, presque zéro. J'entends : par rapport, non seulement à l'étendue de leurs curiosités, peut -être oiseuses, mais surtout à ce qu'il leur était indispensable de connaître pour le bon exercice de leur métier propre. Quand, par aventure, on se trouvait recueillir soi-même une indication de quelque importance, il arrivait (j'en ai donné un exemple) que, faute d'avoir à sa p ortée un centre de renseignements à qui la transmettre, on dût se résoudre, en désespoir de cause, à précipiter l'informateur chez le commandant de l'armée en personne. Comme si, à un chef accablé de tant de

\footnotetext{
1 Sur les mauvaises habitudes des $2^{\text {es }}$ bureaux, bien avant la guerre, voici le témoignage écrasant de B. de Jouvenel, La Décomposition de l'Europe libérale, p. 212 : «Notre étatmajor apporte une vanité puérile à étaler dans les pages de L'Annuaire (L'Annuaire militaire de la S.D.N.) des forces que nous n'avons pas, des militaire s de carrière dont on n'a point reçu les engagements et des réservistes qu'on ne convoque pas. Il renforce ainsi la thèse allemande. » Pour 1914, cf. les Mémoires de Joffre, p. 249 (faux renseignement sur les corps de réserve allemands). [juillet 1942.]
} 
responsabilités, les données de cet ordre n'auraient pas dû arriver seulement déjà rassemblées et filtrées ! D'ailleurs, ces centres, ces « agences », pour reprendre la comparaison que j'ai déjà employée, chargées à la fois de renseigner et de recevoir les renseignements, ce n'est pas uniquement dans l'état-major, en son ensemble, qu'il eût convenu d'en prévoir le fonctionnement sous la forme du deuxième bureau. A l'intérieur de chaque bureau, il aurait été au moins aussi nécessaire, à mon sens, de spécialiser un officier dans ce rôle, qui eût largement suffi à l'occuper. Croira-t-on qu’il fut aisé de ravitailler des unités en munitions, vivres, matériel du génie ou essence et de fixer l'emplacement de dépôts de munitions, de gares de ravitaillement en vivres, de parcs du génie ou de camions-réservoirs, sans savoir, les trois quarts du ${ }_{\text {p.108 }}$ temps, où se trouvaient ces unités ni où se trouvait l'ennemi ? ${ }^{1}$

Les erreurs de méthode de notre deuxième bureau et de bien d'autres services, dans l'ensemble des armées, n'étaient certa inement pas, pour la plupart, passées inaperçues de nos chefs, et je suis persuadé que, parmi ceuxci ou dans leur entourage immédiat, il se trouvait plus d'un esprit trop juste pour ne pas les condamner, dans son for intérieur, avec sévérité. Comment se fait-il, cependant, qu'elles n'aient presque jamais provoqué une sanction, voire un simple déplacement? «On ne sait plus punir dans l'armée française », disaient, parfois, mes jeunes camarades de l'active. Formule, sans doute, un peu brutale. Mais la crise d'autorité qu'elle exprimait n'est pas contestable. Elle demande, seulement, à être analysée de plus près.

J'ai beaucoup fréquenté, autrefois, les officiers de troupe. Je ne doute pas qu'il ne se soit rencontré parmi eux, cette fois -ci comme naguère, un grand nombre d'hommes capables de diriger leur unité avec une équitable et souple fermeté, aussi éloignée du désordre - dont, personnellement, j’abhorre l'image - que des absurdes brimades du légendaire «chien du quartier». C'est un beau métier que celui de ${ }_{\text {p.109 }}$ commandant de compagnie, de bataillon ou de régiment, quand il est noblement exercé, à la française ; et j'ai souvent observé qu'il développe, chez les esprits bien nés, des vertus d'humanité, pour lesquelles je professe la plus vive admiration. J'ai eu plaisir à les retrouver

\footnotetext{
1 Vieille tare de nos états-majors, d'ailleurs, que cette incapacité de renseigner. Dans ses Mémoires, le duc de Fezensac rapporte qu'ayant reçu, un jour, de Ney la mission de porter un ordre à un des généraux subordonnés du maréchal, il voulut demander où il devait aller : «Point d'observations, me répondit le maréchal. Je ne les aime point », et Fezensac d'ajouter: «On ne nous parlait jamais de la situation des troupes. Aucun ordre de mouvement, aucun rapport ne nous était communiqué. Il fallait sinnformer comme on pouvait ou plutôt deviner. » (Cité par M. LEROY, La Pensée de Sainte-Beuve, p. 56.) Voilà une observation que nous aurions pu contresigner : n'est -ce pas, ô Lachamp. [juillet 1942.]
} 
près de moi, dans le séduisant officier d'état-major qui, avant de partir pour de plus hautes destinées, fut quelque temps notre sous-chef de bureau. «Depuis qu'il n'est plus là, personne ne s'occupe plus de nous », disaient mélancoliquement nos secrétaires. Il n'y a que les maladroits pour redouter que la sympathie se puisse confondre avec la familiarité.

Que, malheureusement, le gouvernement des hommes n'ait pas été pratiqué, partout, avec autant de mesure et d'humaine int elligence, certains rapports, dignes de foi, m'en donnent l'assurance. Il y a deux mots que je voudrais voir rayés du vocabulaire militaire : ceux de «dressage » et de «mise au pas ». Bons, peut-être, pour l'armée du Roi Sergent, ils n'ont rien à faire dans une armée nationale. Non que je nie, le moins du monde, que là comme ailleurs, peut-être plus qu'ailleurs, une discipline ne soit nécessaire et, par suite, l'apprentissage de cette discipline. Mais elle ne saurait être que la prolongation des vertus civiles et, selon le beau mot que Pierre Hamp appliquait au vrai courage, « une forme de la conscience professionnelle ». Un officier s'étonnait un jour devant moi que les dames téléphonistes, employées au Central de l'armée, fissent si bien leur service . " aussi bien vraiment que des soldats », disait-il, d'un ton inimitable, où le scandale l'emportait encore sur la surprise. Un pareil orgueil de caste le rendait-il fort capable de commander des troupes levées, dans le peuple entier, pour la défense du pays, et dont la plus grande partie se composait d'hommes que la vie avait déjà habitués à l’indépendance du foyer ?

Pratiquement, la «mise au pas » se confond ${ }_{\text {p.110 }}$ presque toujours avec le respect imposé de formes extérieures, dont la valeur n'est pas niable, quand elles servent d'expression à une discipline plus profonde, mais qui ne sauraient être exigées avec profit si, en même temps, un courant de confiance n'a su être créé, assez fort pour que, chez presque tous, l'observance de ces gestes de déférence n'en naisse spontanément. Je consens qu'on « dresse » l'homme ; mais ce ne saurait être sans se tourner vers l'homme tout entier, que les vrais chefs savent bien comment prendre. Était-ce un de ces chefs-là, le colonel qui - je suis sûr de l'anecdote - cassa de son grade un sousofficier parce qu'un jour de très grand froid, il l'avait rencontré les mains dans les poches de sa capote? qui, à longueur de journée, faisait paraître des notes sur la tenue et, cependant, laissait sa troupe, en plein hiver, geler dans des cantonnements mal organisés ?

J'ai pu assister, moi-même, aux effets d'une pareille tentative de «redressement». C'était en Normandie, lors de notre regroupement, après la campagne de Flandre. Que nos soldats avaient donc alors de bonne volonté et de gentillesse ! Il n'est aucun de nous, même parmi les vieux durs à cuire, qui n'en ait été ému. Ils débarquaient du train, éreintés par un long voyage, affamés souvent, quelquefois sans autres vêtements que les hardes hétéroclites que les Anglais leur avaient distribuées, après naufrage. Ils avaient perdu, en route, leurs unités, leurs chefs directs, leurs «copains ». Fréquemment, pour rejoindre enfin le stationnement où ils retrouveraient un peu de cette 
atmosphère d'entraide collective, si néces saire à l'homme de troupe, il leur fallait encore parcourir, à pied, bien des kilomètres. Pas une plainte, pourtant ; un brave «merci » récompensant toute attention qu'on pouvait avoir pour eux ; le contentement, non seulement de se sentir, provisoirement du moins, à l'abri, mais aussi de revoir sain et sauf tel ou tel officier dont ${ }_{\text {p.111 }}$ le sort les avait inquiétés. J'ai reçu là quelques poignées de main qui m'ont fait chaud au coeur. En vérité, le souvenir de ces journées m'empêchera toujours, si jamais j'en étais tenté, de désespérer du peuple français.

Vint, pour nous commander, un général animé certainement des meilleures intentions, parfaitement sincère dans sa foi militaire, dur à lui-même comme aux autres, mais chez qui le sens psychologique ne s'él evait pas à la hauteur des autres qualités. Il jugea que l'ambiance n'était pas tout à fait celle d'une caserne bien tenue et voulut y remédier. Les rondes d'officiers se multiplièrent et les observations sur les vareuses incorrectes plurent de toutes parts. Échappés à ce que les journaux appelaient déjà, pompeusement mais non sans quelque justesse, l'enfer des Flandres, beaucoup d'entre nous avaient cru pouvoir faire venir leur femme, dans les villages où nous logions : les simples soldats au moins aussi souvent que les officiers, de sorte que l'égalité n'était nullement blessée. Le général sévit. Un guerrier peut, s’il lui plait, aller au bordel; les embrassements conjugaux, par contre, sont pour lui péché d'amollissement. Comme notre nouveau chef était, à sa façon, un juste, il commença, d'ailleurs, par infliger quinze jours d'arrêts de rigueur au vieux général du cadre de réserve, qui nous avait gouvernés avant lui ; ne l'avait-il pas rencontré, un soir, bras dessus bras dessous avec sa vénérable épouse ? On rit. L'homme du rang n'en fut point consolé. En quelques jours, la température morale avait changé. Symptôme significatif: le salut aux officiers, jusque-là offert avec un cordial empressement, ne le fut plus que d'une main parcimonieuse et, visiblem ent, par contrainte. Un pseudo-dressage avait ruiné, avec une merveilleuse promptitude, la bonne et saine humeur d'une troupe venue du feu et destinée, croyait -on, à y retourner.

Parmi les personnes qui avaient vécu en p.112 1914-1918, sous l'occupation allemande et l'ont, de nouveau, subie, au cours de ces dernières semaines, plusieurs, sans s'être concertées, m’ont fait part d'une observation, dont j'ai été vivement frappé : comparée à l'armée du régime impérial, celle du régime nazi leur a paru de moeurs «plus démocratiques ». La distance entre l'officier et le soldat semble moins infranchissable (les officiers pourtant continuent à ne pas rendre bien exactement le salut; j'en ai été moi-même le témoin). Du haut en bas, on sent plus nettement l'accord dans une commune bonne volonté. Cette union des âmes, qu'a su réaliser un mysticisme, dont la grossièreté ne doit pas nous dissimuler la puissance, il serait désastreux que, chez nous, l'empire de vieilles traditions à la prussienne, profondément antinomiques à notre véritable esprit national et peut-être désuètes en Prusse même, puisse jamais la compromettre. 
A droit ou à tort, l'armée française ne l'avait donc pas oublié et peut -être pas assez le vieil art de punir. Il est trop certain, par contre, que le commandement n'a pas su, comme il l'aurait pu et dû, mettre à profit les longs mois d'attente dont l'ennemi lui abandonna la libre disposition pour pratiquer, dans les cadres, les nettoyages nécessaires. Quelques limogeages retentissants marquèrent, à la $I^{\text {re }}$ Armée, la période des opérations. Mais fallait-il attendre jusque-là, c'est-à-dire trop tard ? Car on connaissait bien, dès auparavant, certaines insuffisances. En veut-on un exemple de plus ? Le commandement de notre Quartier Général d'Armée était exercé par un vieil officier, dont la cordialité bon enfant ne masquait à personne la parfaite inaptitude. « Il y a trente-deux ans que je ne comprends pas », se plaisait-il à répéter. Je serais bien étonné si, de bouche en bouche, le candide aveu, dont nous fîmes tant de gorges chaudes, n'était pas parvenu jusqu'aux oreilles du plus élevé en dignité de nos chefs. A vrai dire, les attributions de cet honorable émule du p.113 capitaine Bravida n'étaient pas, tant que nous restâmes à Bohain, d'une importance capitale. Chacun savait, cependant, qu'en cas d'opérations actives, elles étaient appelées à devenir beaucoup plus lourdes. Elles comportaient, en particulier, d'après le règlement même, la direction de ce service automobile de l'état-major qui, avant comme, malheureusement, après le 10 mai, laissa toujours tant à désirer. D'autre part, le renvoi d'un officier de ce rang n'eût assurément pas souffert autant de difficultés que le déplacement d'un généralissime ou d'un commandant d'armée. Nous n'en conservâmes pa s moins notre falot chef de bataillon durant l'hiver entier, puis tout le long de la campagne - pendant laquelle nous ne le vîmes, d'ailleurs, à peu près jamais — jusqu'au jour où, sur le point de s'embarquer, il disparut mystérieusement, à Dunkerque. Comment? La légende s'empara de sa fin. Mieux vaut avouer que nous n'en sûmes jamais rien et supposer - comme cela est, après tout, fort possible - qu'il mourût simplement pour la France ou, par malencontre, fut fait prisonnier. Ce n'était certes pas sa faute si on l'avait maintenu dans un poste fort au-dessus de ses modestes capacités. Il ne fut pas le seul dans ce cas. La rude main du Joffre de 1914 nous avait manqué et nous aurions eu grand besoin de quelques-uns de ses jeunes Turcs. Certains vivaient bien encore. Mais vieillis, chargés d'honneurs, gâtés par une longue vie de bureaux et d'habileté.

Car la mollesse du commandement eut son origine avant tout, je crois, dans des habitudes contractées durant la paix. La manie paperassière y fut pour beaucoup. Ce chef de $2^{\mathrm{e}}$ bureau, qui omit de transmettre au seul officier intéressé un renseignement de première importance, supposez-le, pour un instant, à la tête d'un grand service, dans une entreprise privée. Que se serait -il passé ? Le patron, j’imagine, l'aurait fait appeler, lui aurait dit, toutes portes closes, ses quatre vérités, enfin l'aurait ${ }_{\text {p.114 }}$ réexpédié à son travail, avec un «ne recommencez pas» bien senti. Et il n'aurait probablement pas recommencé. Prenez maintenant le cas, tel que je l'ai vu en réa lité ; si j'avais cru pouvoir obtenir d'abord de mon supérieur immédiat, puis du chef d’État - 
major, puis du général d'Armée lui -même qu'une observation fût adressée à l'officier coupable, il m'aurait fallu leur soumettre une note écrite. Pis encore, cette note, selon les sacro-saintes règles hiérarchiques, n'aurait pu avoir d'autre destinataire que le commandant du Corps d'Armée lui -même : car, d'échelon en échelon, on ne correspond qu'entre chefs. L'affaire eût revêtu, dans ces conditions, une gravité telle que tout le monde me déconseillait de m’y lancer ; d'édulcoration en édulcoration, mon papier serait resté en panne, au bout du compte, si jamais il y avait abordé, sur une auguste table. Ajoutez la peur des «histoires », le souci de diplomatie qui, chez des hommes en mal d'avancement devient une seconde nature, la peur de mécontenter un puissant d'aujourd'hui ou de demain. Il fut décidé un jour sur ma proposition que l'allocation en essence d'un Corps d'Armée serait diminuée, celle d'un autre augmentée d'autant. D'où deux notes de service parallèles. L'avis de retranchement, le sous-chef d'état-major qui remplaçait alors le chef, le fit signer par le général Blanchard; il se réserva, par contre, la signature du papier, qui, au second Corps d'Armée, ann onçait d'agréables facilités de consommation. Ainsi paraissait-il n'être pour rien dans la mauvaise nouvelle, pour tout dans la bonne. C'est de la sorte qu'on soigne sa carrière. On la compromet en grondant ou, du moins, quand on n'a pas le coeur bien trem pé, on craint, à tort quelquefois, de la compromettre ainsi. La routine, enfin, est, par essence, accommodante. On s'était accoutumé, durant de longues années de bureaucratie, à beaucoup d'insuffisances, qui prenaient rarement un caractère tragique. Les temps changèrent. Non les moeurs. Pour ${ }_{\text {p.115 }}$ faire court, ce serait sans doute assez de dire que les états-majors du temps de paix n'étaient pas une bonne école pour le caractère. On ne le vit que trop, de toutes façons ${ }^{1}$.

Un vieux dicton militaire décrit les sentiments mutuels de deux officiers gravissant ensemble les degrés de la hiérarchie: "Lieutenants, amis. Capitaines, camarades. Commandants, collègues. Colonels, rivaux. Généraux, ennemis. » Les discordes des grands chefs, dont on s'entretenait parfois, autour de moi à mots couverts, le lecteur se doute bien que j'ai été mal placé

\footnotetext{
${ }^{1}$ Il y a, d'ailleurs là, un gros problème. Nul texte ne le po se avec plus d'éclat que le tome premier des Mémoires de Joffre. On n'y trouvera pas seulement l'étonnante liste des généraux quil fallut relever de leur poste dans les premiers mois de la guerre (par exemple, de la mobilisation au 6 septembre 1914, la moitié au moins des commandants de divisions d'infanterie active, la moitié exactement des commandants de divisions de cavalerie). La remarque de Joffre à propos d'un général de corps d'armée : «Il avait fait preuve d'incapacité à passer de la mentalité du temps de paix à la mentalité du temps de guerre », elle vaut, évidemment, pour la plupart des chefs ainsi «limogés », pour près de la moitié, en somme, des chefs du temps de paix. Mais alors, qu'est-ce donc que l'éducation militaire, si elle prépare à tout, sauf à la guerre ? [Juillet 1942.1
} 
pour en parler savamment. Attisées par les clientèles qui, fatalement, ourdissent autour de chaque «patron » tout un réseau de dévouements et d'intrigues, le déplorable foisonnement des organes du commandement ne leur avait que trop bien préparé le terrain. Avons-nous jamais compris, dans l'armée française, que plus l'ordre ou le renseignement ont à traverser de sédiments successifs, plus ils risquent de ne pas arriver à temps ; que, pis encore, là où le nombre de chefs superposés est trop grand, la responsabilité se

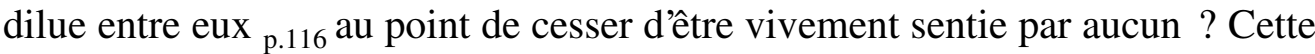
tare de notre bureaucratie militaire sévissait à tous les niveaux. J'ai déjà indiqué que si, dans le service de l'essence, nous avions observé, à la lettre, le règlement, un escalier à triple degré eût séparé, des exécutants, le représentant de l'Armée. Entre le commandant d'un régiment d'infanterie et la division, l'état-major de l'infanterie divisionnaire fait écran: «organe de retardement », disions-nous, au temps où j'étais moi -même fantassin. Je serais étonné si le surnom avait, depuis, perdu sa raison d'être. Plus haut, il y avait l'Armée ; le Groupe d'Armées, simple instrument de coordination stratégique, en principe, mais qui souvent tenta de sortir de ce rôle ; le Commandement du Théâtre d'opérations du Nord-Est, chargé de la conduite de la guerre sur tout le front français, Alpes exceptées; le Commandement en chef des Forces Terrestres enfin. Lorsque s'opéra le partage des attributions entre les deux derniers échelons - ou, pour user de termes humains, entre l'état-major Georges et l'état-major Gamelin — j'assistais à un exposé sur la nouvelle organisation du G.Q.G. Le conférencier s'exprimait aussi clairement que possible. Je ne fus pourtant pas le seul à ne tirer de son discours qu'une conclusion un peu nette : on allait, inévitablement, au chaos et aux perpétuels chevauchements. Divers échos, venus, par la suite, à mes oreilles, m'ont montré que nous n'avions pas tort. Encore comptions -nous sans ce troisième embryon d'état-major, caché dans les plus intimes replis du temple : le cabinet militaire du généralissime !

Tout cela se passait loin de moi. J'ai eu, par contre, maintes occasions de mesurer exactement les rivalités des bureaux entre eux et, tout près des cimes, celles de l'État-Major général (alias le G.Q.G.) avec l’État-Major de l'Armée (c'est-à-dire le Ministère).

L'un des plus remarquables officiers qu'il m'ait été ${ }_{\text {p.117 }}$ donné de rencontrer - le lieutenant-colonel, dont je rappelais plus haut la sollicitude envers nos secrétaires - m'a dit un jour : «Dans un état-major, il ne devrait pas exister de bureaux ». Par quoi il entendait que ce sectionnement, peut-être inévitable, est gros de dangers. Car chaque partie du tout risque, par un penchant presque fatal, de se prendre elle-même pour un tout et la petite société close se croit une patrie. Le $3^{\mathrm{e}}$ bureau, qui est l'asile des stratège $\mathrm{s}$ et que les mauvaises langues, chez nous, avaient surnommé le «trust des cerveaux », fait, ordinairement, figure de saint des saints. Fiers de leur rôle qui est, en effet, entre tous important et délicat, les officiers dont il se compose ne s'astreignent pas toujours à collaborer assez étroitement avec leurs camarades 
plus éloignés de la pure source de l'art militaire. Ils semblent, quelquefois, mépriser un peu trop des activités sans lesquelles cependant les plus belles flèches tracées sur la carte des opérations resteraient de vains signes. Il en va de même, pour d'autres raisons, du deuxième bureau, hanté par le culte du secret. Quelques grinchus exceptés, l'urbanité des formes reste entière. Elle protège efficacement le quant-à-soi. Ces cloisons étanches sont de partout. Mais nulle part, mes expériences ne me les ont montrées plus redoutables qu'au sommet même du commandement, je veux dire, au G.Q.G.

Là, j'ai perdu, un jour de janvier, une après-midi entière à essayer d'obtenir des deuxième et quatrième bureaux une action commune, sans $\mathrm{y}$ réussir. La question, on le devine, avait trait à l'essence. On va pouvoir juger qu'elle n'était pas sans gravité. Mais comme elle mettait en jeu des tiers, qu'aujourd'hui encore je n'ai pas le droit de compromettre, for ce m'est d'user de quelques circonlocutions.

Il y avait, quelque part, dans un petit pays neutre, à peu près à égale distance de la frontière française et de la frontière allemande, un certain dépôt de ${ }_{\text {p.118 }}$ carburants. Mon informateur ordinaire ne s'était pas contenté de me renseigner sur la capacité des bacs, qui était assez considérable. Il m'avait fait dire : «Je puis, selon vos préférences, les maintenir toujours à plein, de façon à faciliter votre ravitaillement, si vos forces se trouvaient amenées à pénétrer un jour sur ce territoire, ou, au contraire, n'y laisser jamais que les quantités strictement nécessaires aux besoins du commerce, afin de ne pas risquer d'abandonner aux Allemands des ressources précieuses. Que l'État -Major français décide. Dès que je les connaîtrai, ses instructions, quelles qu'elles soient, seront exécutées. » Le problème revenait, en somme, à savoir qui notre commandement estimait devoir atteindre d'abord ce point, en cas de violation, par l'Allemagne, de la neutralité : les ennemis, ou nous. Il ne dépassait pas seulement, de beaucoup, ma compétence personnelle. L'armée qui bordait ce secteur de la frontière n'était pas la mienne. Bien plus : elle n'appartenait même pas à notre Groupe d'Armées. Point d'autre issue, par conséque nt, que d'aller demander ses ordres au G.Q.G.

Je vis d'abord le $2^{\mathrm{e}}$ bureau, auquel j'avais d'autres informations à communiquer. Quand j'arrivai au sujet brûlant, ces messieurs me dirent, non sans raison: «Nous sommes là pour renseigner, non pour décider. Allez trouver le $4^{\mathrm{e}}$.» Ils ne m'offrirent cependant pas de m'accompagner et sans doute savaient-ils bien pourquoi. Peut-être, d'ailleurs, eût-il été plus naturel de m'adresser directement à l'aide major général chargé des opérations ou à ses représentants. Mais le non-initié frappe-t-il de sa propre main à la porte du sanctuaire? Me voici donc en route, par la longue rue de la Ferté-sousJouarre, peuplée de gendarmes, vers le $4^{\mathrm{e}}$ bureau, dont les aîtres, cela va de soi, m'étaient déjà familiers. On m’y prom ena de chambre en chambre. Partout le refrain fut le même : «L'ennemi, connaissons pas. Nous mettons des ravitaillements, français, à votre ${ }_{\text {p.119 }}$ disposition. Un point, c'est tout. $\mathrm{Au}$ 
reste, votre informateur, est-ce un homme bien sûr? S’il nous tendait un piège?

- Le $2^{\mathrm{e}}$ bureau se porte garant de la valeur des renseignements.

— Oh! le $2^{\mathrm{e}}$ bureau ! Et puis, se mêle-t-il donc d'essence ? S'il a commencé à s'occuper de votre affaire, qu'il continue.

- Je veux bien ; mais, si tel est votre sentiment, j'aime rais que vous le lui téléphoniez.

J'obtins, du moins, cette satisfaction. D'un bout à l'autre du fil, la conversation me parut un peu aigre. Chacun se renvoyait la balle. Après quelques minutes, le $2^{\mathrm{e}}$ bureau termina par un assez sec : «Cela ne me regarde pas. » Ainsi, des propriétaires se querellent à propos d'un mur mitoyen. Il n'y avait qu'un intérêt auquel personne ne semblait songer : celui de l'Armée française. Étant, par tempérament, têtu, je repris la conversation avec le $4^{\mathrm{e}}$. D'échelon en échelon, on finit par me conduire à deux lieutenants-colonels. Je m'exprimais avec beaucoup de chaleur. Trop probablement, eu égard à la modestie de mon grade. Je m'aperçus, à temps, que je commençais à dépasser les bornes du respect hiérarchique et, comme un scandale n'eût évidemment abouti qu'à ruiner, sans appel, le succès de mon entreprise, je m'arrêtai net. Aussi bien, le découragement, malgré tout, me gagnait. Je ne remportai, pour tout butin, que quelques vagues promesses: on soumettrait la question, vraisemblablement, à l'aide -major général des services ; celui-ci, peut-être, jugerait utile d'en saisir son collègue des Opérations... Il faut bien, pour se débarrasser d'un fâcheux ou d'un fou, se donner l'air de céder un peu à son humeur. En fait, je n'entendis plus jamais parler de rien.

Cependant, je supportais difficilement liidée de laisser sans réponse le «sympathisant» qui, de l'autre côté de la frontière, avec un total p.120 désintéressement et non sans quelques dangers pour sa personne, nous avait offert son aide. L'intérêt pratique de ces propositions, si évident fût-il, n'était pas seul en jeu. Notre silence eût dénoncé à un étranger les incertitudes du commandement français. C'était déjà trop que de les connaître nous-mêmes. D'accord avec l'ami franç ais, qui m'avait servi d'intermédiaire et, lui, ne portait pas l'uniforme, je fis donc dire là-bas: «Ne remplissez pas vos cuves.» L'abus de pouvoir était affreux. Les événements devaient m'empêcher d'en avoir beaucoup de remords : comme nous l'avions prévu, les Allemands, quand l'orage éclata, arrivèrent bons premiers.

Ce furent également mes enquêtes sur les ressources en essence qui m'enseignèrent comment, en marge de la guerre que nous poursuivions ou préparions contre les Allemands, un autre grand combat se livrait dans nos murs mêmes. Il mettait aux prises le G.Q.G. avec l'E.M.A., La Ferté-sousJouarre avec Paris et la tradition en remontait, sans doute, aux jours lointains de Chantilly, de Joffre et de Gallieni. Un premier sondage n'avait donné sur les dépôts belges que des renseignements encore incomplets. Notre 
informateur ne demandait qu'à fournir davantage. Mais par quel canal lui faire connaître nos besoins ? Impossible de songer à l'appeler à Paris. Il ne tenait, d'autre part, à entrer en cont act ni avec l'attaché militaire, dont la visite eût risqué de le compromettre ni avec les agents du Service Secret, plus habitués à manier des indicateurs mercenaires qu'à s'entretenir avec de très honorables négociants et, d'ailleurs, assez peu compétents pour parler d'essence. Il me parut que le plus simple était de demander à notre intermédiaire français de se rendre lui-même à Bruxelles, sous le prétexte, tout naturel, d'un déplacement d'affaires. Tel fut aussi l'avis du $2{ }^{\text {e }}$ bureau du Groupe d'Armées, qui suivait de près la question. Restait à procurer à ce missionnaire bénévole les visas nécessaires et à les lui ${ }_{\text {p.121 }}$ obtenir sans qu’à la perte du temps du voyage, acceptée avec beaucoup d'abnégation, s'ajoutât celle de longues stations dans les antichambres de la police ou des ambassades. La chose ne semblait guère devoir souffrir de difficultés; je n'avais pas seulement les meilleures raisons du monde de pouvoir répondre d'un de mes proches ; lui-même était bien connu et estimé à Paris dans le monde du commerce et son activité professionnelle le mettait en rapports constants avec la Défense nationale; le Groupe d'Armées enfin et, de plus haut, le G.Q.G. se portaient caution. Cependant, il fallait passer par le $2^{\mathrm{e}}$ bureau du Ministère. Malgré la recommandation expresse du Groupe d'Armées, parlant au nom du G.Q.G., comme au sien propre, ou peut-être à cause de cela même, nos gens ne voulurent rien entendre. "Nous ne connaissons pas ce monsieur; nous ignorons ce qu'il compte faire. » (Inutile de dire qu'on les avait parfaitement mis au courant.) « Nous nous refusons à prendre aucune responsabilité. Qu'il se débrouille. » Il se débrouilla, en effet, au prix d'ennuyeuses démarches que, par bonheur, ses relations personnelles abrégèrent un peu. Et je me rendis compte, mieux qu'auparavant, qu'il n'y avait pas, au vrai, une Armée française, mais, dans l'Armée, plusieurs chasses gardées.

Je devais le voir, plus clairement encore et dans des circonstances beaucoup plus tragiques, quand il s'agit de reconstituer, en Normandie, avec les rescapés des Flandres, un semblant de forces armées. Nous n'avons pas seulement, à ce moment-là, passé incessamment, de général en général, qui parfois changeaient dans le cours de la même journée et dont chacun, aussitôt pris son commandement, s'empressait de défaire ce que son prédécesseur avait commencé. Par-dessus nos têtes et à nos dépens, ou plutôt aux dépens du pays, se poursuivait l'âpre querelle du G.Q.G. et du Ministère. Nous dépendions, en principe, du second, du moins au début; car la p.122 Normandie, censée province fort éloignée du front (qui pourtant, dès lors, était sur la Somme), n'appartenait pas à la zone des armées. Mais, c'était le G.Q.G. qui devait nous utiliser. Sans que j'aie besoin d'y insister, on devine bien que ce duel n'aida pas à hâter notre regroupement ni notre réarmement. L'ennemi était, littéralement, aux portes de la cité et déjà plus qu'à ses portes. Les partis n'avaient pas, pour autant, fait taire leurs discordes. Non point partis 
politiques, en l'es pèce. Partis militaires et, par là même, plus coupables encore.

Le courage personnel est, chez qui choisit la carrière des armes, la plus obligatoire de toutes les vertus professionnelles : si indispensable, en vérité, à la bonne conscience du groupe, quill y est de règle de la tenir pour allant de soi. Je suis certain que la grande majorité des officiers de l'active a été fidèle à cette brave tradition. S’il y eut, çà et là, des exceptions — j'en ai connu une ou deux durant la dernière guerre ; j'ai cru en retrouver quelques -unes durant celle-ci - elles n'atteignent en rien l'honneur de la collectivité. Elles prouvent simplement que l'habit ne réussit pas toujours à faire le moine, et aussi qu'il est partout des êtres assez dé pourvus d'imagination pour adopter un métier sans se représenter à quoi il engage : celui de soldat, par exemple, sans réaliser qu'un jour, peut -être, la vie de garnison devra céder le pas à la guerre. Ces faibles sont, au fond, avant tout, de pauvres gens qui se sont trompés. Reste qu'il est, dans le mépris du danger, bien des nuances et des degrés. Mais comment en parler un peu longuement, sans blesser, dans nos mémoires, de secrètes pudeurs ? Quiconque a vu le feu le sait bien : aux âmes les mieux trempées il arrive parfois de ne dompter qu'à grand-peine la peur : tandis qu'à p.123 d'autres moments, chez le même homme, l'indifférence semble s'établir sans le moindre effort, comme un produit spontané de l'action nécessaire, de l'habitude ou, simplement, du bon équilibre cérébral.

Aussi bien, le courage n'est-il pas affaire de carrière ou de caste. L'expérience de deux guerres - de la première surtout - minncline à penser qu'il n'est guère, chez les hommes un peu sains, de disposition de l'âme plus couramment répandue. Du moins, dans notre peuple, où la plupart des cerveaux sont solides et les corps bien membrés. A tort, beaucoup d'officiers simaginent que les plus braves soldats se recrutent parmi les violents, les aventureux ou les apaches. J'ai toujours o bservé, au contraire, que ces brutaux résistent mal à tout danger un peu soutenu. Faire preuve de courage, c'est, pour le soldat, proprement faire son métier. Un honnête garçon a-t-il, dans la vie courante, coutume de remplir exactement sa tâche quotidienne : à l'établi, aux champs, derrière un comptoir et, oserai-je l'ajouter, à la table de travail de l'intellectuel ? Il continuera, tout naturellement, sous la bombe ou la mitraille, à s'acquitter, avec la même simplicité, du devoir du moment. Surtout, si, au besoin inné de la besogne consciencieusement accomplie, s'ajoute l'instinct collectif. Celui-ci revêt bien des nuances diverses, depuis l'élan, à demi irraisonné, qui porte l'homme à ne pas abandonner son camarade jusqu'au sacrifice consenti à la communauté nationale. Mais c'est presque insensiblement que les formes les plus élémentaires conduisent aux plus hautes. Je n'ai pas connu, en 1914-1918, de meilleurs guerriers que les 
mineurs du Nord ou du Pas-de-Calais. A une exception près. Elle m'étonna longtemps, jusqu'au jour où j'appris, par hasard, que ce trembleur était un «jaune »: entendez un ouvrier non syndiqué, employé comme briseur de grèves. Aucun parti pris politique n'est ici en cause. Simplement, là où manquait, en temps de paix, le sentiment de la solidarité de classe, ${ }_{\text {p.124 }}$ toute capacité de s'élever au-dessus de l'intérêt égoïste immédiat fit de même défaut sur le champ de bataille. L'infanterie de Verdun et de la Somme était une armée de réservistes, dans ses rangs et, pour une large part, dans ses cadres. Réservistes aussi, en des jours moins éloignés de moi, mes sûrs amis du parc d'essence et des camions -réservoirs qui, sans souci d'inquiétantes flammes, mirent tant de fois le feu aux bacs dont le contenu ne devait pas être laissé à l'enn emi ; qui ravitaillèrent les chars à si peu de distance d'une ligne de feu très mobile qu'à plusieurs reprises il leur fallut ramener leurs citernes sans prendre le temps d'en relever, flottant derrière les voitures comme une longue traîne, les tuyaux d'al imentation. Censés «service de l'arrière », ils n'avaient, pour la plupart, pas d'armes ! Il était, modestement, chauffeur de profession le troupier au grand coeur qui, blessé à mort au cours d'un de ces ravitaillements, refusa de permettre qu'on le relev ât. «Je suis foutu. Partez. Je ne veux pas qu'un copain se fasse abîmer à cause de moi. » J'ai vu de près, durant les quatre ans de mon autre campagne - la vraie - plus d'un trait auquel celui-ci fait écho. Je m'arrête. Si je me laissais aller, je ne me tairais pas avant demain.

On a pourtant, cette fois-ci, beaucoup parlé des défaillances de la troupe. Notamment de ses officiers. On a raconté des histoires de fuite, où l'auto du chef aurait, de beaucoup, devancé la panique des piétons. On a cité des cas d'abandon de poste. On a évoqué des « sauve-qui-peut» venus d'en haut. Je n'y étais point. Mais il n'est pas nécessaire d'avoir assisté en personne aux événements pour faire la part, assurément grande, de la légende : tout peuple vaincu cherche son Ganelon, ou, au pis-aller, rejette sa défaite sur quelques maîtres lièvres. Admettons cependant, comme je le crains, que, dans ces bruits, tout ne soit pas faux; que, dans l'armée combattante, il y ait eu

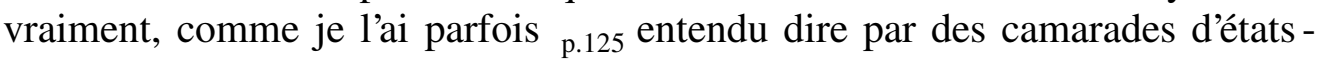
majors, «crise des cadres » ${ }^{1}$. Là encore, la responsabilité du haut commandement a été lourde.

\footnotetext{
${ }^{1}$ Je pense aujourd'hui, d'après beaucoup de témoignages recueillis au cours de ces deux ans, que les défaillances dans le commandement des troupes ont été sensiblement moins rares que je ne voulais le croire, au sortir même de la défaite. Je laisse naturellement mon texte tel quel. Mais pour être scrupuleusement véridique, il faudrait, je le crains, l'accentuer. L'aveu est douloureux et je ne le fais pas sans peine. Sans doute une certaine crise de la moralité de groupes de classes (chez les officiers de réserve comme dans l'active) était-elle plus profonde qu'on n'osait l'imaginer. Qu'elle n'eût pas tout contaminé, chacun le sait aussi. A côté de ces faiblesses, dans les mêmes milieux, que de beaux actes de courage. Ce sont ces contrastes qui rendent l'histoire si difficile à nuancer. Aussi bien, la crise de la moralité collective, dans certaines couches de la nation, et les réactions de ces mêmes éléments, contre la crise, nous ne
} 
Les cadres subalternes ou moyens de la troupe étaient faits, pour une fraction considérable, de vieux officiers de garnisons. Or, quoi qu'on en pense dans certains milieux, l'illusion est grave d'imaginer que la routine des revues de détail, des exercices sur le champ de manoeuvre et des menues histoires de discipline intérieure prépare efficacement au commandement direct des hommes, dans une vie d'aventures guerrières, brusquement privée de l'étai du règlement. Au développement des qualités qu'exigent des circonstances si nouvelles, beaucoup de professions civiles sont une bien meilleure école : pour peu, du moins, qu'elles comportent certains éléments de responsabilité humaine comme d'adaptation aux changeantes conditions de l'action. Ajoutez l'atmosphère débilitante d'une carrière de petits fonctionnaires, médiocrement occupés, car tel est bien, prestige à part, le train d'existence habituel de beaucoup de capitaines ou de chefs de bataillon, dans le temps de ${ }_{\text {p.126 }}$ paix. Les âmes vraiment ardentes ou soutenues seulement par un vigoureux sentiment du devoir échappent à ces poisons. Toutes ne s'élèvent pas aussi haut. La période d'attente, jusqu'au 10 mai, aurait pu permettre d'opérer l'épuration nécessaire et, par suite, le rajeunissement, qui n'était pas moins indispensable ; contre l'ankylose du caractère, il n'est pas de protection plus sûre qu'un cerveau encore souple, dans un corps encore i rrigué par un sang généreux. Le capitaine Coignet ni ses émules des guerres napoléoniennes n'étaient assurément des génies, mais ils atteignaient à peine l'âge mûr. L'armée allemande, à son tour, même quand on n'a fait que l'entrevoir en passant, donne, par rapport à la nôtre, une incontestable impression de jeunesse. L'élagage, nous le savons déjà, n'eut pas lieu. Pas plus, d'ailleurs, qu'on ne se préoccupa suffisamment de pousser vers les postes de sous lieutenants et de lieutenants, au prix, peut-être, d'un certain supplément de formation, ces sous-officiers de réserve, dont on ne pouvait pourtant point ignorer, après l'expérience de 1914, combien il y avait, dans leurs rangs, de ressources d'autorité, de compétence et de dévouement. J'en connais que leur s colonels empêchèrent de se rendre aux cours d'aspirants parce quils estimaient avoir trop besoin d'eux, ou, hélas ! parce que le «piston » n'était pas suffisant. Comptait-on sur le tri, par le feu ? C'était oublier que la guerre pouvait ne pas durer quatre ans, ni même, en fait, aussi longtemps que des premiers combats d'août 1914 à la course à la mer.

J'ai déjà suffisamment insisté sur les effets de la surprise. Le mot ne doit pas être entendu que dans son sens purement stratégique. Les pires paralysies du caractère eurent leur origine dans l'état de stupéfaction et de scandale où un rythme de guerre inopiné jeta des hommes préparés, par leurs éducateurs, à une tout autre image du combat. Ce choc psychologique n'épargna pas les officiers de troupes. Mais, p.227 nulle part les ravages n'en furent plus visibles que dans certains services de demi-arrière: étapes, places, états-majors territoriaux. Là, comme partout, quelques âmes vigoureuses se raidirent contre 
l'épreuve : je sais tel commandant d'étapes, mutilé de l'autre guerre, qui s'offrit comme volontaire pour chercher à dégager un détachement de chars. Ailleurs, malheureusement le repli, sans doute inévitable, prit trop souvent des allures de fuite et, parfois, devança l'événement. Le G.Q.G. dut renv oyer à son poste le général commandant une région militaire; ce chef avait abandonné sa ville, sans ordre, pour la belle raison qu'à son avis l'ennemi n'en était plus assez loin. De pareilles faiblesses, dont ce n'est pas le seul exemple, méritent assurément le blâme. Sans doute appellent-elles aussi quelque pitié. Dans une autre ambiance, les mêmes personnages se seraient peut-être très honorablement montrés. Là où le sort les avait placés, leur besogne quotidienne prolongeait celle du temps de paix et l'atmosphère mentale avait une odeur poussiéreuse de bureau ou de chefferie. Il était convenu, surtout, qu'on n'était pas sur le front. L'ennemi rompit le contrat. Que n'avait -on mieux expliqué, par avance, à ces honnêtes serviteurs, un peu trop vieillis, pour la plupart, sous le harnois, comment, dans une guerre de vivacité, l'arrière risque toujours de devenir l'avant ?

Le terrible fut que ce désarroi gagna des milieux beaucoup plus chargés de responsabilités. Nous sommes plusieurs à avoir pu en noter, avec horreur, les affreux progrès, presque au jour le jour, chez quelques-uns des officiers qui occupaient les charges les plus considérables de l'état-major; chez ceux, notamment, à qui revenait, en propre, le gouvernement des opérations. Les premiers symptômes du mal étaient des signes encore tout extérieurs : yeux p.128 hagards, barbes mal rasées, nervosité qui, d'une agitation fébrile, pour de petites choses, passait brusquement aux feintes d'une impossible sérénité. Quand un chef commence à dire : «A quoi bon ? », gare aux exécutants ! Puis ce fut la marée montante d'un désespoir qui, au lieu d'aiguillonner à l'action, semblait chercher son refuge dans une sorte de paresse somnolente. Je n'ai guère connu de spectacle plus démoralisant que certains affalements dans les fauteuils du troisième bureau. Bien entendu, on se raccrochait, par moment, aux plus invraisemblables illusions, surtout quand linitiative du salut paraissait devoir venir d'autres que nous. Toute une journée durant, à Attiches, on s'enivra ainsi de l'image d'une secourable armée qui, disait -on, avançait, «à marches forcées », sur Arras et Bapaume. On n'en retombait ensuite que plus bas dans l'atonie de la volonté. L'exemple de celle -ci venait de très haut. «Faites ce que vous voudrez, mon général. Mais, au moins, faites quelque chose. » Ainsi, un de mes camarades entendit un jour, à Lens, un des commandants de corps d'armée interpeller, en ces termes, le général Blanchard.

Je devais, pour ma part, entendre pire. Je fus indiscret, sans doute. Mais bien malgré moi. Tout le mal vint de mes habitudes nocturnes. Je n'ai jamais, 
durant la campagne entière, voulu coucher à la cave. Non, certes, par gloriole. Mon refus se fondait, beaucoup plus simplement, sur une application raisonnée, et, je crois, raisonnable, du calcul des probabilités. J'ai le malheur d'être fort rhumatisant. Les chances pour qu'une nuit à l'humidité me laissât tout perclus montaient, selon mon estimation, à quelque chose comme $90 \%$. Que pesait, en regard, l'ordre de vraisemblance, presque infime, d'une bombe frappant juste le P.C. ? Cependant, il ne m'était pas toujours aisé de trouver un gîte à ma convenance. En guise de lits, nous usions, depuis Lens, de brancards. Au château d'Attiches, j'avais d'abord fait installer le p.129 mien dans notre bureau même, au rez-de-chaussée. Le choix, à l'expérience, se montra malheureux. Bien que je ne fusse pas de service, il arriva, deux nuits de suite, que des généraux, entrant dans la pièce et m’y trouvant à leur portée, me tirèrent de mon sommeil pour me demander un renseignement ou m’inviter à leur servir de guide dans les dédales de notre logis. Il m'eût été vraiment difficile de leur répondre, sans me lever: "Secouez donc le camarade, d'à côté, ce n'est pas aujourd'hui mon tour de garde. »

Pour la troisième nuit, qui était celle du 25 au 26 mai, je résolus de chercher mieux. Il y avait au premier étage toute une suite de chambres réservées à de plus haut placés que moi. Entre elles, par contre, courait un long corridor, qui pouvait être considéré comme bien vacant. Je priai qu'on y montât ma couche, et ma tâche finie en bas, comme de coutume assez tard, j'allai prendre quelques heures de repos.

Je fus réveillé, au petit matin, par le bruit d'une porte qui se refermait, puis d'une conversation. Quelqu'un venait de pénétrer dans la pièce d'à côté et causait avec son occupant, sans qu'aucun des deux interlocuteurs se préoccupât, le moins du monde, d'étouffer les sons. Je n'ai jamais su qui était le visiteur: sans doute quelque personnage de haut grade. Mais sa voix ne m'était pas familière. Je ne reconnus, en revanche, que trop bien celle qui lui répondit. Elle appartenait, incontestablement, au général Blanchard. D'ailleurs, les termes mêmes de l'entretien eussent suffi à chasser toute hésitation. Dans l'innocence de mon âme, soucieux uniquement de choisir, dans le corridor, une place à l'abri des courants d'air, j'étais allé me nicher au seuil même de la chambre que j'aurais dû évi ter comme le feu. Quand je me rendis compte de ce qui se passait, il était déjà trop tard pour manifester ma présence ; pouvais-je consentir à avouer que j'avais surpris une partie des propos échangés? Quelque horreur que j'aie de tous les genres de menso nge, force fut de me résigner à ${ }_{p .130}$ feindre le sommeil. Personne du reste ne me découvrit. Cependant, le dialogue se poursuivait. Je n'en compris pas tout, ne tentant pour cela nul effort. De ce qui arriva jusqu'à mes oreilles, j'ai oublié une bonne part. Mais il est une chose dont je suis sûr, absolument sûr, d'une certitude supérieure à tout démenti : j'entendis le général Blanchard dire, avec plus de sang-froid que je ne l'eusse cru possible : "Je vois très bien une double capitulation. » Et nous n'ét ions que le 26 mai ! Et nous avions encore les moyens, sinon de nous sauver, du moins de nous battre longuement, 
héroïquement, désespérément, comme, en juillet 1918, les îlots de combat encerclés, sur la ligne avancée du front de Champagne, et de retenir ainsi devant nous, en les usant, un grand nombre de divisions allemandes. Ces mots, je les ai portés avec moi, pendant les jours qui suivirent, comme un lourd secret, d'autant plus pesant que je ne voulais le partager avec personne. Ils m'ont donné le friss on. Ils me le donnent encore.

Reconnaissons-le bien, en effet, dans cette expression pour une fois sans détour, le spectre qui a jeté son ombre affreuse sur l'agonie de nos armées de Flandre. Pis encore: sur l'agonie de toutes les armées françaises. «Capitulation »: le mot est de ceux qu'un vrai chef ne prononce jamais, fût ce en confidence ; qu'il ne pense même jamais. Pas plus qu'il n'annonce à ses troupes, comme devait le faire, le 17 juin, un maréchal jusque-là chargé de tant de gloire, son dessein de solliciter «la cessation des hostilités », avant, bien avant, d'être, à quelques conditions que ce fût, assuré de l'obtenir. Quand un camarade, dont la bravoure était, entre toutes, éclatante, eut écouté, comme moi, ce discours tristement fameux, il me dit : «Nous sommes l'un et l'autre, sans doute, assez sûrs de nous-mêmes. Nous le sentons pourtant bien qu'un rude effort nous sera maintenant nécessaire pour ne pas céder à l'instinct qui nous portera à éviter, beaucoup plus que par le passé, ${ }_{\text {p.131 }}$ de nous exposer. Car, est-il idée plus agaçante que de mourir au dernier matin d'une guerre ! De quel coeur le soldat moyen, désormais, va-t-il pouvoir se battre ? » Être un vrai chef, c'est, avant tout peut -être, savoir serrer les dents ; c'est insuffler aux autres cette confiance que nul ne peut donner s’il ne la possède lui -même ; c'est refuser, jusqu'au bout, de désespérer de son propre génie ; c'est accepter, enfin, pour ceux que l'on commande en même temps que pour soi, plutôt que l'inutile honte, le sacri fice fécond. Jadis, des hommes qui n'étaient ni des sots, ni, devant le péril personnel, des lâches, avaient eux aussi trop promptement succombé devant l’infortune. A leur mémoire, l'histoire militaire ne réserve que mépris. «Depuis que j'ai regardé autour de moi, je comprends l'état d'âme de Dupont à Baylen et Bazaine à Metz. »C'est de la bouche d'un jeune officier d'active que, vers la fin de mai, j'ai recueilli ces mots terribles. Mais sans doute était-ce, plutôt, Bazaine qu'il fallait dire ; s’il est vrai, comme l'événement a semblé le prouver, que, dans cet ultime renoncement à tout effort, le découragement eut pour alliés l'esprit de parti et les basses ambitions politiques. En 1940, Bazaine a réussi.

Pour que le chef puisse se roidir contre l'épreuve, il lui faut, avant toute chose, dans un corps non surmené, un cerveau sain. Bazaine n'était pas seulement un politicien. C'était, aussi, un homme usé. Dans le rapide effondrement des ressorts moraux, dans notre commandement, une mauvaise hygiène de travail fut pour beaucoup. Dès les premiers jours de Valenciennes, 
alors que la situation, sérieuse sans doute, n'avait encore rien qui justifiât le moindre affolement, nous avons vu, non sans effroi, plusieurs officiers, que leurs fonctions appelaient aux décisions les plus graves, passer des nuits blanches, manger à la hâte, sans heures fixes, et, dans le ${ }_{\text {p.132 }}$ courant du jour, errant de bureau en bureau ou papillonnant d'affaire en affaire, manquer à se réserver les moments de réflexion posée dont eût pu naître le salut. Probablement, en martyrisant leur guenille, croyaient-ils faire preuve de stoïcisme, de même qu'en courant de droite et de gauche, ils se donnaient l'illusion de l'activité. C'était oublier que la guenille se ve nge toujours et que, sans un emploi du temps bien réglé, il n'est pas d'activité vraiment féconde. On a toujours, dès les périodes les plus calmes, accepté trop aisément, dans les états-majors, une atmosphère de perpétuel dérangement. Il eût fallu, au contraire, s'y dresser, par avance, à l'organisation des heures, qui, dans la bataille, ne saurait assurément être bien rigoureuse, mais n'en doit pas moins demeurer l'idéal. Nous avons souvent entendu vanter, dans les milieux militaires, le légendaire sommeil du père Joffre. Que ne l'a -t-on mieux imité ?

Cependant, les défaillances du caractère eurent, je crois, leur principale origine dans l'intelligence et sa formation.

Par deux fois, dans deux campagnes différentes, à plus de vingt ans d'intervalle, j'ai e ntendu des officiers brevetés dire de l'enseignement quils avaient reçu : «L'École de Guerre nous a trompés. » Ce n'est pourtant point qu'aux deux dates elle ait enseigné les mêmes choses. Rien, certainement, n'était, en 1939, plus étranger a l'esprit de nos chefs que les doctrines de Grandmaison - ce «criminel » s'écriait l'un d'eux — si chères aux stratèges de 1914 ; rien de plus opposé à leur vision de la guerre que le mépris de l'artillerie lourde, l'éloge de l'assaut à la baïonnette lancé contre des positions fortifiées, le dogme de l'offensive à tout prix. Mais, plus importantes que la matière même des leçons, les méthodes n'avaient pas assez changé.

Le capitaine T..., tempérament critique, sil en fut, mais aussi vrai tempérament de chef, avait coutume de vitupérer drôlement contre les «idées générales » p.133 dont ses maîtres de l'École de Guerre s'étaient efforcés de lui inspirer le respect. «Les idées générales, ça n'existe pas. » Je ne prendrai pas cette condamnation à mon compte. Ce qui est vrai - et ce que T..., au fond, voulait dire - c'est qu'une idée, dans le domaine des sciences positives ou des techniques, n'a de valeur que comme image ou raccourci de faits concrets. Faute de quoi, elle se réduit à son étiquette, qui ne recouvre plus qu'un peu de vide. Or, tout professeur le sait bien, et un historien, peut-être, mieux que personne, il n'est pas, pour une pédagogie, de pire danger que d'enseigner des mots au lieu de choses. Piège d'autant plus mortel, en vérité, que les jeunes cerveaux sont, à l'ordinaire, déjà trop enclins à se griser de mots et à les prendre pour des choses. Précisément parce que les brevetés sont les intellectuels de l'armée et tirent, de la conscience de ce rôle, le sentiment de leur supériorité, je les ai toujours trouvés, pour la plupart, étonnamment sensibles aux formules. «Quelle tristesse de combattre sur son propre sol», 
nous disait un jour, en 1916, notre colonel, brillant sujet de l'École de Guerre, alors que nous montions vers les tranchées de départ de la Somme, dont il ne devait pas revenir. Mais, bien vite, il se reprit : "Qu’importe ! La stratégie nous apprend que le seul objet qui compte est de vaincre l'armée ennemie, où qu'elle soit. » Nos moissons ravagées, nos usines prisonnières, notre minerai de fer employé à forger les canons allemands : tout cela ne pesait plus rien, du moment que l'esprit pouvait chercher refuge dans une phrase de manuel. Dans quelques pages, qui demeurent parmi les plus solides d'une oeuvre terriblement mêlée, Taine a expliqué comment le trait le plus caractéristique, sans doute, du génie napoléonien fut le pouvoir de découvrir, invariablement, derrière les signes, les réalités. Je crains que les modernes successeurs de Napoléon n'aient laissé perdre beaucoup de cet art souverain. A Rennes, le 17

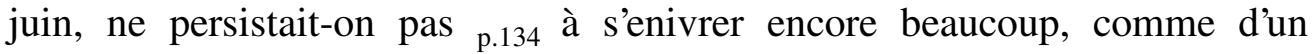
philtre, du beau mot de «position »?

Un enseignement qui n'a été que passivement reçu risque toujours de laisser seulement des traces un peu fugaces. Celui que l'on donne soi-même marque bien davantage l'esprit. Or, il n'était guère, parmi nos chefs ou nos camarades, d'ancien élève qui ne fût, à son tour, peu ou prou, monté en chaire. De tous les sports que pratique l'armée, le sport pédagogique compte, en effet, parmi les plus en vogue et, depuis les théories aux élèves caporaux jusqu'aux leçons savantes du C.H.E.M., elle présente l'image d'une immense ruche scolaire. Appartenant moi-même à la corporation des faiseurs de cours et n'y figurant point, hélas! parmi les plus jeunes, je puis bien le dire : il faut toujours se méfier un peu des vieux pédagogues. Ils se sont constitué forcément, au cours de leur vie professionnelle, tout un arsenal de schémas verbaux auxquels leur intelligence finit par s'accrocher, comme à autant de clous, parfois passablement rouillés. En outre, étant hommes de foi et de doctrine, ils inclinent, le plus souvent sans s'en douter, à favoriser, parmi leurs disciples, les dociles plutôt que les contredisants. Rares, du moins, sont ceux qui conservent jusqu'au bout un cerveau assez souple, et, vis-à-vis de leurs propres partis pris, un sens critique assez délié pour échapper à ces péchés de métier. Combien le danger n'est -il pas encore plus grand quand, les auditeurs étant aussi des subordonnés, la contradiction prend nécessairement allure d’indiscipline ! Les hauts rangs des états-majors étaient peuplés de professeurs déjà mûrs et les troisième bureaux à l'ordinaire, de leurs meilleurs élèves sélectionnés, comme tels. Ce n'étaient peut-être pas, pour l'adaptation au neuf, d'excellentes conditions.

Je n’ignore pas qu'aux élèves de l'École de Guerre on s'efforçait d'enseigner des choses, beaucoup de choses. J'ai eu entre les mains plusieurs de leurs p.135 mémentos, bourrés de chiffres, de calculs horaires, de données sur les portées de tir et les consommations en munitions ou essence. Tout cela, sans conteste, fort utile et généralement fort bien su. Mais il y avait, à côté de cela, le Kriegsspiel, l’indispensable et périlleux Kriegsspiel. Voyez les maîtres et disciples, qui manient les unités sur la carte, à grand renfort de flèches 
multicolores. Quel don d'imagination ne leur faudrait-il pas à l'un comme à l'autre, pour garder sans cesse présentes à l'esprit les réalités sous -jacentes à ces signes : le pénible cheminement des colonnes, les multiples incidents de la route, les bombardements, les inévitables retards, la soupe cuite après l'heure fixée, l'agent de liaison qui s'égare ou le chef qui perd la tête ? Quelle gymnastique d'assouplissement cérébral, surtout, ne serait pas nécessaire pour faire, assez large, la part de l'imprévu, c'est -à-dire, avant tout, de l'ennemi ?

Certes, cet ennemi, vrai trouble-fête de la stratégie, il n'était personne qui n'eût cherché, d'avance, à deviner ce qu'il f erait, afin de préparer, en conséquence, la riposte. Par malheur, dans cette guerre, comme, d'ailleurs, en août 1914 ou au printemps de 1917, avant l'offensive Nivelle, le mal -appris ne fit jamais ce qu'on attendait de lui. Je ne crois pas que la faute en ait été, au propre, de ne pas assez prévoir. Les prévisions n'avaient été établies, au contraire, qu'avec trop de détail. Mais elles s'appliquaient, chaque fois, seulement à un petit nombre d'éventualités. Dieu sait que nous l'avions assez fignolée, notre «manoeuvre Dyle »! Pour ma modeste part, je pourrais encore dire, si je n'avais brûlé mes archives, comment mes ravitaillements devaient être organisés, en Belgique, au jour J. 9. Hélas ! à J. 9, je n'avais plus - et pour cause - de dépôts en Belgique et presque plus de dépôts à l'arrière. Surtout, on s'était habitué, dans les écoles du temps de paix, à accorder une foi excessive au p.136 thème de manoeuvre, aux théories tactiques, au papier, en un mot, et à se persuader, inconsciemment, que tout se passerait comme il était écrit. Quand les Allemands eurent refusé de jouer leur jeu, selon les règles de l'École de Guerre, on se trouva aussi désemparé que le mauvais orateur devant linterpellation à laquelle son rôle ne lui fournit pas de réplique. On crut tout perdu et, par suite, on laissa tout perdre, parce que, pour guider l'action, trop tenue en lisières jusque-là par le dogme ou le verbe, il n'eût plus été de ressources que dans un esprit de réalisme, de décision et d'improvisation, auquel un enseigneme nt trop formaliste n'avait pas dressé les cerveaux.

C'est à l'histoire que la stratégie, telle qu'elle s'étudie ordinairement en tous pays, demande cette substance concrète, dont elle éprouve le besoin, sans parvenir toujours à se la donner. Comment en serait-il autrement ? L'art militaire appartient à ce genre de techniques auxquelles l'expérimentation directe est interdite. Un constructeur d'auto, sỉl conçoit l'idée d'une nouvelle voiture, n'a, pour en apprécier le fonctionnement., quà construire un mod èle. Un maitre ès sciences du combat, par contre, veut-il examiner le comportement vraisemblable de deux armées, d'un type donné, sur le champ de bataille? On le voit mal appeler sous les armes des dizaines de milliers d'hommes, puis, les ayant organisés à sa guise, les forcer à s'entre -tuer. Il y a bien les grandes manoeuvres. Mais, précisément parce qu'on ne s'y tue point, ces «petites guerres », comme on les nommait autrefois, ne fournissent, on le sait, de la vraie guerre, qu'une image étrangement déf ormée, parfois, dans ses prétentions à la ressemblance, jusqu'au grotesque. Force est, dans ces 
conditions, de se rejeter sur les exemples du passé qui nous sont autant d'expériences naturelles.

Des faiblesses de notre préparation stratégique, accuserons-nous donc la part qu'y tenait l'histoire ? ${ }_{\text {p.137 }}$ Certains se le sont demandé : «Faut-il croire que l'histoire nous ait trompés ? »Ce doute, dans les dernières heures de notre séjour en Normandie, déjà assombries par la défaite, je l'ai surpris sur les lèvres d'un jeune officier à peine sorti de l’École. S'il entendait, par là, jeter le soupçon sur l'enseignement soi -disant historique quill avait reçu, d'accord. Mais cet enseignement n'était pas l'histoire. Il se plaçait, en vérité, aux antipodes de la science qu'il croyait représenter.

Car l'histoire est, par essence, science du changement. Elle sait et elle enseigne que deux événements ne se reproduisent jamais tout à fait semblables, parce que jamais les conditions ne coïncident exactement. Sans doute, reconnaît-elle, dans l'évolution humaine, des éléments sinon permanents du moins durables. C'est pour avouer, en même temps, la variété, presque infinie, de leurs combinaisons. Sans doute, admet-elle, d'une civilisation à l'autre, certaines répétitions, sino n trait pour trait, du moins dans les grandes lignes du développement. Elle constate alors que, des deux parts, les conditions majeures ont été semblables. Elle peut s'essayer à pénétrer l'avenir ; elle n'est pas, je crois, incapable d'y parvenir. Mais ses leçons ne sont point que le passé recommence, que ce qui a été hier sera demain. Examinant comment hier a différé d'avant-hier et pourquoi, elle trouve, dans ce rapprochement, le moyen de prévoir en quel sens demain, à son tour, s'opposera à hier. Sur ses feuilles de recherche, les lignes, dont les faits écoulés lui dictent le tracé, ne sont jamais des droites ; elle n'y voit inscrites que des courbes, et ce sont des courbes encore que, par extrapolation, elle s'efforce de prolonger vers l'incertain des te mps. Peu importe que la nature propre de son objet l'empêche de modifier à son gré les éléments du réel, comme le peuvent les disciplines d'expérimentation. Pour déceler les rapports qui, aux variations spontanées des facteurs, lient celles des ${ }_{\text {p.138 }}$ phénomènes, l'observation et l'analyse lui sont des instruments suffisants. Par là, elle atteint les raisons des choses et de leurs mutations. Elle est, en un mot, authentiquement une science d'expérience puisque, par l'étude des réalités, qu'un effort d'intell igence et de comparaison lui permet de décomposer, elle réussit, de mieux en mieux, à découvrir les va-et-vient parallèles de la cause et de l'effet. Le physicien ne dit pas : «L'oxygène est un gaz, car, autour de nous, nous ne l'avons jamais vu que tel. » Il dit : «L'oxygène, dans certaines circonstances de température et de pression, qui sont, autour de nous, les plus fréquentes, se présente à l'état gazeux. » L'historien, pareillement, sait bien que deux guerres qui se suivent, si, dans l'intervalle, la structure sociale, les techniques, la mentalité se sont métamorphosées, ne seront jamais la même guerre.

Or, contre l'enseignement historique, tel qu'il s'est presque invariablement pratiqué dans les écoles militaires, il n'est pas d'acte d'accusation pl us terrible 
que cette simple et irréfutable constatation : aux chefs de 1914, il a persuadé que la guerre de 1914 serait celle de Napoléon ; aux chefs de 1939., que la guerre de 1939 serait celle de 1914. J'ai feuilleté jadis les conférences célèbres de Foch, professées, si mes souvenirs sont exacts, aux environs de 1910. Rarement lecture m'a procuré un pareil effarement. Certes, la bataille napoléonienne y est admirablement démontée. Mais elle est aussi donnée en exemple, sans souci du changement des temps. Non, j’imagine, que, çà et là, il ne soit possible de découvrir quelques remarques, jetées en passant, sur les différences de l'armement ou de l'équipement du terrain. Était -ce suffisant ? Il eût fallu avant toute description donner le holà au lecteur, lui dire : «Attention, les combats qui vont être racontés se déroulaient dans des pays où les routes étaient infiniment plus espacées qu'aujourd'hui, où les transports affectaient $_{\text {p.140 }}$ encore une lenteur quasi médiévale. Ils se sont livrés entre des armées dont la puissance de feu était, par rapport à la nôtre, infime et qui pouvaient tenir la baïonnette pour reine, parce que la mitrailleuse ni le barbelé n'étaient inventés. Si, de leur histoire, tu as, malgré tout, quelques leçons à tirer, ce sera à condition de le rappeler toujours que, partout où ces facteurs nouveaux sont appelés à jouer, l'expérience ancienne, qui ne les comportait point, perd toute valeur. » Avec les ouvrages ou les cours des modernes successeurs de Foch, je n'ai eu, je l'avoue, qu'un contact plus lointain. Le résultat m’assure que l'esprit n'avait pas évolué.

Cependant, le commandement de 1914 devint celui de 1918. Malgré bien des erreurs sanglantes, il sut modifier ses procédés et les adapta. Au début de 1918, le général Gouraud, qui était un pédagogue zélé et ingénieux, présenta un jour à divers officiers, parmi lesquels je me trouvais, deux compagnies d'infanterie : l'une armée à la façon de 1914 et manoeuvrant comme telle ; l'autre, du type nouveau, dans sa composition, son armemen t et l'articulation de sa manoeuvre. Le contraste était saisissant. Mais ce n'était qu'un exemple pris à la base même. La métamorphose avait atteint la conduite de la guerre presque tout entière. Comment se fait-il que nos chefs de 1940 aient été incapables de la même docilité à la leçon des choses ?

Sans doute, convient-il de tenir compte, très largement, d'une formidable différence de durée. Comment une guerre de rapidité laisserait-elle le temps de réparer les erreurs de son début ? Là où les états-majors de 1914-1918 avaient eu quatre années, nous n'eûmes que quelques semaines. Un singulier génie aurait été nécessaire pour opérer le retournement, en pleine bataille, et, sans doute, l'état du matériel ne l'eût qu'incomplètement permis. C'était avant l'événement quîl aurait fallu savoir dégager les p.140 nouvelles données du problème stratégique. Or, s'adapter, par avance, à une réalité simplement prévue et analysée par les seules forces de l'esprit, c'est là probablement, pour la plupart des hommes, un exercice mental singulièrement plus difficile que de modeler leur action, au fur et à mesure, sur des faits directement observés.

Ces remarques pourtant n'expliquent pas tout et l'excuse n'est pas suffisante. Car, en somme, il n'est pas possible que nous ay ons tout ignoré, 
durant la paix, des méthodes de l'armée allemande et de ses doctrines. Car, surtout, nous avions sous les yeux, depuis l'été, l'exemple de la campagne de Pologne, dont les leçons étaient assez claires et que les Allemands, pour l'essentiel, devaient, dans l'Ouest, se borner à recommencer. Ils nous firent le cadeau de huit mois d'attente, qui auraient pu être aussi de réflexion et de réforme. Nous n'en avons pas profité. Pourquoi ? Il faut introduire ici un facteur humain et psychologique dont l'importance fut considérable. Qu'étaient nos chefs de 1940 ? Des généraux de corps d'armée ou d'armée, qui avaient fait la dernière guerre comme chefs de bataillon ou colonels. Leurs principaux adjoints? Des commandants de compagnie de 1918. Tous, à des degrés divers, ils restaient dominés par leurs souvenirs de la campagne de la veille. Qui s'en étonnera ? Ces glorieuses expériences, ils ne les avaient pas seulement cent fois ressassées, par la parole ou l'écrit ; ils n'en avaient pas seulement tiré une matière pédagogique. Elles adhéraient à leur conscience, avec toute la ténacité d'images de jeunesse. Elles avaient l'éclat de choses vues, dont les résonances vibraient au plus intime de la mémoire affective. Tel épisode, où d'autres n'auraient aperçu que le froid exemple d'un cours de stratégie, c'était, pour eux, comme pour nous tous, anciens combattants, les inoubliables évocations du danger personnellement bravé, du ${ }_{\mathrm{p} .141}$ camarade tué à côté de soi, de la rage devant un ordre mal donné, de l'enivrem ent au spectacle de l'ennemi en fuite. Beaucoup d'entre eux avaient dû, en 1915 ou 1917, partir, en tête de leurs unités, à l'assaut de tranchées encore intactes ; fermant les yeux, ils revoyaient les corps de leurs hommes, moissonnés par les mitrailleuses, dans les barbelés. Puis, dans les états-majors, ils avaient aidé à monter les opérations savantes et lentes, dont devaient un jour sortir la victoire : la conquête du plateau de la Malmaison, qui fut comme l'essai d'une tactique encore fraîche; la résistance, en profondeur, de l'armée Gouraud, le 15 juillet 1918. Mal préparés, par l'enseignement qu'ils avaient reçu ou qu'ils donnaient eux-mêmes, à comprendre, d’instinct, l'irrésistible loi du changement, quelle rare malléabilité d'intelligence ne leur au rait-il pas fallu pour se dépêtrer des liens du déjà vu et du déjà fait ? Tout les portait, au contraire, à imaginer que pour gagner la nouvelle guerre, il suffisait d'éviter les fautes qui avaient failli faire perdre la précédente, de répéter les méthodes qui avaient, une première fois, assuré le succès. J'écrivais à un ami, vers le mois de février: "Une chose est sûre : si notre commandement fait des bêtises, ce ne seront pas celles des attaques de Champagne ou de l'offensive Nivelle. » Hélas! le champ des erreurs n'a pas de limites et ce qui fut hier sagesse peut devenir, demain, folie.

Sans doute, l'envoûtement du passé eût-il été moins fort sur des cerveaux moins sclérosés par l'âge. J'ai pu observer, avec une clarté croissante au fur et à mesure du déroulement de la campagne, que les jeunes officiers d'état major, dont la plupart n'avaient pas pris part à la dernière guerre, voyaient ordinairement plus juste que leurs chefs. Les trop bons élèves, à vrai dire, restaient obstinément fidèles aux doctrines apprises. Ils tenaient 
malheureusement ${ }_{\text {p.142 }}$ les postes les plus influents. Beaucoup d'autres, en revanche, après avoir plus ou moins juré sur la parole du maître, commençaient à secouer les entraves intellectuelles d'une formation quils inclinaient à juger sévèrement. Même parmi les officiers plus mûrs, anciens combattants de 1914 ou de 1918, encore loin, cependant, de la vieillesse, beaucoup n'étaient pas incapables de renouvellement. Mais quoi ! Notre commandement était un commandement de vieillards.

Les règles de l'avancement, en temps de paix, qui font des chefs de bataillon de quarante ans, nous ont donné des généraux de soixante. Et, comme il arrive communément, ces personnages chenus, chargés d'honneurs et, pour quelques-uns, d'une ancienne gloire, ayant complètement oublié qu'eux-mêmes, aux jours de leurs exploits passés, avaient été jeunes, ne nourrissaient pas de plus cher souci que de barrer la route à leurs cadets. On n'a pas accordé assez d'attention, dans le public, à la loi qui, peu avant la guerre, dota la hiérarchie militaire de deux nouveaux échelons. Longtemps, il n'y avait pas eu, dans l'armée, de grade supérieur à celui de général de division. Une lettre de service, octroyée au gré du gouvernement ou du G.Q.G., suffisait à fixer les attributions des officiers généraux de ce rang : elle pouvait les habiliter aussi bien au commandement d'une armée, voire de toutes les armées, qu'à celui d'un corps d'armée ou, tout bonnement, d'une division. Est-il cependant, de vrai paradis, sans un grand nombre de marches étagées autour du céleste trône ? Un beau jour, il fut décidé que, jusque-là simples fonctions, les postes de généraux d'armée et de corps d'armée deviendraient des grades. Inoffensive satisfaction d'amour-propre, dira-t-on peut-être, consentie à quelques hommes un peu puérilement assoiffés de distinction. Oh que non! Car là où les grades diffèrent, la discipline veut, irrévocablement, p.143 que le plus élevé entraîne l'exercice du droit au commandement. Impossible, dorénavant, à un jeune divisionnaire de prendre, par exemple, une armée, s'il n'a été, d'abord, pour le moins, promu, en forme, général de corps d'armée : puisqu'une fois à la tête de sa nouvelle unité, il aura, par définition, sous ses ordres des subordonnés de ce grade. Or, le passage d'un grade à l'autre est, naturellement, soumis à des règlements ou à des usages qui le rendent beaucoup plus lent et difficile qu'un pur changement d'emploi. Les membres du Conseil supérieur de la Guerre, haussés, tous, de par la réforme qu'ils avaient sans doute inspirée, à la nouvelle dignité de généraux d'armée, avaient désormais l'espoir de se perpétuer, quoi qu'il arrivât, dans la direction de la nation en armes. En vérité, si ce système avait existé dans la dernière guerre, je doute qu'on eût pu voir jamais un lieutenantcolonel de 1914 - il s'appelait Debeney - conduire la première armée, en 1918, aux victoires de Montdidier et de Saint-Quentin, ni le colonel Pétain le Pétain de notre jeunesse - gravir, brûlant les étapes, assez de glorieux degrés, pour défiler enfin, en un clair matin d'été, sous l'Arc de Triomphe, au premier rang de toutes les troupes françaises. 
Aussi bien, quand on se fut avisé, dès les premiers échecs, que peut-être notre haut commandement n'était pas sans reproches, à quel sang jeune et frais demanda-t-on les moyens de lui rendre quelque force ? A la tête des armées, on plaça le chef d'état-major d'un des généralissimes de l'ancienne guerre ; comme conseiller technique du gouvernement, on fit choix d'un autre de ces généralissimes : le premier d'ailleurs ancien vice-président du Conseil supérieur ; le second qui, vers le même temps, avait été ministre de la Guerre ; tous deux, par suite, à ces titres divers responsables, pour une large part, des méthodes dont les vices éclataient à tous les yeux. p.144 Tant exerçaient encore d'empire sur les âmes, dans les milieux militaires et jusque chez nos gouvernants civils, la superstition de l'âge, le respect d'un prestige, vénérable certes, mais qu'il eût fallu bien plutôt, ne fût-ce que pour le protéger, rouler révérencieusement dans le linceul de pourpre des dieux morts, le faux culte, enfin, d'une expérience, qui, puisant ses prétendues leçons dans le passé, ne pouvait que conduire à mal interpréter le présent. A vrai dire, un très récent général de brigade fut bien appelé aux conseils du gouvernement. Qu'y fit-il ? Je ne sais. Je crains fort, cependant, que, devant tant de constellations, ses deux pauvres petites étoiles n'aient pas pesé bien lourd. Le Comité de Salut Public eût fait de lui un général en chef. Jusqu'au bout, notre guerre aura été une guerre de vieilles gens ou de forts en thèmes, engoncés dans les erreurs d'une histoire comprise à rebours ; une guerre toute pénétrée par l'odeur de moisi qu'exhalent l'École, le bureau d'état-major du temps de paix ou la caserne. Le monde appartient à ceux qui aiment le neuf. C'est pourquoi, l'ayant rencontré devant lui, ce neuf, et incapable d'y parer, notre commandement n'a pas seulement subi la défaite ; pareils à ces boxeurs, alourdis par la graisse, que déconcerte le premier coup imprévu, il l'a acceptée.

Mais, sans doute, nos chefs n'auraient-ils pas, avec autant de coupable complaisance, succombé à ce découragement, dont une sage théologie a fait un des pires péchés, s'ils avaient été seulement mal assurés de leur propre talent. Au fond de leur coeur, ils étaient prêts, d'avance, à désespérer du pays même qu'ils avaient à défendre et du peuple qui leur fournissait leurs soldats. Ici, nous quittons le domaine militaire. C'est plus loin et plus profond qu'il faut chercher les racines d'un malentendu trop grave pour ne pas devoir compter parmi les principales raisons du désastre. 


\section{CHAPITRE III}

\section{EXAMEN DE CONSCIENCE D'UN FRANÇAIS}

p.145 Dans une nation, jamais aucun corps professionnel n'est, à lui seul, totalement responsable de ses propres actes. Pour qu'une pareille autonomie morale soit possible, la solidarité collective a trop de puissance. Les étatsmajors ont travaillé avec les instruments que le pays leur avait fournis. Ils ont vécu dans une ambiance psychologique qu'ils n'avaient pas tout entière créée. Ils étaient eux-mêmes ce que les milieux humains dont ils tiraient leur origine les avaient faits et ce que l'ensemble de la communauté française leur avait permis d'être. C'est pourquoi, ayant dit de son mieux, à la mesure de son expérience, ce quil a cru voir des vices de notre commandement militaire et de leur part, dans la défaite, un honnête homme ne saurait, sans se donner l'impression d'une sorte de trahison, en rester là. L'équité veut que le témoignage du soldat se prolonge en un examen de conscience du Français.

Certes, je n'aborde pas, de gaîté de coeur, cette partie de ma tâche. Français, je vais être contraint, parlant de mon pays, de ne pas en parler qu'en bien ; il est dur de devoir découvrir les faiblesses d'une mère douloureuse. Historien, je sais mieux que quiconque les difficultés d'une analyse qui, pour ne pas demeurer trop imparfaite, devrait remonter jusqu'aux ramifications causales les plus lointaines, les plus complexes et, dans l'état actuel des sciences humaines, les plus cachées. Qu’importent ici, cependant, de petits

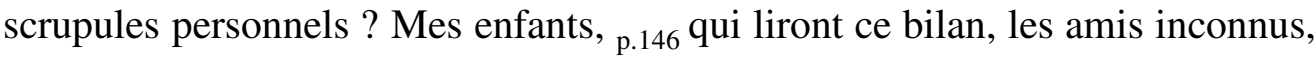
sous les yeux desquels il tombera peut-être un jour, comment accepter qu'ils puissent lui reprocher d'avoir biaisé avec le vrai et, sévère pour certaines erreurs, d'avoir gardé complaisamment le silence sur trop d'autres fautes où tout citoyen eut sa part?

\section{$*$}

Les combattants sont rarement satisfaits de l'arrière. Il faut un coeur singulièrement large, quand on couche à la dure, pour pardonner aux compagnons des jours passés leurs lits bien douillets et, sous la mitraille, pour évoquer, sans amertume, la fructueuse sécurité des boutiques que les chalands n'ont pas désertées ou les paisibles charmes du café de province, dont les terrasses ne connaissent de la guerre que les méditations stratégiques. La bataille s'achève-t-elle en désastre ? C'est alors que la brèche, entre les deux moitiés de la nation, menace d'être la plus durable. Le troupier, conscient de 
ses propres sacrifices, refuse de se tenir pour responsable de leur inutilité. Ses chefs, qui redoutent son jugement, l'encouragent à cherch er les coupables partout ailleurs que dans l'armée. Ainsi naît la fatale légende du coup de poignard dans le dos, propice aux redressements à rebours et aux pronunciamientos. Les pages qui précèdent l'ont assez montré : tous les anciens soldats de 1940 ne sont pas disposés a écouter ces semeurs de discorde. Mais force est de reconnaître que l'arrière aussi a beaucoup péché.

Y avait-il d'ailleurs, pouvait -il y avoir un véritable arrière, au sens où nous nous étions instinctivement habitués à entendre le mot? La France en armes de 1915-1918 était faite de plusieurs bandes de territoires alignées en profondeur. Dans la gradation du danger, chacune se distinguait par une ${ }_{\text {p.147 }}$ teinte différente. La brûlante zone du front venait d'abord : mobile, certes, mais qu'on estimait avoir subi un effroyable recul, si elle s'était déplacée seulement des abords de Saint-Quentin aux faubourgs de Noyon. Soit, une demi-heure d'auto. Un peu plus loin, s'étendait, étiré sur une assez mince largeur, le demi-arrière, celui des cantonnements de repos, encore relativement exposé. Enfin, l'arrière proprement dit déroulait, à l'infini, la tranquillité de ses champs et de ses villes. Sans doute, de temps à autre, une brusque alerte, qu'on jugeait presque scandaleuse, se permettait de troubler, pour un moment, le calme de cet heureux asile : un Junker survolait Paris ; un zeppelin laissait choir des bombes ; la Bertha lançait inopinément ses obus, tantôt dans le bassin d'un jardin public, tantôt, avec un plus cruel succès, contre un pilier d'église. Nous frémissions, dans nos tranchées, en pensant à nos familles. Qu'était-ce, pourtant, auprès de nos souvenirs plus récents ?

Car le bombardement par avions et la guerre de vitesse sont venus jeter le désarroi dans cette belle ordonnance du péril. Il n'est plus de ciel sans menace et la force de pénétration des éléments motorisés a mangé la distance. Des centaines de personnes ont trouvé la mort, en quelques minutes, dans Rennes la bretonne où, hier encore, on se serait volontiers cru aussi à l'abri qu'au coeur de l'Amérique. Les routes du Berry ont subi la mitraille, qui ne fait pas de différence entre le soldat et l'enfant. Ces horreurs, à vrai dire, sont-elles si nouvelles que certains l'ont pensé ? Assurément, dans l'intensité et surtout la rapidité, le bombardier ailé, comme fléau destructeur, n’a pas de précédent. Mais le temps n'est pas si loin où les guerres entassaient, communément, beaucoup plus de victimes parmi les campagnes, pillées et affamées, ou le long des rues des villes prises à sac que dans les rangs mêmes des combattants. Seuls, quelques lecteurs de vieux p.148 grimoires s'en souvenaient. Le proche passé est, pour l'homme moyen, un commode écran ; il lui cache les lointains de l'histoire et leurs tragiques possibilités de renouvellement. Loin de ces époques barbares où le guerrier n'était pas seul à se faire tuer! Parmi les populations de l'arrière, comme dans ses bureaux d'intendance ou de garnison, on voulait croire à la distinction des genres.

On aurait eu pourtant quelques bonnes raisons d'en douter et, probablement, au fond des coeurs, n'y croyait-on pas si fort. Car les 
avertissements n'avaient pas manqué. Nous les avait -on assez fait passer sous les yeux, dans les cinémas, ces atroces images de l'Espagne en décombres ? Nous l'avait -on assez raconté, reportage après reportage, le martyre des villes polonaises ? En un sens, on ne nous que trop avertis. J'en demeure persuadé : à cette sournoise insistance sur la corde du bombardement aérien, la propagande ennemie ne fut pas étrangère. Paris eût peut-être été défendu, la superstition des villes ouvertes n'eût pas tant gêné les opérations, si l'opinion s'était représenté avec moins de vivacité le sort de Madrid, de Nankin ou de Varsovie. On en avait assez dit pour nous faire peur ; pas assez et pas dans les termes qu'il eût fallu pour que le sentiment commun acceptât l'inévitable et, sur les conditions nouvelles ou renouvelées de la guerre, consentît à remodeler la morale du civil.

Je n'ai pas, je crois, l'âme inaccessible à la pitié. Peut-être les spectacles que deux guerres successives m'ont imposés l'ont -ils quelque peu endurcie. Il est un de ces tableaux, cependant, auquel je sens bien que je ne m'habituerai jamais : celui de la terreur sur des visages d'enfants fuyant la chute des bombes, dans un village survolé. Cette vision-là, je prie le ciel de ne jamais me la remettre sous les yeux, dans la réalité, et le moins souvent possible dans mes rêves. Il est atroce que les guerres puissent ne pas épargner l'enfance, non seulement ${ }_{\text {p.149 }}$ parce qu'elle est l'avenir mais surtout parce que sa tendre faiblesse et son irresponsabilité adressent à notre protection un si confiant appel. A Hérode, la légende chrétienne n'aurait sans doute pas été si sévère, si elle n'avait eu à lui reproc her que la mort du précurseur. L’inexpiable crime fut le Massacre des Innocents.

Devant le péril national et les devoirs qu'il prescrit, tous les adultes, par contre, sont égaux et c'est un étrange malentendu que de prétendre reconnaître à aucun d'eux je ne sais quel privilège d'immunité. Qu'est -ce, au vrai, qu'un «civil », au sens que le mot revêt en temps de guerre ? Rien de plus qu'un homme auquel le nombre de ses années, sa santé, parfois sa profession, jugée particulièrement nécessaire à la défense, interdisent de porter utilement les armes. Se voir ainsi empêché de pouvoir servir son pays, de la façon dont tout citoyen doit souhaiter le faire, est un malheur ; on ne comprend point pourquoi il conférerait le droit de se soustraire au danger commun. D’ici peu d'années, je serai hors d'état d'être mobilisé. Mes fils prendront ma place. En conclurai je que ma vie sera devenue plus précieuse que les leurs ? Il vaudrait beaucoup mieux, au contraire, que leur jeunesse fut conservée aux dépens, sill le fal lait, de mon vieil âge. Il y a longtemps qu'Hérodote l'a dit : la grande impiété de la guerre, c'est que les pères alors mettent les fils au tombeau. Nous plaindrions nous d'un retour à la loi de la nature ? Quant à la nation, il n'est pas pour elle de pire tragédie que d'être contrainte à sacri fier les existences sur lesquelles repose son destin. Auprès de ces forces fraîches, les autres n'ont qu'un bien faible poids. Je n'excepterai même pas les femmes. Du moins, en dehors des jeunes mères, dont le salut est indispensable à leurs enfants. Nos compagnes rient des pâmoisons de leurs aïeules. Elles ont bien raison et je ne vois pas que 
le courage leur soit moins naturel qu'à nous ni moins ${ }_{\text {p.150 }}$ obligatoire. Au temps des armées de métier, le soldat professionnel, tantôt seigneur, tantôt mercenaire, versait son sang pour ses mandants. En échange, les populations non combattantes l'entretenaient de leurs redevances ou lui payaient salaire. S’il laissait entamer leur sécurité, elles pouvaient légitimement se plaindre. C'était une rupture de contrat. De nos jours où quiconque en a la force se fait soldat, personne, dans la cité menacée, n'échappe à la levée en masse, à ses gênes ni à ses risques. Là est la seule voie claire. Le reste n'est que sensiblerie — ou lâcheté.

Ces vérités paraissent si simples qu'on éprouve quelque pudeur à les rappeler. Furent-elles, cependant, durant les mois que nous venons de vivre, toujours assez unanimement comprises ? Pour le croire, nous avons vu trop d'administrateurs s'imagine $r$ obéir au devoir de leurs charges en suppliant que leur ville ne fût pas défendue, trop de chefs, civils ou militaires, obtempérer à cette fausse conception de l'intérêt public. A vrai dire, ces âmes timorées n'étaient pas seulement poursuivies par le souci, en soi fort touchant, d'épargner des vies humaines. Les terribles destructions de biens, dont s'était accompagnée la guerre de 1914-1918, avaient laissé de cuisants souvenirs. On savait qu'elles avaient cruellement mutilé le patrimoine artistique du pays ; qu'elles en avaient surtout largement compromis la prospérité. On s'estima sage de tout accepter plutôt que de subir, à nouveau, ce double appauvrissement. Singulière sagesse, qui ne se demandait point s'il peut être, pour une civilisation comme pour une économie, pire catastrophe que de se laisser vaincre par une nation de proie !

Un jour vint où l'on s'avisa de déclarer villes ouvertes toutes celles qui ont plus de 20.000 habitants. Passe encore pour un village de croquants d'être bombardé, ravagé, incendié, pensaient apparemment ces bons apôtres. Une ville de bonne ${ }_{\text {p.151 }}$ bourgeoisie, songez donc ! ... Et ce fut ainsi que, pendant que les cadets de Saumur se faisaient tuer sur la Loire, l'ennemi avait déjà, dans leur dos, franchi les ponts de Nantes, interdits au combat.

Il faut avoir le courage de le dire. Cette faiblesse collective n'a peut -être été, souvent, que la somme de beaucoup de faiblesses individuelles. Des fonctionnaires ont fui, sans ordre. Des ordres de départ ont été prématurément donnés. Il y eut, à travers le pays, une vraie folie de l'exode. Qui de nous n'a rencontré, sur les routes, parmi les files d'évacués, des cohortes de pompiers, juchés sur leurs pompes municipales ? A l'annonce de l'avance ennemie, ils couraient mettre en sûreté leurs personnes, avec leurs biens. Par ordre, je le veux croire. Tout pouvait bien, là-bas, périr dans l'incendie, pourvu que fût conservé, loin des braises, de quoi l'éteindre... Beautés de la bureaucratie, diront certains. Hélas ! le mal était plus profond. Je sais tel centre industriel où l'on vit les principaux chefs d'entreprise, à l'approche des colonnes allemandes, abandonner précipitamment leurs usines, sans même assurer la paye des ouvriers. Mobilisés, ils auraient, j’imagine, accompli leur devoi r jusqu'au bout. Restés « civils », ils avaient oublié et on ne leur avait pas assez 
répété qu’il n'est plus, en temps de guerre, de métier. La nation armée ne connaît que des postes de combat.

Me trompé-je ? Vais-je, à mon tour, céder à la tentation qui porte les hommes déjà vieillissant à rabaisser, devant leurs souvenirs de jeunesse, les générations suivantes ? Il m'a semblé que, même chez les mobilisables, quelque chose s'était perdu de ce puissant élan d'égalité dans le danger, qui avait, en 1914, soulevé la plupart d'entre nous. Sans doute avait-on trop présenté à notre peuple certaines exemptions de service moins comme de fâcheuses et un peu humiliantes nécessités que comme des faveurs, voire des droits. Aux paysans, on avait trop ${ }_{\text {p.152 }}$ dit: «Pourquoi les ouvriers et pas vous ? », aux pères de famille : «Vos enfants vous réclament», aux anciens combattants : «Deux fois, vraiment c'est beaucoup. » Quand le ministère de l'Armement fut réorganisé et développé, la ruée de beaucoup d'officiers de réserve vers ses paisibles bureaux nous écoeure un peu. Ils partaient, en s'écriant : «Quel ennui ! mais on a tant besoin de moi !» Étaient-ils tous, vraiment, à ce point indispensables ? Et n'aurait-il pas été possible, assez souvent, de mettre, à leur place, de plus vieux ? Il m'est arrivé d'entendre parfois des personnes bien intentionnées exprimer le souhait qu'à notre jeunesse intellectuelle, du moins, les fatales hécatombes de la dernière guerre fussent épargnées. A mon sens, ce sentiment sonnait faux. Certes, il est affreux que sur la Marne, l'Yser ou la Somme, tant d'espoirs aient péri. Nos forces spirituelles en ont longuement saigné. Mais, en regard du sort des armes, était-il encore une fois rien qui dût entrer en balance ? Notre liberté intellectuelle, notre culture, notre équilibre moral, quel coup pouvait les atteindre plus sûrement que la défaite ? Aussi bien, devant le sacrifice, on ne saurait concevoir d'exceptions. Nul n'a le droit de croire sa vie plus utile que celle de ses voisins, parce que, chacun, dans sa sphère, petite ou grande, trouvera toujours des raisons, parfaitement légitimes, de se croire nécessaire.

Je ne sais quelle part ce souci d'économiser le sang des jeunes put avoir dans le singulier retard mis à lever et instruire les recrues. Au moment de la débâcle, la classe 1940, dans sa majorité, venait à peine d'être appelée ; elle n'avait encore reçu, pratiquement, aucune instruction. Quant aux adolescents un peu moins âgés et dont beaucoup ne demandaient quà suivre les traces de leurs aînés, dans la plupart des villes, rien n'avait été tenté pour leur préparation militaire. De cette invraisemblable négligence quels furent les responsables ? le ${ }_{\text {p.153 }}$ commandement ou le gouvernement politique ? (Mais si les états-majors avaient insisté, n'auraient -ils pas enlevé la décision ? ) Sur les motifs, je ne suis pas mieux renseigné. Faut-il croire que l'interminable période d'attente, presque sans pertes, avait fait oublier à nos chefs la nécessité de tenir tout prêts les renforts dont, la bataille venue, ils devaient éprouver un si urgent besoin ? Tel n'aurait pas été, en ce cas, un des effets les moins désastreux de cette longue «pourriture de la guerre », comme disaient les Allemands, qui nous en ont consciemment offert le fallacieux bénéfice. «Nous avons trop d'hommes », disait un officier à un de mes collègues, qui, 
renvoyé comme père de famille, demandait à rester sous les drapeaux. Craignait-on de manquer d'armes ? Ou enfin, hanté par le souvenir de cette infortunée classe seize, que, les larmes aux yeux, nous avions vu naguère précipitée, presque au sortir de l'enfance, dans la fournaise de la Somme, a-ton, comme j'en formais l'hypothèse à l'instant, cédé aux conseils d'une pitié un peu molle ? Il est sûr, en tout cas, qu'à nos dirigea nts et, sans doute, à nos classes dirigeantes, quelque chose a manqué de l’implacable héroïsme de la patrie en danger.

A dire vrai, ce mot de classes dirigeantes ne va pas sans équivoque. Dans la France de 1939, la haute bourgeoisie se plaignait volontiers d'avoir perdu tout pouvoir. Elle exagérait beaucoup. Appuyé sur la finance et la presse, le régime des «notables » n'était pas si « fini » que cela. Mais il est certain que les maîtres d'antan avaient cessé de détenir le monopole des leviers de commande. A côté d'eux, sinon les salariés en masse, du moins les chefs des principaux syndicats comptaient parmi les puissances de la République. On l'avait bien ${ }_{\text {p.154 }}$ vu, en 1938, par l'usage qu'un ministre, munichois entre les munichois, sut faire de leur truchement pour répandre dans l'opinion un esprit de panique, favorable à ses propres faiblesses. Or, les défaillances du syndicalisme ouvrier n'ont pas été, dans cette guerre-ci, plus niables que celles des états-majors.

Je vais parler ici de choses que je n'ai pas vues, de mes propres yeux. L'usine de guerre ou d'avant -guerre se trouvait, on le devine, assez loin de mon champ d'horizon. Mais j'ai recueilli, à ce sujet, trop de dépositions concordantes, elles émanent de milieux trop différents, depuis les ingénieurs jusqu'aux ouvriers mêmes, pour m'autoriser à mettre leurs conclusions en doute. On n'a pas assez travaillé, dans les fabrications de guerre ; on n'a pas fait assez d'avions, de moteurs ou de chars. De cela, je pense, les salariés n'ont assurément pas été les seuls ni, sans doute, les principaux responsables. Ils auraient mauvais gré à plaider l'innocence. Oublieux qu’ils tenaient, eux aussi, à leur façon, poste de soldats, ils ont cherché, avant tout, à vendre leur peine au plus haut prix ; donc à fournir le moins d'efforts possible, durant le moins de temps possible, pour le plus d'argent possible. En temps normal, rien de plus naturel. «Matérialisme sordide», s'écriait un jour un homme politique, qu'on n'eût pas imagin é si épris de pure spiritualité. Il nous la baillait belle. L'ouvrier est marchand de force humaine. Les marchands de drap, de sucre ou de canons auraient mauvais gré à se scandaliser, s'il applique, à son tour, la grande loi du commerce, qui est de donner peu, pour beaucoup recevoir. Mais, légitime à d'autres moments, cette attitude, parmi un peuple en danger et face aux sacrifices des combattants, était devenue cruellement hors de saison. Un de mes voisins de campagne, plombier 
mobilisé dans une usine, m'a raconté comment ses camarades lui cachaient ses outils, pour l'empêcher de faire plus ou plus vite que ne le voulait la coutume non $_{\text {p.155 }}$ écrite de l'atelier. Voilà, pris à la vie même, un terrible acte d'accusation.

Sans doute, y aurait-il beaucoup d'injustice à supposer absolument général, dans toute une classe, un pareil mépris des intérêts nationaux. Je consens volontiers qu'il ne fut pas sans exceptions. Qu'il ait été largement répandu suffit cependant pour que ses conséquences aient lourdement pesé dans la balance de la guerre. Il exige une explication.

On a répété, sur tous les tons, que cette guerre avait, beaucoup moins que la précédente, fait appel aux sentiments profonds de la nation. C'est, je crois, une grave erreur. Il n'est pas dans le tempé rament de notre peuple de souhaiter jamais la guerre. Aucun Français, en 1939, n’aspirait à « mourir pour Dantzig ». Mais aucun, non plus, en 1914, à «mourir pour Belgrade »; et la camarilla qui tissait ses trames autour des Karageorge n'était ni mieux c onnue de nos paysans ou de nos ouvriers que, vingt-cinq ans plus tard, le gouvernement corrompu des «colonels » de Pologne ni plus propre, si elle l'eût été, à soulever l'enthousiasme de nos foules. Quant à l'Alsace -Lorraine, s’il est vrai que l'image des provinces martyres surgit brusquement, dès les premiers combats d'août 1914, hors de l'ombre discrète où, quelques jours plus tôt, on la voyait encore enveloppée, ce fut seulement sous l'effet de nécessités déjà consenties. Puisqu'il avait fallu prendre les armes, on n’imagina plus guère qu'il fût possible de les déposer sans avoir, d'abord, délivré les frères perdus. Durant la paix, sur une opinion soucieuse avant tout de la sécurité du foyer, jamais les beaux yeux des Alsaciennes des lithographies n'auraient eu assez d'empire pour lui faire accepter que, dans le seul dessein d'en sécher les larmes, on précipitât, de gaîté de coeur, le pays vers les plus atroces dangers.

La vérité est que, les deux fois, la source de l'élan ${ }_{\text {p.156 }}$ populaire fut la même. «Ils ne cessent de chercher querelle à tout le monde. Ils veulent tout prendre pour eux. Plus on leur cédera, plus ils réclameront. Cela ne peut plus durer. » Ainsi me parlait, dans mon petit village de la Creuse, un de mes voisins, peu avant mon départ pour Strasbourg. Un paysan de 1914 n'eût pas dit autrement. Si, d'ailleurs, une des deux guerres devait, plus que l'autre, s'accorder aux penchants intimes des masses et surtout des masses ouvrières, c'était, sans nul doute, la seconde. En raison, précisément, de ce caractère «idéologique » qu'on lui a tant reproché et qui, pourtant, donnait au sacrifice un surcroît de beauté. Pas plus qu'en 1914, afin de libérer l'Alsace-Lorraine, le Français de l'usine ou des campagnes n'eût admis, en 1939, de verser son sang, spontanément, pour abattre les dictatures. Mais, dans une lutte engagée contre celles-ci et par leur faute, il eut conscience de servir une grande oeuvre humaine ; en douter, serait méconnaître tout ce qui au fond d'un vieux peuple policé, comme le nôtre, se cache de noblesse inexprimée. L'absurdité de notre propagande officielle, son irritant et grossier optimisme, sa timidité et, par- 
dessus tout, l'impuissance de nos gouvernants à définir honnêtement leurs buts de guerre, ont bien pu, pendant de trop longs mois dinaction, obscurcir un peu ces premières et vives clartés. En mai 1940, l'esprit de la mobilisation n'était pas mort. Sur les hommes qui en ont fait leur chant de ralliement, la Marseillaise n'avait pas cessé de souffler, d'une même haleine, le culte de la patrie et l'exécration des tyrans.

Seulement, dans les milieux de salariés, ces instincts, encore très forts et dont un gouvernement moins timoré eût su entretenir la flamme, étaient combattus par d'autres tendances moins anciennes de la consc ience collective. Sur le syndicalisme, les gens de ma génération avaient, au temps de leur jeunesse, fondé les plus vastes espoirs. Nous ${ }_{\text {p.157 }}$ comptions sans le funeste rétrécissement d'horizon devant lequel l'élan des temps héroïques a peu à peu succombé. Fut-ce l'effet d'une politique des salaires qui, presque nécessairement, conduit à grandir, hors de toute mesure, les menus intérêts du moment? de la subtile diplomatie, des ruses électorales, des intrigues de clans où s'embarbouillèrent les dirigeants d es groupes ? des moeurs bureaucratiques contractées par les administrations ouvrières ? Le fait est que la déviation, à peu près universelle en tous pays, semble avoir participé d'une sorte d’inéluctable fatalité.

On sait le mot dont Marx se plaisait à stigmatiser les mouvements sociaux sans envergure : Kleinbürgerlich. A-t-il été rien de plus «petit bourgeois » que l'attitude, durant ces dernières années et pendant la guerre même, de la plupart des grands syndicats, de ceux des fonctionnaires, notamment ? Il m'est arrivé d'assister, quelquefois, aux assemblées de mon métier. Ces intellectuels ne s'entretenaient, presque jamais, je ne dirai pas que de gros sous, mais de petits sous. Ni le rôle de la corporation, dans le pays ni même son avenir matériel ne paraissaient exister pour eux. Les profits du présent bornaient impitoyablement leurs regards. Je crains bien qu'il n'en ait été de même ailleurs. Ce que j'ai aperçu durant la guerre, ce que j'aperçois, pendant l'après -guerre, des postiers et, plus encore, des cheminots ne m'a guère édifié. Braves gens, certes, dans leur immense majorité, nul n'en doute ; héros même a l'occasion, quelques -uns l'ont bien montré. Mais est -il sûr que la masse, que, surtout, ses représentants aient compris grand-chose à l'élargi ssement du devoir si impérieusement prescrit par une époque comme la nôtre ? J'entends : dans l'exercice quotidien du métier qui demeure, après tout, la pierre de touche de la conscience professionnelle. En juin, dans plusieurs villes de l'Ouest, j'ai vu c eci : de ${ }_{\text {p.158 }}$ malheureuses femmes qui, d'étape en étape, cherchaient à regagner leurs foyers, erraient par les rues, en traînant à bout de bras d'inhumains fardeaux. La raison? De peur d’infliger aux employés quelques heures d'un travail supplémentaire ou plus que de coutume intensif, les gares avaient jugé bon de fermer leurs consignes. Ces oeillères, cet engoncement administratif, ces rivalités de personnes, ce manque de souffle enfin, si éloigné du dynamisme d'un Pelloutier, expliquent le mol affaissement des syndicats dans toute l'Europe et jusque chez nous, devant les 
premiers coups des pouvoirs dictatoriaux. Leur conduite, pendant la guerre, n'a pas eu autre origine. Peu importent, çà et là, quelques déclarations sonores, qui visaient la galerie. Les foules syndicalisées n'ont pas su se pénétrer de l'idée que, pour elles, rien ne comptait plus devant la nécessité d'amener, le plus rapidement et complètement possible, avec la victoire de la patrie, la défaite du nazisme et de tout ce que ses imitateurs, sil triomphait, devaient, nécessairement, lui emprunter. On ne leur avait pas appris, comme ç'eût été le devoir de véritables chefs, à voir plus loin, plus haut et plus large que les soucis du pain quotidien, par où peut être compromis le pain même du lendemain. L'heure du châtiment a aujourd'hui sonné. Rarement incompréhension aura été plus durement punie.

Et puis, il y avait aussi l'idéologie internationaliste et pacifiste. Je suis, je m'en flatte, un bon citoyen du monde et le moins chauvin des hommes. Historien, je sais tout ce que contenait de vérité le cri fameux de Karl Marx : «Prolétaires de tous les pays, unissez-vous!» J'ai trop vu la guerre, enfin, pour ignorer qu'elle est une chose à la fois horrible et stupide. Mais l'étroitesse d'âme que je dénonçais tout à l'heure a consisté précisément à refuser d'accorder ces sentiments avec d'autres élans, non moins respectables. Je n'ai jamais cru qu'aimer sa patrie ${ }_{\text {p.159 }}$ empêchât d'aimer ses enfants ; je n'aperçois point davantage que l'international isme de l'esprit ou de la classe soit irréconciliable avec le culte de la patrie. Ou plutôt je sens bien, en interrogeant ma propre conscience, que cette antinomie n'existe pas. C'est un pauvre coeur que celui auquel il est interdit de renfermer plus d'une tendresse. Laissons, cependant, ce domaine de l'affectif. Quiconque a la pudeur de soi même et horreur des grands mots, trop vulgarisés pour traduire comme il le faudrait des réalités spirituelles si intimes, ne s'y tiendra jamais longtemps sans malaise. Aussi bien, ce n'est pas sur un pareil terrain que nos pacifistes nous invitaient, ordinairement, à les suivre.

Ils invoquaient avant tout l'intérêt ; et c'est en se faisant de cet intérêt prétendu une image terriblement étrangère à toute vraie connaissance du monde qu'ils ont lourdement induit en erreur les disciples, un peu moutonniers, qui, en eux, mettaient leur foi.

Ils disaient que le capitalisme français était dur à ses serviteurs et ils n'avaient, certes, pas tort. Mais ils oubliaient que la victoir e des régimes autoritaires ne pouvait manquer d'aboutir à l'asservissement presque total de nos ouvriers. N'apercevaient-ils donc pas, autour d'eux, tout prêts à s'en saisir et presque à la souhaiter, les futurs profiteurs de notre défaite ? Ils enseignaient, non sans raison, que la guerre accumule les ravages inutiles. Mais ils omettaient de distinguer entre la guerre qu'on décide volontairement de faire et celle qui vous est imposée, entre le meurtre et la légitime défense. Leur demandait-on s'ils nous conseillaient de tendre le cou au bourreau ? Ils répondaient : «Personne ne vous attaque. »Car ils aimaient à jouer sur les mots et peut-être, ayant perdu l'habitude de regarder en face leur pensée, se laissaient-ils eux-mêmes prendre dans les filets de leurs propres équivoques. 
Le voleur de grand chemin ne crie pas à sa victime : « ${ }_{\text {. }} 160$ Donne-moi ton sang. » Il consent à lui offrir le choix : «La bourse ou la vie. » De même, au peuple dont il poursuit l'oppression, le peuple agresseur : «Abdique ta liberté ou accepte le massacre. » Ils proclamaient que la guerre est affaire de riches ou de puissants à laquelle le pauvre n'a pas à se mêler. Comme si, dans une vieille collectivité, cimentée par des siècles de civilisation commune, le plus humble n'était pas toujours, bon gré mal gré, solidaire du plus fort. Ils chuchotaient — je les ai entendus - que les hitlériens n'étaient pas, en somme, si méchants qu'on affectait de les peindre : on s'épargnerait sans doute plus de souffrances en leur ouvrant toutes grandes les portes qu'en s'opposant, par la violence, à l’invasion. Que pensent -ils, aujourd'hui, ces bons apôtres dans la zone occupée, tyrannisée, affamée ?

Comme la parole quils prêchaient était un évangile d'apparente commodité, leurs sermons trouvaient un facile écho dans les instincts paresseusement égoïstes qui, à côté de virtualités plus nobles, dorment au fond de tout coeur humain. Ces enthousiastes, dont beaucoup n'étaient pas personnellement sans courage, travaillaient, inconsciemment, à faire des lâches. Tant il est véritable que la vertu, si elle ne s'accompagne pas d'une sévère critique de l'intelligence, risque toujours de se retourner contre ses buts les plus chers. Instituteurs, mes frères, qui, en grand nombre, vous êtes, au bout du compte, si bien battus ; qui, au prix d'une immense bonne volonté, aviez su créer, dans notre pays aux lycées somnolents, aux universités prisonnières des pires routines, le seul enseignement peut-être dont nous puissions être fiers ; un jour viendra bientôt, je l'espère, un jour de gloire et de bonheur, où une France, enfin libérée de l'ennemi et, dans sa vie spirituelle plus libre que jamais, nous rassemblera de nouveau pour les discussions d’idées. Ce jour-là, instruits par une ${ }_{\text {p.161 }}$ expérience chèrement acquise, ne songerez-vous pas à changer quelque chose aux leçons que vous professiez hier?

Le plus singulier était, sans doute, que ces intransigeants amoureux du genre humain ne s'étonnaient pas de se rencontrer, sur les routes de la capitulation, avec les ennemis-nés de leur classe et de leurs idéaux. A dire vrai, l'alliance, si étrange qu'elle pût paraître, remontait parfois, en esprit, plus haut que l'inimitié. Car, parmi les hommes qu'après avoir tant de fois combattus, sur les champs de bataille électoraux, ils acceptaient ainsi pour associés dans l'oeuvre de la paix à tout prix, beaucoup étaient naguère sortis de leurs rangs même pour voler vers des destinées plus fructueuses. Ces transfuges avaient rejeté, comme un incommode déguisement, toute apparence des ardeurs révolutionnaires anciennes. Mais de leur passage dans les sectes dont ils s'étaient fait un utile tremplin, ils gardaient du moins une indélébile empreinte. Ils y avaient perdu le sens des valeurs nationales et ne devaient plus jamais le retrouver. Ce n'est point hasard si la débâcle a amené au pouvoir un ministre qui, jadis, fut à Kienthal ; si les Allemands parviendront, peut-être, à y hausser un agitateur des rues, qui, avant de revêtir, dans les 
années d'avant guerre, une fallacieuse pelure de patriotisme, avait été un des chefs du communisme. Il n'est pas, contre une certaine école politique, de plus terrible condamnation : on peut, quand on s'y est formé, tout oublier de ce qu'on y apprit ; de beau, souvent, et de noble ; tout, sauf une négation : celle de la patrie.

Ainsi, bien que les besoins généraux de la défense nationale se confondissent plus que jamais avec les intérêts propres des salariés, ses exigences les plus évidentes trouvèrent, devant elles, une opinion ouvrière tristement incertaine de sa voie. A ce désarroi, les invraisemblables contradictions du communisme français ajoutèrent encore un nouveau p.162 ferment de trouble. Mais nous touchons ici à un autre ordre de problèmes, qui sont, proprement, ceux de la pensée.

Ce n'est pas seulement sur le terrain militaire que notre défaite a eu ses causes intellectuelles. Pour pouvoir être vainqueurs, n'avions -nous pas, en tant que nation, trop pris lhabitude de nous contenter de connaissances incomplètes et d’idées insuffisamment lucides ? Notre régime de gouvernement se fondait sur la participation des masses. Or, ce peuple auquel on remettait ainsi ses propres destinées et qui n'était pas, je crois, incapable, en lui-même, de choisir les voies droites, qu'avons -nous fait pour lui fournir ce minimum de renseignements nets et sûrs, sans lesquels aucune conduite rationnelle n'est possible ? Rien en vérité. Telle fut, certainement, la grande faiblesse de notre système, prétendument démocratique, tel, le pire crime de nos prétendus démocrates. Passe encore si l'on avait eu à déplorer seulement les mensonges et les omissions, coupables, certes, mais faciles en somme à déceler, qu'inspire l'esprit de parti ouvertement avoué. Le plus grave était que la presse dite de pure information, que beaucoup de feuilles même, parmi celles qui affectaient d'obéir uniquement à des consignes d'ordre politique, servaient, en fait, des intérêts cachés, souvent sordides, et parfois, dans leur source, étrangers à notre pays. Sans doute, le bon sens populaire avait sa revanche. Il la prenait sous la forme d'une méfiance croissante envers toute propagande, par l'écrit ou par la radio. L'erreur serait lourde de croire que l'électeur vote toujours « comme le veut son journal». J'en sais plus d'un, parmi les humbles, qui, recevant chaque jour le quotidien du cru, vote, presque constamment, contre lui et peut-être cette imperméabilité à des conseils sans sincérité nous offre-t-elle, aujourd'hui, dans l'état où nous voyons la France, un de nos meilleurs motifs de consolation, comme d'espoir. On avouera cependant ${ }_{\text {p.163 }}$ que, pour comprendre les enjeux d'une immense lutte mondiale, pour prévoir l'orage et s'armer dûment, à l'avance, contre ses foudres, c'était là une médiocre préparation mentale. Délibérément - lisez Mein Kampf et les conversations avec Rauschning — l'hitlérisme refuse à ses foules tout accès au vrai. Il remplace la persuasion par la suggestion émotive. Pour nous, il nous faut choisir : ou faire, à notre tour, de notre peuple un clavier qui vibre, aveuglément, au magnétisme de quelques chefs (mais lesquels ? ceux de l'heure présente manquent d'ondes) ; ou le former à être le 
collaborateur conscient des représentants qu'il s'est lui -même donnés. Dans le stade actuel de nos civilisations, ce dilemme ne souffre plus de moyen terme... La masse n'obéit plus. Elle suit, parce qu'on l'a mise en transes, ou parce qu'elle sait.

Était-ce donc que nos classes aisées et relativement cultivées, soit par dédain, soit par méfiance, n'avaient pas jugé bon d'éclairer l'homme de 1 a rue ou des champs ? Ce sentiment existait, sans doute. Il était traditionnel. Ce n'est pas de gaîté de coeur que les bourgeoisies européennes ont laissé « les basses classes » apprendre à lire. Un historien pourrait citer là-dessus bien des textes. Mais le mal avait pénétré plus loin dans les chairs. La curiosité manquait à ceux-là mêmes qui auraient été en position de la satisfaire. Comparez ces deux journaux quasi homonymes : The Times et Le Temps. Les intérêts, dont ils suivent, l'un et l'autre, les or dres, sont de nature semblable ; leurs publics des deux côtés, aussi éloignés des masses populaires; leur impartialité, également suspecte. Qui lit le premier, cependant, en saura toujours, sur le monde, tel quil est, infiniment plus que les abonnés du second. Même contraste d'ailleurs entre notre presse la plus orgueilleuse de ce qu'elle nomme sa «tenue» intellectuelle et la Frankfurter Zeitung, par exemple: la p.164 Frankfurter d'avant l'hitlérisme, voire celle encore d'aujourd'hui. Le sage, dit le p roverbe, se contente de peu. Dans le domaine de linformation notre bourgeoisie était vraiment, au sens du sobre Épicure, terriblement sage.

Cent autres symptômes confirment celui-là. Au cours de deux guerres, j’ai fréquenté beaucoup d'officiers, de réserve ou d'active, dont les origines étaient extrêmement diverses. Parmi ceux qui lisaient un peu et déjà étaient rares, je n'en ai presque vu aucun tenir dans ses mains un ouvrage propre à mieux lui faire comprendre, fût-ce par le biais du passé, le temps présent. J'ai été le seul à apporter, au $4^{\mathrm{e}}$ bureau, le livre de Strasser sur Hitler; un seul de mes camarades me l'a emprunté. La misère de nos bibliothèques municipales a été maintes fois dénoncée. Consultez les budgets de nos grandes villes : vous vous apercevrez que c'est indigence qu'il faudrait dire. Au temps où l'Allemagne ne brûlait pas encore les livres, j'eus l'occasion de pénétrer vers le $1^{\text {er }}$ novembre 1918, à Vouziers, dans une «bibliothèque de campagne » abandonnée par les troupes ennemies en retraite. Elle contenait bien autre chose que des romans policiers ou des tracts politiques. Avons-nous jamais rien tenté de pareil ? Aussi bien n'est -ce pas seulement à l'art de connaître les autres que nous nous sommes laissés devenir étrangers. La vieille maxime du « connais-toi toi-même », qu'en avons -nous fait? On m'a raconté que dans une commission internationale, notre délégué se fit moquer, un jour, par celui de la Pologne : de presque toutes les nations, nous étions les seuls à ne pas pouvoir produire une statistique sérieuse des salaires. Nos chefs d'entreprises ont toujours mis leur foi dans le secret, favorable aux menus intérêts privés, plutôt que dans la claire connaissance, qui aide l'action collective. Au siècle de la chimie, ils ont conservé une mentalité d'alchimistes. Voyez p.165 encore 
les groupes qui, naguère, se sont donné chez nous pour mission de combattre le communisme. De toute évidence, seule une enquête honnêtement et intelligemment conduite, à travers le pays, pouvait leur fournir les moyens de connaître les causes d'un succès dont ils s'inquiétaient si fort ; par suite d'en entraver peut-être la marche. Qui dans leurs rangs s'en est jamais avisé ? Peu importe, ici, le dessein politique. Qu'on l'approuve ou le blâme, le symptôme vraiment grave est que la technique intellectuelle de ces puissantes associations d’intérêts se soit montrée à ce point déficiente. Comment s'étonner si les états-majors ont mal organisé leurs services de renseignements? Ils appartenaient à des milieux où s'ét ait progressivement anémié le goût de se renseigner; où, pouvant feuilleter Mein Kampf, on doutait encore des vrais buts du nazisme, où, parant lignorance du beau mot de « réalisme », on semble en douter encore aujourd'hui.

Le pis est que cette paresse de savoir entraîne, presque nécessairement, à une funeste complaisance envers soi-même. J'entends, chaque jour, prêcher par la radio, le « retour à la terre ». A notre peuple mutilé et désemparé, on dit «tu t'es laissé leurrer par les attraits d'une civili sation trop mécanisée ; en acceptant ses lois et ses commodités, tu t'es détourné des valeurs anciennes, qui faisaient ton originalité ; foin de la grande ville, de l'usine, voire de l'école ! Ce qu'il te faut, c'est le village ou le bourg rural d'autrefoi s, avec leurs labeurs aux formes archaïques, et leurs petites sociétés fermées que gouvernaient les notables ; là, tu retremperas ta force et tu redeviendras toimême ». Certes, je n'ignore pas que sous ces beaux sermons se dissimulent en vérité assez mal — des intérêts bien étrangers au bonheur des Français. Tout un parti, qui tient aujourd'hui ou croit tenir les leviers de commande, n'a jamais cessé de regretter l'antique docilité qu'il p.166 suppose innée aux peuples modestement paysans. (On pourrait bien s'y tromper, d'ailleurs. Ce n'est pas d'hier que nos croquants ont, comme disaient les vieux textes, « la nuque dure »). Surtout, l'Allemagne, qui a triomphé par la machine, veut s'en réserver le monopole. C'est sous l'aspect de collectivités purement agricoles contraintes, par suite, d'échanger, à des prix imposés, leurs blés ou leurs laitages contre les produits de sa grande industrie, qu'elle conçoit les nations, dont elle rêve de grouper autour d'elle, comme une valetaille, l'humble compagnonnage. A travers le micro, la voix qui parle notre langue vient de làbas.

Ces bucoliques avis, pourtant, ne sont pas exclusivement choses d'aujourd'hui. Toute une littérature de renoncement, bien avant la guerre, nous les avait rendus déjà familiers. Elle stigmatisait l' « américanisme ». Elle dénonçait les dangers de la machine et du progrès. Elle vantait, par contraste, la paisible douceur de nos campagnes, la gentillesse de notre civilisation de petites villes, l'amabilité en même temps que la force secrète d'u ne société qu'elle invitait à demeurer de plus en plus résolument fidèle aux genres de vie du passé. Propos d'un académisme un peu bêlant, dont eussent souri nos vieux auteurs rustiques, un Noël du Fail ou un Olivier de Serres. Le vrai travail des 
champs a plus de stoïcisme que de douceur et c'est seulement dans les églogues que le village fait figure d'un asile de paix. Tout, pourtant, dans cette apologie de la France rurale, n'était pas faux. Je crois fermement que l'avantage demeure, grand, pour un peuple, encore à l'heure présente, de s'enraciner fortement dans le sol. Par là il assure à son édifice économique, une rare solidité, il se réserve surtout un fond de ressources humaines, proprement irremplaçables. Pour le voir vivre, chaque jour, pour avoir naguère combattu à ses côtés et m'être beaucoup penché sur son histoire, je sais ce ${ }_{\text {p.167 }}$ que vaut l'authentique paysan français, dans sa verte robustesse et sa finesse sans fadeur. Je suis sensible, tout comme un autre, au charme discret de nos vieux bourgs et je n’ignore pas quils furent la matrice où longtemps s'est formée la partie la plus agissante de la collectivité française.

Nous résignerons-nous, cependant, à n'être plus, comme les Italiens nous ont annoncé leur volonté de ne pas le demeurer, qu'un «musée d'antiquailles »? Ne nous le dissimulons pas : le choix même ne nous est plus permis. Pour le croire encore possible, nous savons trop bien le sort que nos ennemis réservent aux musées. Nous voulons vivre, et, pour vivre, vaincre. Or, ayons le courage de nous l'avouer, ce qui vient d'être vaincu en nous, c'est précisément notre chère petite ville. Ses journées au rythme trop lent, la lenteur de ses autobus, ses administrations somnolentes, les pertes de temps que multiplie à chaque pas un mol laisser-aller, l'oisiveté de ses cafés de garnison, ses politicailleries à courtes vues, son artisanat de gagne-petit, ses bibliothèques aux rayons veufs de livres, son goût du déjà vu et sa méfiance envers toute surprise capable de troubler ses douillettes habitudes : voilà ce qui a succombé devant le train d'enfer que menait, contre nous, le fameux «dynamisme » d'une Allemagne aux ruches bourdonnantes. Ne fût-ce qu'afin de préserver, dans notre vieux patrimoine, ce qui peut et doit l'être, il nous faut l'ada pter aux nécessités d'une ère nouvelle. La voiture à âne était peut être un mode de transport bonhomme et charmant. Mais à refuser de lui substituer, là où cela est souhaitable, l'auto, nous finirions par nous voir enlever jusqu'à nos bourricots. Or, pour faire du neuf, il faut d'abord s’instruire. Si nos officiers n'ont pas su pénétrer les méthodes de guerre qu'imposait le monde d'aujourd'hui ce fut, dans une large mesure, parce qu'autour d'eux, notre bourgeoisie, dont ils étaient issus, p.168 fermait trop paresseusement les yeux. Nous serons perdus, si nous nous replions sur nousmêmes; sauvés, seulement, à condition de travailler durement de nos cerveaux, pour mieux savoir et imaginer plus vite.

Pour retrouver aussi cette cohérence de la pensée qu'une ét range maladie semble avoir fait perdre, depuis quelques années à quiconque, chez nous, se piquait, peu ou prou, d'action politique. A vrai dire, que les partis qualifiés de «droite » soient si prompts aujourd'hui à s’incliner devant la défaite, un historien ne saurait en éprouver une bien vive surprise. Telle a été presque tout au long de notre destin leur constante tradition : depuis la Restauration jusqu’à l'Assemblée de Versailles. Les malentendus de l'affaire Dreyfus avaient bien 
pu, un moment, paraître brouiller le jeu, en confondant militarisme avec patriotisme. Il est naturel que les instincts profonds aient repris le dessus; et cela va très bien ainsi. Pourtant, que les mêmes hommes aient pu, tour à tour, manifester la plus absurde germanophobie et nous pousser à entrer, en vassaux, dans le système continental allemand, s'ériger en défenseurs de la diplomatie à la Poincaré et vitupérer contre le «bellicisme » prétendu de leurs adversaires électoraux, ces palinodies supposent, chez ceux des chefs qui étaient sincères, une invraisemblable instabilité mentale; chez leurs fidèles, une insensibilité non moins choquante aux pires antinomies de l'entendement. Certes, je n’ignore pas que l'Allemagne de Hitler éveillait des sympathies auxquelles celle d'Ebe rt ne pouvait pas prétendre. La France, du moins, restait toujours la France. Tient-on, cependant à trouver, coûte que coûte, une excuse à ces acrobaties ? La meilleure serait sans doute que leurs adversaires, à l'autre extrémité de l'échelle des opinions, ne fussent pas moins déraisonnables. Refuser les crédits militaires et, le lendemain, réclamer des « canons pour l'Espagne »; prêcher, d'abord, p.169 l'antipatriotisme ; l'année suivante, prôner la formation d'un « front des Français »; puis, en fin de compte, se dérober soi-même au devoir de servir et inviter les foules à s'y soustraire: dans ses zigzags, sans grâce, reconnaissons la courbe que décrivirent, sous nos yeux émerveillés, les danseurs sur corde raide du communisme. Je le sais bien; de l'au tre côté de la frontière, un homo alpinus brun, de moyenne taille, flanqué pour principal porte-voix d'un petit bossu châtain, a pu fonder son despotisme sur la mythique suprématie des «grands aryens blonds ». Mais les Français avaient eu, jusqu’ici, la réputation de têtes sobres et logiques. Vraiment, pour que s'accomplisse, selon le mot de Renan, après une autre défaite, la réforme intellectuelle et morale de ce peuple, la première chose quill lui faudra rapprendre sera le vieil axiome de la logique classique : A est A, B est B ; A n'est point B.

Sur les causes profondes de pareilles faiblesses, il y aurait, cela va de soi, beaucoup à dire et à chercher. Notre bourgeoisie, qui reste, malgré tout, le cerveau de la nation, avait sans doute davantage le goût des études sérieuses au temps où elle était, en une large mesure, une classe de rentiers. L'homme d'affaires, le médecin, l'homme de loi doivent, aujourd'hui, peiner durement à leurs bureaux. Quand ils en sortent, il semble quils ne gardent plus de force que pour s'amuser. Peut -être une meilleure organisation du temps, sans rien enlever à l'intensité du travail, leur rendrait-elle plus de loisirs. L'amusement cependant prend-il, d'aventure, forme intellectuelle ? Il se raccorde rarement à l'action, même indirectement. Car une vieille tradition nous porte à aimer l'intelligence pour l'intelligence, comme l'art pour l'art, et à les mettre à part de la pratique. Nous avons de grands savants, et nulles techniques ne sont moins scientifiques que les nôtres. Nous lisons, quand nous lisons, pour nous cultiver : ce qui est fort bien. Mais nous ne pensons pas assez ${ }_{\mathrm{p} .170}$ qu'on peut, et doit, quand en agit, s'aider de sa culture. 
Il lui faudra enfin à ce peuple se remettre à l'école de la vraie liberté d'esprit. «Il est bon qu'il y ait des hérétiques »: les milieux militaires n'étaient pas les seuls à avoir perdu de vue cette maxime de sagesse. Passe encore pour l'opinion traditionaliste. Cela était selon sa nature. Mais que dire de ce qu'on appelait les partis «avancés»? J'ai, personnellement, pour l'oeuvre de Karl Marx l'admiration la plus vive. L'homme était, je le crains, insupportable; le philosophe, moins original, sans doute, que certains n'ont prétendu le dépeindre. Comme analyste social, nul n'eut plus de puissance. Si jamais les historiens, adeptes d'une science renouvelée, décident de se donner une galerie d'ancêtres, le buste barbu du vieux prophète rhénan prendra place, au premier rang, dans la chapelle de la corporation. Est-ce assez cependant pour que ses leçons servent éternellement de gabarit à toute doctrine ? D'excellents savants qui, dans leur laboratoire, ne croyaient qu'à l'expérience ont écrit des traités de physiologie ou des chapitres de physique «selon le marxisme ». Quel droit avaient-ils, après cela, de moquer la mathématique «hitlérienne»? Des partis, qui professaient la mutabilité des formes économiques, excommuniaient les mal avisés qui refusaient de jurer selon la parole du maître. Comme si des théories nées de l'observation des sociétés européennes, telles qu'elles se présentaient vers les années 60, et nourries des connaissances sociologiques d'un savant de ce temps, pouvaient continuer à faire loi en 1940.

Condorcet parlait mieux, qui, imprégné du ferme rationalisme du dixhuitième siècle, disait, dans son fameux rapport sur l'instruction publique, « ni la Constitution française, ni même la Déclaration des Droits ne seront présentées à aucune classe de ${ }_{\text {p.171 }}$ citoyens comme des tables descendues du ciel, qu'il faut adorer et croi re ».

Je l'entends bien, sans qu'on ait besoin de me le souffler : les dirigeants des groupes étaient, en leur for intérieur, beaucoup moins fidèles à cette orthodoxie de façade qu'ils ne le laissaient penser. Ne les retrouvons -nous pas là, cependant, dans leur horrible association, les vices intellectuels qui ont tant fait pour notre perte : avec le goût de l'équivoque, un sens insuffisamment aigu du constant écoulement du monde ? Contre les hommes d'extrêmegauche, comme contre les états-majors - car il arrive que, dans une nation, les pires adversaires respirent, sans s'en douter, la même atmosphère mentale - c'était, il faut l'avouer, Hitler qui avait raison. Non pas le Hitler des grandes harangues aux foules. Celui des confidences, qui disait un jour à Rauschning, à propos, précisément, du marxisme : « Nous savons, nous, qu’il n'y a pas d'état définitif, qu'il y a une évolution perpétuelle. L'avenir est le fleuve inépuisable des possibilités infinies d'une création toujours nouvelle. »

A un universitaire, on pardonnera d'attribuer une assez large part de responsabilité à l'enseignement ; et, pédagogue lui-même, d'exposer crûment les défauts de nos méthodes pédagogiques. Oscillant sans trêve entre un humanisme à l'ancienne mode, parvenu à demeurer toujours bien fidèle à sa valeur esthétique, et le goût souvent intempérant des nouveautés, aussi 
incapable de préserver efficacement les valeurs esthétiques et morales de la culture classique que d'en créer de fraîches, notre enseignement secondaire fait beaucoup trop peu pour développer l'énergie intellectuelle. Comme les universités leurs étudiants, il accable les élèves d'examens. Aux sciences d'observation, si propres, pourtant, à développer l'initiative des yeux et de la matière grise, il accorde peu de place. Il s'étend sur la physiologie végétale avec raison; il néglige presque totalement la ${ }_{\text {p.172 }}$ botanique, en quoi il a grandement tort. Alors que les écoles anglaises s'efforcent d'encourager le hobby, la marotte de l'esprit (herbiers, collections de pierres, photographie, que sais-je encore ? ), les nôtres détournent pudiquement les regards de toutes ces «fantaisies » ou les abandonnent au scoutisme, dont le succès dénonce, plus clairement peut-être que tout autre symptôme, les carences de l'éducation «nationale ». J'ai connu plus d'un bon élève qui, sorti du lycée, n'a jamais ouvert un livre sérieux ; plus d'un cancre ou demi -cancre, chez qui se révèle aujourd'hui un goût profond de la culture. Une fois par hasard, l'aventure n'aurait rien de scandaleux. Répétée, elle devient troublante.

Est-ce dépit d'amoureux ? Historien, j’inclinerai à être particulièrement sévère à l'enseignement de l'histoire. Ce n'est pas l'École de Guerre seulement qui arme mal pour l'action. Non certes que, dans nos lycées, on puisse lui reprocher de négliger le monde contemporain. Il lui accorde, au contraire, une place sans cesse plus exclusive. Mais, justement, parce qu'il ne veut plus regarder que le présent, ou le très proche passé, il se rend incapable de les expliquer : tel un océanographe qui, refusant de lever les yeux vers les astres, sous prétexte quils sont trop loin de la mer, ne saurait plus trouver la cause des marées. Le passé a beau ne pas commander le présent tout entier. Sans lui, le présent demeure inintelligible. Pis encore peut-être : se privant, délibérément, d'un champ de vision et de comparaison assez large, notre pédagogie historique ne réussit plus à donner, aux esprits qu'elle prétend former, le sens du différent ni celui du changement. Ainsi notre politique rhénane, après 1918, s'est fondée sur une image périmée de l'Europe. Elle persistait à croire vivant ce mort: le séparatisme allemand. Ainsi, nos diplomates ont obstinément mis leur foi dans les Habsbourg, ces fantômes décolorés pour albums de salons bien pensants; on craint les p.173 Hohenzollern plus que Hitler. Autant de faire-part de décès qu'une histoire véritable n'aurait pas omis d'envoyer. Attachés, en outre, presque sans exceptions, aux manifestations les plus superficielles de la vie des peuples, qui sont aussi, aux époques voisines de nous, les plus aisées à saisir, nos programmes scolaires entretiennent l'obsession du politique. Ils reculent, pudiquement, devant toute analyse sociale. Par là, ils manquent à en suggérer le goût. Qu'on veuille bien ne pas m'accuser de beaucoup trop demander à un B. A. de collège ou d'école primaire ! Je ne crois nullement plus difficile d'intéresser un enfant aux vicissitudes d'une technique, voire aux apparentes étrangetés d'une civilisation ancienne ou lointaine, qu'à un changement de ministère ; et ce n'est certes pas dans un manuel selon mon coeur que j'ai vu 
congrument exposer à des élèves de neuvième comment la monarchie de juillet avait, à la «pairie héréditaire », substitué la «pairie à vie ». N'y avai t-il pas mieux à apprendre à ces marmots : rien de plus humain, de plus capable de frapper utilement leur malléable imagination, de plus instructif pour leur dressage de futur citoyen de la France et de la planète. Ici aussi, nous réclamons, toutes fenêtres désormais ouvertes, un grand balayage de l'atmosphère. Ce sera là tâche des jeunes. Pour réformer la préparation intellectuelle du pays, comme le commandement de ses armées, nous comptons sur eux, beaucoup plutôt que sur les cinq académies, les plus hautes autorités de l'Université ou le Conseil supérieur de la Guerre.

On charge de tous les péchés notre régime politique d'avant guerre. Je ne suis point, pour ma part, tenté d'en dire beaucoup de bien. Que le parlementarisme ait trop souvent favorisé l'intrigue, aux dépens de l'intelligence ou du dévouement. Il me ${ }_{\text {p.174 }}$ suffit, pour en être persuadé, de regarder autour de moi. Les hommes qui nous gouvernent aujourd'hui sont, pour la plupart, issus de ces marécages. Sils renien t maintenant les moeurs qui les ont faits ce quils sont, ce n'est que ruse de vieux renards. Linfidèle employé, qui s'est ouvert un coffre -fort, ne laisse pas traîner ses fausses clefs : il aurait bien trop peur qu'un plus malin que lui ne les ramassât, pour le dépouiller, à son tour, du butin.

Lorsque l'heure aura sonné du vrai redressement, lorsque nous pourrons exiger, de nouveau, d'être dirigés au grand jour et commander aux factions de s'effacer, si elles ont perdu la confiance du pays, nous n'aurons pas, assurément, qu’à remettre, paresseusement, nos pas, dans les empreintes d'avant-hier. Les assemblées, de dimensions monstrueuses, qui prétendaient nous régir, étaient un legs absurde de l'Histoire. Des États -Généraux, réunis pour dire «oui » ou «non», pouvaient bien dénombrer leurs membres par centaines. Une chambre gouvernante se voue au chaos, dès qu'elle accepte d'être une foule ; et c'est d'ailleurs un problème de savoir si une chambre, faite pour sanctionner et contrôler, peut gouverner. Notre machinerie de partis exhalait un parfum moisi de petit café ou d'obscurs bureaux d'affaires. Elle n'avait même pas pour elle l'excuse de la puissance, puisqu'elle s'est effondrée aux premiers souffles de l'arbitraire, comme un château de cartes. Prisonniers de dogmes qu'ils savaient périmés, de programmes qu’ils avaient renoncé à réaliser, les grands partis unissaient, fallacieusement, des hommes qui, sur les grands problèmes du moment - on le vit bien après Munich s'étaient formé les opinions les plus opposées. Ils en séparaient d'autres, qui pensaient exactement de même. Ils ne réussissaient pas, le plus souvent, à décider de qui serait au pouvoir. Ils servaient simplement de tremplin aux habiles, qui se chassaient l'un l'autre du pinacle. 
p.175 Nos ministres et nos assemblées nous ont, incontestablement, mal préparés à la guerre. Le haut commandement, sans doute, les y aidait peu. Mais rien, précisément, ne trahit plus crûment la mollesse d'un gouvernement que sa capitulation devant les techniciens. En 1915, les commissions des Chambres avaient, pour nous doter d'artillerie lourde, plus fait que tous les artilleurs ensemble. Que leurs héritières n'ont-elles agi de même, et plus à temps, pour les avions et les chars ! L'histoire du ministère de l'Armement semble une leçon de déraison; il est inouï que, pour l'improviser, il ait fallu attendre les premiers mois de la campagne. C'est dès le jour de la mobilisation qu'il eût dû surgir, avec ses cadres tout prêts. Rarement, le Parlement refusait les crédits, si les spécialistes savaient les demander avec assez de courage. Il n'avait pas la force de les contraindre à les bien employer. En outre, capable de se résigner à frapper l'électeur à la bourse, il craignait beaucoup plus de le gêner. Sa répugnance à imposer aux réservistes les périodes d'exercice nécessaires a porté un coup très grave au principe des armées nationales. Il est vrai que les routines de la caserne, fort peu favorables à un emploi rationnel de ces stades d'instruction, lui avaient frayé la vo ie. A plusieurs reprises, les présidents du Conseil avaient dû réclamer les pleins pouvoirs. C'était avouer que la machine constitutionnelle grinçait. Mieux eût valu la réformer, avant qu'il fût trop tard. Solution de facilité, on ne voit point que ces ple ins pouvoirs eux-mêmes aient beaucoup servi à renforcer la pratique gouvernementale ni à y remettre de l'ordre. Gâtés par la pratique des couloirs, nos chefs politiques croyaient sinformer quand ils ne faisaient que recueillir des potins au hasard des rencontres. Les Problèmes mondiaux comme les problèmes nationaux ne leur apparaissaient plus que sous l'angle des rivalités personnelles.

Ce régime était donc faible. Il n'était pas si ${ }_{\text {p.176 }}$ méchant qu'on l'a voulu peindre. Parmi les crimes dont on l'a accusé, certains semblent bien purement imaginaires. On a répété que les passions partisanes et, surtout anticléricales, avaient désorganisé l'armée. Je puis témoigner qu'à Bohain, le général Blanchard se rendait, chaque dimanche, à la messe. Supposer qu'il eût, pour cela, attendu la guerre, serait faire à son courage civique l'injure la plus gratuite. Il avait cent fois raison, puisque telle était sa foi, d'accomplir ainsi, publiquement, son devoir de fidèle. Lincroyant qui lui en eût su mauvais gré aurait été un sot ou une âme de boue. Mais je ne vois pas que ces convictions religieuses, loyalement affirmées, l'aient empêché d'obtenir, sous des gouvernements dits « de gauche », une armée, et de la conduire à la défaite.

Aussi bien, gouvernaient-ils tant que cela, nos Parlements et les ministres sortis de leurs rangs? Des systèmes antérieurs, ils avaient gardé plusieurs grands corps publics quils étaient bien loin de diriger étroitement. Sans doute, les préoccupations de parti ne manquaient pas d'intervenir, as sez souvent, dans le choix des chefs d'équipe. De quelque côté que soufflât le vent du moment, les désignations qu'elles imposaient étaient rarement les plus heureuses. Mais le recrutement de base restait presque exclusivement corporatif. Asile préféré des fils de notables, l'École des Sciences Politiques 
peuplait de ses élèves les ambassades, la Cour des Comptes, le Conseil d'État, l'Inspection des Finances. L'École Polytechnique, dont les bancs voient se nouer, pour la vie, les liens d'une si merveilleuse solidarité, ne fournissait pas seulement les états-majors de l'industrie ; elle ouvrait l'accès de ces carrières d'ingénieurs de l'État, où l'avancement obéit aux lois d'un automatisme quasi mécanique. Les Universités, par le moyen de tout un jeu de conseils et de comités, se cooptaient à peu près complètement elles-mêmes, non sans quelques dangers pour le renouvellement ${ }_{\text {p.177 }}$ de la pensée, et offraient à leurs maîtres des garanties de permanence, que le système présent a, provisoirement, dit-il, abolies. Fort de sa richesse et du prestige que, même sur les âmes, en apparence, les plus philosophiques, exerce toujours le hochet d'un titre, l'Institut de France conservait, pour le mal ou pour le bien, sa dignité de puissance intellectuelle. Si la politique influait, d'aventure, sur le choix de l'Académie, ce n'était assurément pas celle de gauche. « Je connais, disait naguère Paul Bourget, trois citadelles du conservatisme : la Chambre des lords, le grand État-Major allemand, l'Académie française. »

Le régime eut-il tort ou raison de respecter ces antiques corporations ? On peut en disserter à perte de vue. Les uns diront : stabilité, tradition d'honneur. Les autres, vers lesquels j'avoue incliner, répliqueront : routine, bureaucratie, morgue collective. Une chose, en tout cas, est certaine : sur deux points, la faute fut lourde.

Quel tollé quand, par l'établissement d'une École d'administration, un ministère de Front populaire prétendit battre en brèche le monopole des «Sciences Po»! Le projet était mal venu. Mieux eût valu certainement favoriser, par des bourses, l'accès de tous aux fonctions administratives et en confier la préparation aux universités, selon le large système de culture générale qui fait la force du Civil Service britannique. Mais l’idée pre mière était juste. Quelle que soit la nature du gouvernement, le pays souffre si les instruments du pouvoir sont hostiles à l'esprit même des institutions publiques. A une monarchie, il faut un personnel monarchiste. Une démocratie tombe en faiblesse, pour le plus grand mal des intérêts communs, si ses hauts fonctionnaires, formés à la mépriser et, par nécessité de fortune, issus des classes même dont elle a prétendu abolir l'empire, ne la servent qu'à contrecoeur.

D’autre part, le système de cooptation qui, p.178 officiel ou non, régnait dans presque tous les grands corps, aboutissait à y fortifier beaucoup trop le pouvoir de l'âge. Comme dans l'armée, l'avancement, à quelques exceptions près, était généralement assez lent et les vieillards, se perpétuant aux sommets, s'ils acceptaient de tendre l'échelle à quelques -uns de leurs cadets, choisissaient, pour cela, de préférence, leurs trop bons élèves. Les révolutions nous paraissent tantôt souhaitables, tantôt odieuses, selon que leurs principes sont ou non les nôtres. Elles ont cependant toutes une vertu, inhérente à leur élan : elles poussent en avant les vrais jeunes. J'abhorre le nazisme. Mais, comme la Révolution française, à laquelle on rougit de la comparer, la 
révolution nazie a mis aux commandes, que ce soit à la tête des troupes ou à la tête de l'État, des hommes qui, parce qu'ils avaient un cerveau frais et n'avaient pas été formés aux routines scolaires, étaient capables de comprendre «le surprenant et le nouveau ». Nous ne leur opposions guère que des messieurs chenus ou de jeunes vieillards.

Cependant un régime, quelle que soit la force de résistance propre acquise par ses rouages, est, avant tout, ce que l'a fait la société même qu'il prétend régir. Il arrive que la machine entraîne le conducteur. Plus souvent, elle vaut ce que valent les doigts qui la manient. Je ris quand j'entends certains hommes d'affaires de ma connaissance, quelques heures après avoir « fait passer », à beaux deniers sonnants, un article dans le plus grave de nos journaux, s'élever éloquemment contre la vénalité de la presse ou s'ils ont commandé à un ancien ministre le livre qui devra défendre leurs bas intérêts, railler ces «fantoches » du Parlement. Qui mérite davantage la corde, le corrompu ou le corrupteur? Nos grands bourgeois se plaignent volontiers du corps enseignant. Au temps où, plus qu'aujourd'hui, ils tenaient les cordons de la bourse, ils trouvaient naturel de donner, par la voie du budget, aux professeurs

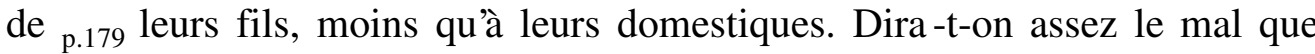
nous a fait la proverbiale avarice française ? Là encore, l'esprit de petite ville n'a pas cessé de triompher.

Surtout, notre mécanisme politique souffrait, jusqu'à en être littéralement coincé, du grand malentendu des Français.

Il est bon, il est sain que, dans un pays libre, les philosophies sociales contraires se combattent librement. Il est, dans l'état présent de nos sociétés, inévitable que les diverses classes aient des intérêts opposés et prennent conscience de leurs antagonismes. Le malheur de la patrie commence quand la légitimité de ces heurts n'est pas comprise.

Il m’est arrivé, çà et là, de prononcer le nom de bourgeoisie. Non sans scrupules. Ces mots, à la fois usés par le temps et sujets à de perpétuelles déviations de sens, encombrent la nomenclature, encore tâtonnante, des sciences humaines, ils enferment, dans des contours trop flous, des réalités trop complexes. Force est bien, cependant, jusqu'à nouvel ordre, d'user du seul vocabulaire qu'un langage imparfait mette à votre disposition. A condition d'en définir les termes. J'appelle donc bourgeois de chez nous un Français qui ne doit pas ses ressources au travail de ses mains; dont les revenus, quelle qu'en soit l'origine, comme la très variable ampleur, lui permettent une aisance de moyens et lui procurent une sécurité, dans ce niveau, très supérieure aux hasardeuses possibilités du salaire ouvrier; dont l'instruction, tantôt reçue dès l'enfance, si la famille est d'établissement 
ancien, tantôt acquise au cours d'une ascension sociale exceptionnelle, dépasse par sa richesse, sa tonalité ou ses prétentions, la norme ${ }_{\mathrm{p} .180}$ de culture tout à fait commune; qui enfin se sent ou se croit appartenir à une classe vouée à tenir dans la nation un rôle directeur et par mille détails, du costume, de la langue, de la bienséance, marque, plus ou moins instinctivement, son attachement à cette originalité du groupe et à ce prestige collectif.

Or, la bourgeoisie, ainsi entendu, avait, dans la France d'av ant guerre, cessé d'être heureuse. Les révolutions économiques, qu'on attribuait à la dernière catastrophe mondiale et qui n'en venaient pas toutes sapaient la quiète stabilité des fortunes. Jadis ressource presque unique de beaucoup de familles, ultime espoir de tant d'autres, qui en étaient encore aux premières pentes du succès, la rente fondait entre des mains étonnées. La résistance du salariat faisait bloc contre toute pression sur les rémunérations ouvrières, amenuisant, à chaque crise, le profit patronal, avec les dividendes. L'expansion de l'industrie, dans les pays neufs, et les progrès de leur autarcie vouaient à une anémie croissante les capitalismes européens et français. La poussée des nouvelles couches sociales menaçait la puissance, économique et politique, d'un groupe habitué à commander. Longtemps il s'était, dans son ensemble, accommodé des institutions démocratiques. Beaucoup de ses membres les avaient même appelées de leurs voeux. C'était que les moeurs, comme à l'ordinaire, avaient retard é sur le droit. Remis au petit paysan et à l'ouvrier, le bulletin de vote n'avait, durant plus d'une génération, pas changé grand-chose à la domination traditionnelle exercée, sur la province, par les notables des classes moyennes. Il les avait même servis, en leur permettant d'éliminer, en partie, des grands postes de l'État, leurs vieux adversaires de la très haute bourgeoisie ou de la noblesse. Chez ces hommes étrangers aux intransigeances aristocratiques, la démocratie flattait un goût très sincère d'hu manité. Elle ne les inquiétait pas encore dans leur bourse ou dans la solidité de leur modeste ${ }_{\text {p.181 }}$ prestige. Mais un jour vint où, favorisé par la tragédie économique, l'électeur du commun fit entendre beaucoup plus haut et plus dangereusement sa voix. Les rancunes furent avivées par un véritable sentiment d’inégalité retournée. Contraint à payer de sa personne, chaque jour plus durement, le bourgeois crut s'apercevoir que les masses populaires, dont le labeur était la source profonde de ses gains, travaillaient au contraire moins que par le passé — ce qui était vrai — et même moins que lui-même : ce qui n'était peut -être pas aussi exact, en tout cas, tenait un compte insuffisant des différentes nuances de la fatigue humaine. On le vit s’indigner que le manoeuvre trouvât le loisir d'aller au cinéma, tout comme le patron ! L'esprit des classes ouvrières, que leur longue insécurité avait accoutumé à vivre sans beaucoup de souci du lendemain, heurtait son respect inné de l'épargne. Dans ces foules au poing levé, exigeantes, un peu hargneuses et dont la violence traduisait une grande candeur, les plus charitables gémissaient de chercher désormais en vain le «bon pauvre» déférent des romans de Mme de Ségur. Les valeurs d'ordre, de docile bonhomie, de hiérarchie sociale 
complaisamment acceptée, auxquelles toute leur éducation avait formé des âmes naturellement peu amies des nouveautés, paraissaient prêtes à être balayées ; et avec elles, peut-être, quelque chose d'assurément beaucoup plus précieux : un peu de ce sens national qui, sans que le riche s'en doute toujours assez, réclame des humbles une dose d'abnégation bien plus considérable que chez leurs maîtres.

Parce que la bourgeoisie était ainsi anxieuse et mécontente, elle était aussi aigrie. Ce peuple dont elle sortait et avec lequel, en y regardant de plus près, elle se fût senti plus d'une affinité profonde, trop déshabituée, d'ailleurs, de tout effort d'analyse humaine pour chercher à le comprendre, elle préféra le condamner. On saurait ${ }_{\text {p.182 }}$ difficilement exagérer l'émoi que, dans les rangs des classes aisées, même parmi les hommes, en apparence les plus libres d'esprit, provoqua, en 1936, l'avènement du Front populaire. Quiconque avait quatre sous crut sentir passer le vent du désastre et l'épouvante des m énagères dépassa, s’il était possible, celle de leurs époux. On accuse aujourdhui la bourgeoisie juive d'avoir fomenté le mouvement. Pauvre Synagogue, à l'éternel bandeau. Elle trembla, j'en puis témoigner, plus encore que l'Église. Il en fut de même pour le Temple. «Je ne reconnais plus mes industriels protestants » me disait un écrivain, né dans leur milieu. «Ils étaient naguère, entre tous, soucieux du bien-être de leurs ouvriers. Les voici, maintenant, les plus acharnés contre eux. »Une longue fente, séparant en deux blocs les groupes sociaux, se trouva, du jour au lendemain, tracée dans l'épaisseur de la société française.

Certes, je n'ai nulle envie d'entreprendre ici l'apologie des gouvernements de Front populaire. Une pelletée de terre, pieusement jetée sur leurs tombes : de la part de ceux qui, un moment, purent mettre en eux leur foi ; ces morts ne méritent rien de plus. Ils tombèrent sans gloire. Le pis est que leurs adversaires y furent pour peu de chose. Les événements mêmes, qui les dépassaient, n'en portent pas, à beaucoup près, tout le poids. La tentative succomba, avant tout, devant les folies de ses partisans ou qui affectaient de l'être. Mais l'attitude de la plus grande partie de l'opinion bourgeoise fut inexcusable. Elle bouda, stupidement, le bien comme le mal. J'ai vu un brave homme, nullement insensible aux plaisirs des yeux, refuser de mettre les pieds à l'Exposition Universelle. Elle avait beau offrir cet incomparable trésor, orgueil de notre nation: les chefs-d'oeuvre de l'art $f$ rançais. Un ministre abhorré l'avait inaugurée. Son achèvement avait été, disait-on, compromis par les exigences des syndicats. C'en était assez pour prononcer sur elle l'anathème. Quelles huées ${ }_{\text {p.183 }}$ lorsqu'on nous parla d'organiser les loisirs. On railla, on boycotta. Les mêmes personnes élèvent aujourd'hui aux nues les mêmes efforts, depuis que l'idée a été reprise, plus ou moins sérieusement, sous un autre nom, par un régime selon leur coeur.

Surtout, quelles qu'aient pu être les fautes des chefs, il y avait, dans cet élan des masses vers l'espoir d'un monde plus juste, une honnêteté touchante, à laquelle on s'étonne qu'aucun coeur bien placé ait pu rester insensible. Mais, 
combien de patrons, parmi ceux que j'ai rencontrés, ai -je trouvés capables, par exemple, de saisir ce qu'une grève de solidarité, même peu raisonnable, a de noblesse : «passe encore », disent-ils, «si les grévistes défendaient leurs propres salaires ». Il est deux catégories de Français qui ne comprendront jamais l'histoire de France, ceux qui refusent de vibrer au souvenir du sacre de Reims ; ceux qui lisent sans émotion le récit de la fête de la Fédération. Peu importe l'orientation présente de leurs préférences. Leur imperméabilité aux plus beaux jaillissements de l'enthousiasme collectif suffit à les condamner. Dans le Front populaire - le vrai, celui des foules, non des politiciens - il revivait quelque chose de l'atmosphère du Champ de Mars, au grand soleil du 14 juillet 1790. Malheureusement, les hommes dont les ancêtres prêtèrent serment sur l'autel de la patrie, avaient perdu contact avec ces sources profondes. Ce n'est pas hasard si notre régime, censément démocratique, n'a jamais su donner à la nation des fêtes qui fussent véritablement celles de tout le monde. Nous avons laissé à Hitler le soin de ressusciter les antiques péans. J'ai connu, à la première armée, des officiers chargés d'entretenir le « moral » des troupes. Le commandement avait, pour cela, fait choix d'un banquier très parisien et d'un industriel du Nord. Ils pensaient que pour glisser «quelques vérités » dans les journaux du front il fallait, d'abord, les enrober de grasses plaisanteries. p.184 Quant au Théâtre aux Armées, plus il donnait de farces graveleuses, meilleur il leur semblait. De plus en plus loin du peuple, dont elle renonçait à pénétrer, pour sympathiser avec eux, les authentiques mouvements d'âme, tour à tour refusant de le prendre au sérieux ou tremblant devant lui, la bourgeoisie, en même temps, s'écartait, sans le vouloir, de la France tout court.

En accablant le régime, elle arrivait, par un mouvement trop naturel, à condamner la nation qui se l'était donné. Désespérant, malgré elle, de ses propres destins, elle finissait par désespérer de la patrie. Criez-vous que j'exagère ? Relisez les journaux que hier elle lisait et inspirait: vous serez édifié. Au temps où la Belgique venait de rejeter l'alliance au profit d'une neutralité tristement fallacieuse, un ami bruxellois me disait : "Vous ne vous imaginez pas le mal qu'ont fait à votre cause vos grands hebdomadaires. Ils proclament, chaque semaine, que vous êtes pourris. Que voulez-vous ! On les croit. » Nous ne les croyions nous-même que trop. Une grande partie de nos classes encore dirigeantes, celles qui nous fournissaient nos chefs d'industrie, nos principaux administrateurs, la plupart de nos officiers de réserve, sont parties en guerre toutes pleines de cette hantise. Ils recevaient les ordres d'un système politique qui leur semblait corrompu jusqu'aux moelles ; ils défendaient un pays quils jugeaient, d'avance, incapable de résister ; les soldats qu'ils commandaient étaient issus d'un peuple, à leur gré, dégénéré. Quel que pût être leur courage personnel et la force de leur patriotisme, étaitce là une bonne préparation mentale pour lutter, comme il l'eût fallu «jusqu'au dernier quart d'heure »? 
Or, ces partis pris, les états-majors ne les partageaient que trop bien. Non qu'ils dussent nécessairement en être à ce point contaminés. Il s'en fallait de beaucoup que les officiers de carrière, même dans p.185 les plus hautes fonctions, sortissent tous de milieux héréditairement favorisés par la fortune. Plus d'un, au contraire, demeurait, par ses origines, très proche des couches populaires. Par profession et par point d'honneur, ils étaient, pour la plupart, fort étrangers à tout bas esprit mercantile. L'avenir du capitalisme, à supposer qu'ils eussent trouvé le temps de réfléchir sur lui, ne leur aurait assurément pas inspiré de considération particulière et une redistribution des richesses n'avait rien pour effrayer le plus grand nombre d'entre eux. Hommes de devoir, dans leur presque totalité, et patriotes fervents, ils étaient les soldats de la France. Ils auraient rougi qu'on pût les prendre pour les mercenaires de quelques intérêts privés ou d'une classe. Mais, que savaient-ils des réalités sociales ? L'école, la caste, la tradition avaient bâti autour d'eux un mur d'ignorance et d'erreur. Leurs idées étaient simples. "A gauche », on était «antimilitariste »; on y pensait mal, on n'y re spectait pas l'autorité, qui fait, comme chacun sait, la force principale des armées. Quant au socialiste, ils le connaissaient de longue date: c'était le mauvais troupier, qui se plaint perpétuellement de l'ordinaire et parfois, pour comble d'horreur, va saisir les journaux de ses jérémiades. Quiconque pactisait avec ces gens-là se trouvait suspect. Roosevelt même avait quelque chose de «bolcheviste » (je l'ai entendu dire, et par un chef d'état-major). Au surplus, étant, dans leur masse, d'esprit peu cu rieux, et, dressés, dès leur adolescence, à fuir l'hérésie, cette courte orthodoxie leur suffisait parfaitement. Ils ne cherchaient, en aucune façon, à sinformer. Parmi les feuilles étalées sur la table de notre popote, le Temps représentait l'extrême rou ge. Ainsi, un groupe de jeunes chefs, recrutés entre les plus intelligents, n'ouvrait jamais un quotidien qui reflétât, si peu que ce soit, les opinions professées, à tort ou à droit, par la majorité des Français.

p.186 Battons notre coulpe. Ce n'est pas d 'aujourd'hui que je le déplore : les hommes auxquels revenait l'honneur de représenter, au cours de ces dernières années, ce qu’il y avait chez nous de tendances d'esprit authentiquement libérales, désintéressées et humainement progressives, ont commis une de leurs plus lourdes fautes, en s'abstenant de tout effort pour se faire mieux comprendre d'un groupe professionnel où subsistaient de si hautes valeurs morales. Le malentendu date, je pense, de l'affaire Dreyfus et notre côté de la barricade n'en porta assurément pas, à l'origine, la responsabilité. Il n'en est pas pour cela plus excusable. Combien de fois, voyant mes camarades boire, comme petit lait, aux sources de haine et de bêtise que continuaient à dispenser, durant la guerre même, de sordides hebdomadaires, ne me suis-je pas dit «Quel dommage que de si braves gens soient si mal renseignés! Quelle honte surtout que personne, jamais, n'ait véritablement cherché à les éclairer. »

Mais le fait est là : et nous pouvons maintenant en mesurer les résultats. Mal instruits des ressources infinies d'un peuple resté beaucoup plus sain que 
des leçons empoisonnées ne les avaient inclinés à le croire, incapables, par dédain comme par routine, d'en appeler à temps à ses réserves profondes, nos chefs ne se sont pas seulement laissé battre. Ils ont estimé très tôt naturel d'être battus. En déposant, avant l'heure, les armes, ils ont assuré le succès d'une faction. Quelques -uns, certes, cherchèrent, avant tout, dans le coup d'État, le moyen de masquer leur faute. D' autres cependant, dans le haut commandement, presque tous dans les rangs de l'armée étaient loin de poursuivre consciemment d'aussi égoïstes desseins. Ils n'ont accepté le désastre que la rage au coeur. Ils l'ont accepté, cependant trop tôt, parce quils lui trouvaient ces atroces consolations : écraser, sous les ruines de la France, un ${ }_{\text {p.187 }}$ régime honni ; plier les genoux devant le châtiment que le destin avait envoyé à une nation coupable.

J'appartiens à une génération qui a mauvaise conscience. De la dernière guerre, c'est vrai, nous étions revenus bien fatigués. Nous avions aussi, après ces quatre ans d'oisiveté combattante, grande hâte de reprendre sur l'établi, où nous les avions laissés envahir par la rouille, les outils de nos divers métiers ; nous voulions, par des bouchées doubles, rattraper le travail perdu. Telles sont nos excuses. Je ne crois plus, depuis longtemps, qu'elles suffisent à nous blanchir.

Nous sommes beaucoup à avoir mesuré, très tôt, l'abîme où la dip lomatie de Versailles et la diplomatie de la Ruhr menaçaient de nous précipiter. Nous comprenions qu'elles réussissaient ce merveilleux coup double : nous brouiller avec nos alliés de la veille ; maintenir toute saignante, notre antique querelle avec les ennemis que nous venions à grand-peine de vaincre. Or, nous n'ignorions pas ce que représentaient de puissance latente et la GrandeBretagne et l'Allemagne. Les mêmes hommes, ou peu s'en faut, que nous avons vus nous conseiller, aujourd'hui avant même que 1 heure en eût sonné, la triste sagesse de Louis XVIII, nous engageaient alors à la magnificence de Louis XIV. Nous n'étions pas assez sots pour croire, avec eux, que dans une France appauvrie, relativement dépeuplée et d'un potentiel industriel médiocre, une pareille politique fût de saison : si tant est qu'elle l'ait jamais été. Comme nous n'étions pas prophètes, nous n'avions pas deviné le nazisme. Mais nous prévoyions bien que sous une forme dont nous nous avouions incapables de dessiner, avec précision, les contours, le sursaut allemand viendrait, un jour, alimenté par les ${ }_{\text {p. } 188}$ rancunes, dont nos folies multipliaient la semence, et que son déclenchement serait terrible. Si l'on nous avait interrogés sur l'issue vraisemblable d'une seconde guerre, nous a urions répondu, sans doute, par l'espoir d'une seconde victoire. Mais, sans nous dissimuler que, dans cette tourmente renouvelée, la civilisation européenne risquait de sombrer à jamais. Nous sentions, d'autre part, dans l'Allemagne 
d'alors, la montée enco re timide de bonnes volontés, franchement pacifiques, honnêtement libérales, qu'il ne tenait qu'à nos chefs d'encourager. Nous savions tout cela. Et pourtant, paresseusement, lâchement, nous avons laissé faire. Nous avons craint le heurt de la foule, les sarcasmes de nos amis, l'incompréhensif mépris de nos maîtres. Nous n'avons pas osé être, sur la place publique, la voix qui crie, d'abord dans le désert, mais du moins, quel que soit le succès final, peut toujours se rendre la justice d'avoir crié sa foi. Nous avons préféré nous confiner dans la craintive quiétude de nos ateliers. Puissent nos cadets nous pardonner le sang qui est sur nos mains !

Tout ce qu'on a lu plus haut sur les faiblesses qui, peu à peu, minaient la robuste santé du pays, sur la léthargie intellectuelle des classes dirigeantes et leurs rancoeurs, sur les illogiques propagandes dont les mixtures frelatées intoxiquaient nos ouvriers, sur notre gérontocratie, sur le malaise de l'armée, dans la nation, tout cela ou presque tout, il y a longtemps que nous nous le murmurions, entre amis choisis. Combien ont eu le cran de parler plus fort ? J'entends bien, nous n'avions pas des âmes de partisans. Ne le regrettons pas. Ceux d'entre nous qui, par exception, se laissèrent embrigader par les parti $\mathrm{s}$, finirent presque toujours par en être les prisonniers beaucoup plutôt que les guides. Mais ce n'était pas dans les comités électoraux que nous appelait notre devoir. Nous avions une langue, une plume, un cerveau. Adeptes des sciences

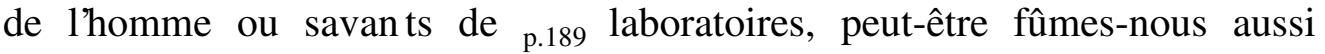
détournés de l'action individuelle par une sorte de fatalisme, inhérent à la pratique de nos disciplines. Elles nous ont habitués à considérer, sur toutes choses, dans la société comme dans la nature, le jeu des forces massives. Devant ces lames de fond, d'une irrésistibilité presque cosmique, que pouvaient les pauvres gestes d'un naufragé ? C'était mal interpréter l'histoire. Parmi tous les traits qui caractérisent nos civilisations, elle n'en connaît pas de plus significatif qu'un immense progrès dans la prise de conscience de la collectivité. Là est la clef d'un grand nombre des contrastes qui, aux sociétés du passé, opposent, si crûment, celles du présent. Une transformation juridique, dès lors qu'elle est perçue, ne se produit pas de la même façon que si elle était demeurée purement instinctive.

Les échanges économiques n'obéissent pas aux mêmes lois, selon que les cours des prix sont ou non connus de l'ensemble des participants. Or, de quoi est faite cette conscience collective, sinon d'une multitude de consciences individuelles, qui, incessamment, influent les unes sur les autres? Se former une idée claire des besoins sociaux et s'efforcer de la répandre, c'est introduire un grain de levain nouveau, dans la mentalité commune ; c'est se donner une chance de la modifier un peu et, par suite, dincliner, en quelque mesure, le cours des événements, qui sont réglés, en dernière analyse, par la psychologie des hommes. Avant tout, nous étions requis, une fois de plus, par la tâche quotidienne. Nous avons, pour la plupart, le droit de dire que nous fûmes de bons ouvriers. Avons-nous toujours été d'assez bons citoyens ? 
Je n'étale pas ces remords par délectation morose. L'expérience ne m'a point appris qu'un péché confessé fût, pour cela, moins lourd à porter. Je pense à ceux qui me liront : à mes fils, certainement, à d'autres, p.190 peut-être, un jour, parmi les jeunes. Je leur demande de réfléchir aux fautes de leurs aînés. Peu importe qu’ils les jugent avec l'implacable sévérité des âmes encore fraîches, ou leur réservent un peu de cette indulgence amusée, dont les générations montantes accordent volontiers au vieil âge le dédaigneux bénéfice. L'essentiel est quills les connaissent, pour les éviter.

Nous nous trouvons aujourd'hui dans cette situation affreuse que le sort de la France a cessé de dépendre des Français. Depuis que les armes, que nous ne tenions pas d'une poigne assez solide, nous sont tombées des mains, l'avenir de notre pays et de notre civilisation fait l'enjeu d'une lutte où, pour la plupart, nous ne sommes plus que des spectateurs un peu humiliés. Qu'adviendra -t-il de nous si, par mal aventure, la Grande-Bretagne doit être, à son tour, vaincue? Notre redressement national en sera, à coup sûr, longuement retardé. Retardé seulement, j'en ai la conviction. Les ressorts profonds de notre peuple sont intacts et prêts à rebondir. Ceux du nazisme, par contre, ne sauraient supporter toujours la tension croissante, jusqu'à l'infini, que les maîtres présents de l'Allemagne prétendent leur imposer. Enfin, les régimes «venus dans les fourgons de l'étranger » ont bien pu jouir, parfois chez nous, d'une certaine durée. Ce n'a jamais été, face aux dégoûts d'une fière nation, que le répit du condamné. N'aper cevons-nous pas déjà que la plaie de l'occupation mord, chaque jour, plus cruellement dans nos chairs. L'apparente bonhomie du début ne trompe plus personne. Pour juger l'hitlérisme, il suffit, à notre opinion, de le regarder vivre. Mais combien j’aime mie ux évoquer l’image d'une victoire anglaise ! Je ne sais quand l'heure sonnera où, grâce à nos Alliés, nous pourrons reprendre en main nos propres destinées. Verrons-nous alors des fractions du territoire se libérer les unes après les autres? Se former, vague après vague, ${ }_{\text {p.191 }}$ des armées de volontaires, empressées à suivre le nouvel appel de la Patrie en danger? Un gouvernement autonome poindre quelque part, puis faire tache d'huile ? Ou bien un élan total nous soulèvera-t-il soudain ? Un vieil historien roule ces images dans sa tête. Entre elles, sa pauvre science ne lui permet pas de choisir. Je le dis franchement : je souhaite, en tout cas, que nous ayons encore du sang à verser : même si cela doit être celui d'êtres qui me sont chers (je ne parle pas du mien, auquel je n'attache pas tant de prix). Car il n'est pas de salut sans une part de sacrifice; ni de liberté nationale qui puisse être pleine, si on n’a travaillé à la conquérir soi-même.

Ce n'est pas aux hommes de mon âge quil appartiendra de reco nstruire la patrie. La France de la défaite aura eu un gouvernement de vieillards. Cela est tout naturel. La France d'un nouveau printemps devra être la chose des jeunes. Sur leurs aînés de l'ancienne guerre, ils possèderont le triste privilège de ne pas avoir à se garer de la paresse de la victoire. Quel que puisse être le succès final, l'ombre du grand désastre de 1940 n'est pas près de s'effacer. Peut -être 
est-ce une bonne chose d'être ainsi contraints de travailler dans la rage ? Je n'aurai pas l'outrec uidance de leur tracer un programme. Ils en tireront euxmêmes les lois du fond de leur cerveau et de leur coeur. Ils en adapteront les contours aux leçons des événements. Nous les supplions seulement d'éviter la sécheresse des régimes qui, par rancune ou orgueil, prétendent dominer les foules, sans les instruire ni communier avec elles. Notre peuple mérite qu'on se fie à lui et qu'on le mette dans la confidence. Nous attendons d'eux aussi que, tout en faisant du neuf, beaucoup de neuf, ils ne rompent point les liens avec notre authentique patrimoine qui n'est point ou qui, du moins, n'est pas tout entier là où de prétendus apôtres de la tradition le veulent mettre. Hitler disait un jour, à Rauschning : «Nous avons raison de ${ }_{\text {p.192 }}$ spéculer plutôt sur les vices que sur les vertus des hommes. La Révolution française en appelait à la vertu. Mieux vaudra que nous fassions le contraire. » On pardonnera à un Français, c'est -à-dire à un homme civilisé — car c'est tout un — s'il préfère, à cet enseignement, celui de la Révolution, et de Montesquieu : «Dans un État populaire, il faut un ressort, qui est la vertu. »Qu'importe si la tâche est ainsi rendue plus difficile! Un peuple libre et dont les buts sont nobles, court un double risque. Mais, est-ce à des soldats qu’il faut, sur un champ de bataille, conseiller la peur de l'aventure ?

Guéret-Fougères (Creuse) : juillet-septembre 1940. 


\section{LE TESTAMENT DE MARC BLOCH ${ }^{1}$}

Clermont-Ferrand, le 18 mars 1943.

Où que je doive mourir, en France ou sur la terre étrangère et à quelque moment que ce soit, je laisse à ma chère femme ou, à son défaut, à mes enfants le soin de régler mes obsèques, comme ils le jugeront bon. Ce seront des obsèques purement civiles : les miens savent bien que je n'en aurais pas voulu d'autres. Mais je souhaite que, ce jour-là soit à la maison mortuaire, soit au cimetière - un ami accepte de donner lecture des quelques mots que voici :

Je n'ai point demandé que, sur ma tombe fussent récitées les prières hébraïques, dont les cadences, pourtant, accompagnèrent, vers leur dernier repos, tant de mes ancêtres et mon père lui-même. Je me suis, toute ma vie durant, efforcé, de mon mieux, vers une sincérité totale de l'expression et de l'esprit. Je tiens la complaisance envers le mensonge, de quelques prétextes qu'elle puisse se parer, pour la pire lèpre de l'âme. Comme un beaucoup plus grand que moi, je souhaiterais volontiers que, pour toute devise, on gravât sur ma pierre tombale ces simples mots : Dilexit veritatem. C'est pourquoi il m'était impossible d'admettre qu'en cette heure des suprêmes adieux, où tout homme a pour devoir de se résumer soi-même, aucun appel fût fait en mon nom, aux effusions

\footnotetext{
${ }^{1}$ Ce texte avait été confié par Marc Bloch aux siens tandis qu'il menait la vie clandestine. Nous en connaissons peu d'une beauté d'âme et d'écriture aussi parfaite.

Quatre ans après avoir écrit ce Témoignage qu'on vient de lire, un an après ces dernières volontés où il se résumait en une forme de diamant, Marc Bloch tombait sous les balles nazies.
} 
d'une orthodoxie, dont je ne reconnais point le credo.

Mais il me serait plus odieux encore que dans cet acte de probité personne pût rien voir qui ressemblât à un lâche reniement. J'affirme donc, sill le faut, face à la mort, que je suis né Juif ; que je n'ai jamais songé à m'en défendre ni trouvé aucun motif d'être tenté de le faire. Dans un monde assailli par la plus atroce barbarie, la généreuse tradition des prophètes hébreux, que le christianisme, en ce qu'il eut de plus pur, reprit pour l'élargir, ne demeure-t-elle pas une de nos meilleures raisons de vivre, de croire et de lutter ? Étranger à tout formalisme confessionnel comme à toute solidarité prétendument raciale, je me suis senti, durant ma vie entière, avant tout et très simplement Français. Attaché à ma patrie par une tradition familiale déjà longue, nourri de son héritage spirituel et de son histoire, incapable, en vérité, d'en concevoir une autre où je puisse respirer à l'aise, je l'ai beaucoup aimée et servie de toutes mes forces. Je n'ai jamais éprouvé que ma qualité de Juif mît à ces sentiments le moindre obstacle. Au cours des deux guerres, il ne m'a pas été donné de mourir pour la France. Du moins, puis-je, en toute sincérité, me rendre ce témoignage : je meurs, comme j'ai vécu, en bon Français.

Il sera ensuite - sil a été possible de s'en procurer le texte - donné lecture de mes cinq citations. 
Nom du document : bloch_defaite_pdf.doc

Dossier :

C:ICSS $\backslash$ Bloch

Modèle :

$\mathrm{C}:$ IWINDOWS $\backslash$ Application

DatalMicrosoft $\backslash$ Modèles $\backslash$ Normal.dot

Titre :

L' étrange défaite

Sujet :

témoignage

Auteur :

Marc Bloch

Mots clés :

Histoire de France, deuxième guerre mondiale, bataille de France, guerre 1939-1940

Commentaires : http://www.uqac.ca/Classiques_des_sciences_sociales/

Date de création : $\quad$ 05/08/05 15:10

$\mathrm{N}^{\circ}$ de révision : 7

Dernier enregistr. le : 05/08/05 15:26

Dernier enregistrement par : Pierre Palpant

Temps total d' édition14 Minutes

Dernière impression sur : $\quad$ 05/08/05 15:26

Tel qu' à la dernière impression

Nombre de pages :

111

Nombre de mots : 47628 (approx.)

Nombre de caractères : 271483 (approx.) 